\title{
Profiling microRNA Expression in the Developing Hippocampus of High Responder and Low Responder Rats
}

\author{
A thesis submitted to \\ the Faculty of Graduate Studies and Research \\ in Partial Fultillment of the requirements of the degree of \\ Master of Science
}

by

Erika M. Jansman

Department of Psychology and Institute of Neuroscience

Carleton University

September 2009

(c) Erika M. Jansman 


\section{Abstract}

Sprague-Dawley rats display variability in their locomotor response to a novel environment, leading to classification as High or Low Responders (HR or LR). HRs also display enhanced neuroendocrine stress reactivity compared to LRs. Previous work demonstrates that the hippocampus, which plays an important role in the hypothalamicpituitary-adrenal (HPA) axis stress response, exhibits differential mRNA expression early in postnatal development between selectively bred HRs and LRs. This thesis extends this work by examining expression patterns of microRNA, endogenous $~ 22$-nucleotide single-stranded RNA molecules that regulate gene expression by targeting specific mRNAs for translational repression and/or degradation. This thesis develops a custom miRNA microarray platform to test the hypothesis that differences in hippocampal miRNA expression will be present in a pattern similar to mRNA expression profiles. These data demonstrate that the custom miRNA microarrays detect differences in miRNA expression between postnatal days (PND) 7, 14, and 21. Furthermore, a subset of microRNAs are differentially expressed between HRs and LRs at PND 14, and 21. 


\section{Acknowledgements}

I would like to thank, first and foremost, Dr. John Stead for the opportunity to work in his laboratory and be a part of this exciting new research. I would also like to thank him for his invaluable knowledge and guidance over the last two years. I could not have asked for a better advisor, I am also very grateful to Dr. Carole Yauk and her team at Health Canada for providing assistance with various aspects of the microarraying process and even equipment when things in the Stead lab did not go according to plan. Thank you to Ben Hoogendoorn from Bio-Rad as well for providing regular technical support in getting the microarray printer up and running. I would also like to extend my appreciation to the faculty and staff in general and Justin Kutzko and Livia Chyurlia in particular for their help on numerous occasions. Furthermore, I would like to acknowledge my defence committee members: Dr. John Stead, Dr. Bruce Pappas, Dr. Alfonso Abizaid, Dr. Maria DeRosa, and Dr. Patrice Smith, and thank them for their time and consideration. Last but certainly not least, I cannot thank my family and friends enough for their continued support and understanding. 


\section{Table of Contents}

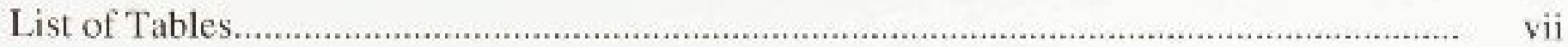

List of Figures.

List of Abbreviations and Acronyms........................................................................... xi

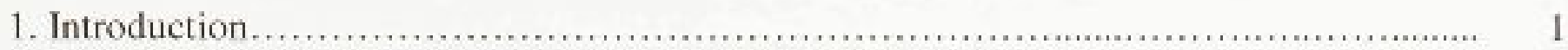

1.1 Overview of Gene Expression and Regulation......................................... I

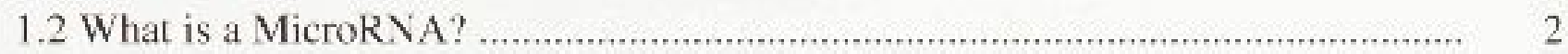

1.3 Biogenesis of MicroRNA ................................................................

1.4 MicroRNA Targets Specific mRNAs to Regulate Gene Expression.................... 4

1.5 Cellular Functions of MicroRNA ................................................. 8

1.6 MicroRNA and Central Nervous System Development.............................. 8

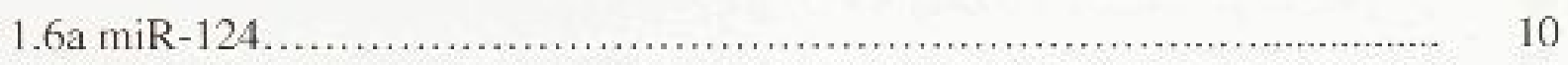

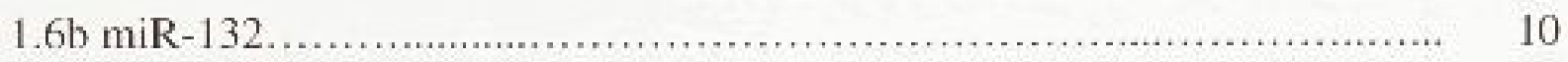

$1.6 \mathrm{c}$ miR-133b .......................................................... 11

1.7 MicroRNA Functions in the Mature Central Nervous System........................... 11

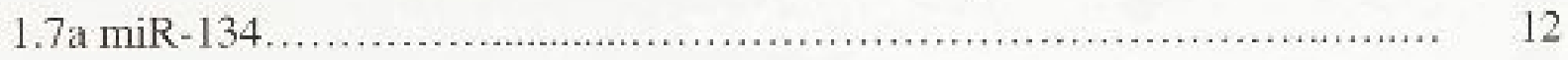

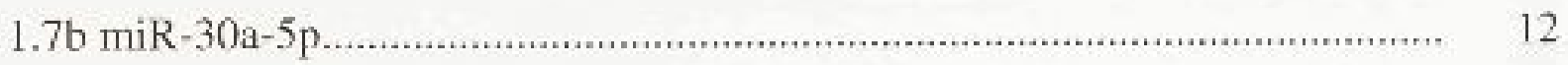

1.8 MicroRNAs and Neurological Disease ............................................ 13

1.9 A Role for MicroRNAs in the HPA Axis Response to Stress....................... 14

$1.10 \mathrm{HR} /$ LR Model of Stress Reactivity .......................................... 15

$1.11 \mathrm{HR} /$ LR Model of Drug Addiction......................................... 17

$1.12 \mathrm{HR} /$ LR Behavioural Differences............................................ 18

1.13 Neurobiological Basis of HR/LR Phenotypes................................... 20

1.14 Differential Gene Expression between HR-LR Phenotypes.......................... 22

1.15 Environmental Influences on HR-LR Phenotypes............................... 23

1.16 Selective Breeding for Divergence in Novelty-Seeking Traits..................... 24

1.17 Differential mRNA Expression in Developing HR-LR Rats...................... 25

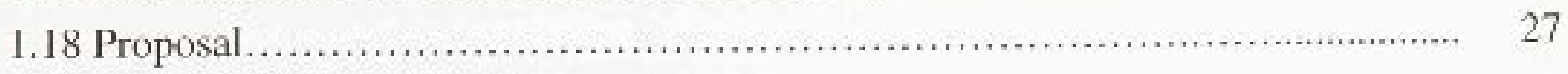

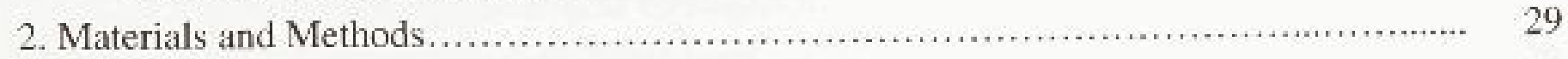

2.1 Animals................................................................................................ 29

2.2 Selective Breeding of HR and LR Animals.................................................. 29

2.3 Sample Collection........................................................................................ 30

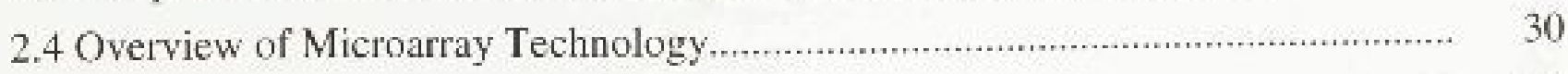

2.5 Microarray Printing Optimization...................................................................... 33 
2.5a Ethidium Bromide and SYBR Green II Test Chips................................ 34

Determining Optimal Printing Humidity ............................................... 35

Determining Optimal Slides and Spotting Solution.................................. $\quad 35$

Reducing Carry-Over Contamination.............................................. 36

Reducing Spot "Donuting "................................................................. $\quad 37$

2.5b NCode MicroRNA Labeling System Test Chips........................................ 39

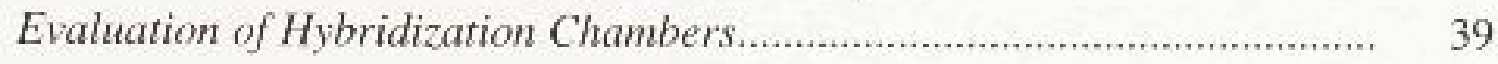

Evaluation of NCode Control Spike-In Concentration................................ 40

2.6 Printing the Experimental Microarrays............................................................ 42

2.6a Description and Positioning of miRNA Probes and Control Spots............ 42

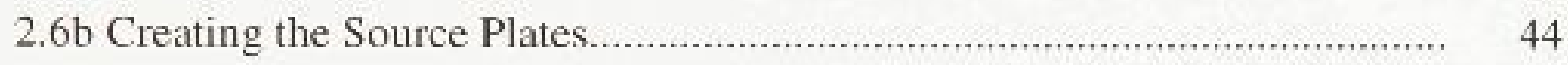

2.6c Printing the Microarrays.................................................................. 45

2.7 MicroRNA and total RNA Isolation......................................................... 45

2.7a MicroRNA Isolation............................................................................... 46

2.7b Total RNA Isolation................................................................................. 47

2.8 Assessment of RNA Quality and Quantity............................................. 47

2.9 Pre-soaking and Pre-hybridizing the Microarrays.............................................. 48

2.10 Overview of the Labelling Procedure................................................................ 49

2.10a Polyadenylation of miRNA …..................................................... 49

2.10b Ligation of Alexa Fluor Dye Molecules.................................................. 49

2.10c Hybridization Procedure................................................................. 50

2.10d Array Wash Procedure ................................................................... 51

2.10e Microarray Scanning....................................................................... 52

2.11 Image and Statistical Analyses .............................................................. 54

2.11a Overview of Analyses.................................................................. 54

$2.11 \mathrm{~b}$ ImaGene Image Analysis............................................................ 54

$2.11 \mathrm{c}$ Evaluating Grid-to-Grid Variation........................................................ 55

2.11d Determining Presence/Absence of Signal............................................... $\quad 55$

2.1 le Microarray Data Normalization........................................................... 56

Within-Array Normalization ............................................................ 56

Between-Array Normalization.......................................................... 57

2.11f Principal Components Analysis .......................................................... 58

Identifying Outliers....................................................................... 58

Evaluation Batch Effects.............................................................. 59 
$2.1 \mathrm{~g}$ Significance Testing............................................................................. 59

$2.11 \mathrm{~h}$ Clustering Algorithms...................................................................... 60

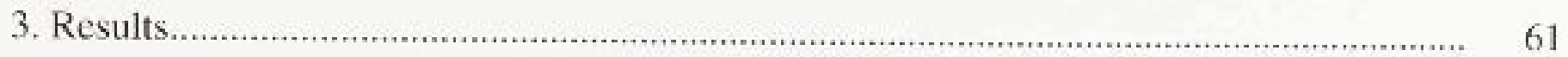

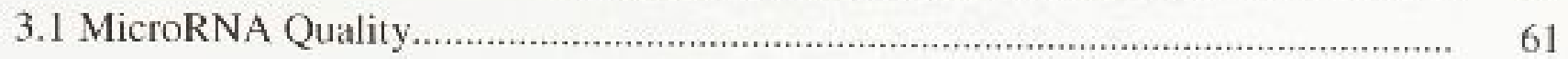

3.2 Evaluating Carry-Over Contamination............................................................. 63

3.3 Evaluating Grid-to-Grid Variability .................................................................. 66

3.4 Microarray Data Normalization ....................................................................... 67

3.5 Outlier Determination....................................................................................... 71

3.6 Removing Batch Effects......................................................................... 72

3.7 Differences in MicroRNA Expression............................................................... 74

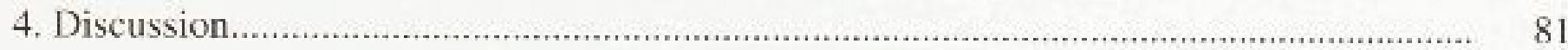

4.1 Creating a Custom MicrokNA Microarray Platform....................................... 81

4.1 la Designing and Printing the Microarrays ................................................ 83

4.1b Reference Design.............................................................................. 86

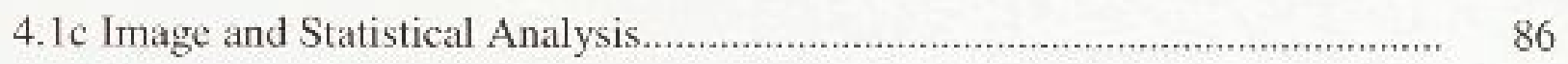

Normalization Techniques.................................................................. 86

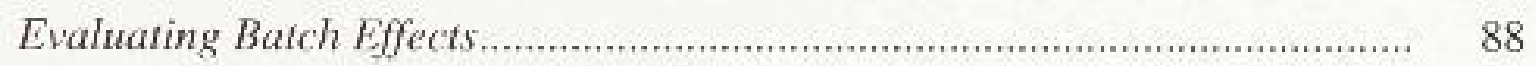

4.2 Comparison of mRNA and miRNA Expression Profiles.................................... 89

4.3 MicroR.VA Function................................................................................ 91

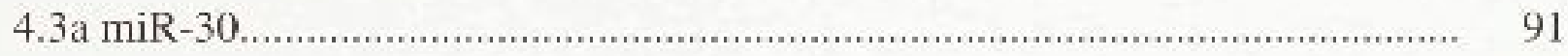

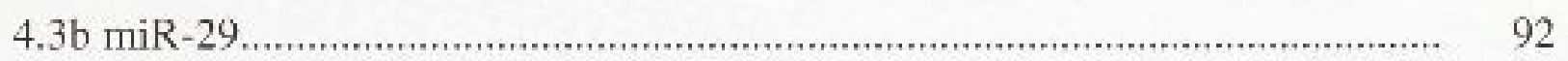

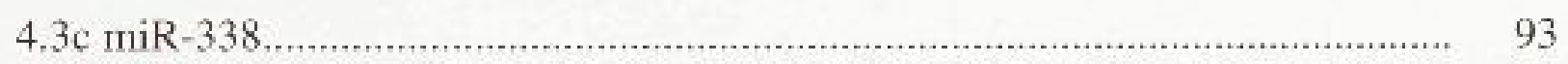

4.4 Limitations and Future Research................................................................... 94

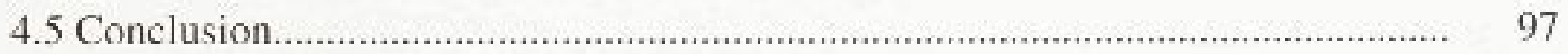

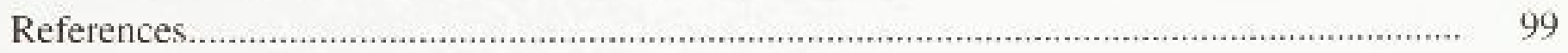




\section{List of Tables}

Table 1. Oligonucleotide sequences used for microarray printing optimization. 


\section{List of Figures}

Figure 1. mRNA expression differences at P7, 14 and 21 in HRs and LRs.

The top panel shows clear differences in mRNA expression between postnatal days 7, 14 . and 21 for both the hippocampus and nucleus accumbens. The bottom panel shows differences in mRNA expression at postnatal day 7 and 14 in the hippocampus only.

\section{Figure 2. Overview of microarray experimental procedure.}

The left branch consists of all steps associated with isolating, quantifying, and labclling miRNA samples, while the right branch consists of all steps associated with designing and printing the microarrays. Both branches converge at the hybridization stage.

\section{Figure 3. Reducing carry-over contamination.}

Probes were printed in columns from top to bottom, with columns on the left printed first. Highlighted areas show buffer-only spots. Left: Signal from buffer-only spots indicates observable carry-over. Right: Carry-over has been virtually eliminated after increasing pin washing and sonication and covering unused air-holes.

\section{Figure 4. Evaluating spot donuting.}

The distance the printing pins travel downward towards the slides was manipulated to evaluate the effect on spot donuting. The top pancl shows z chip down settings of 109.58 $\mathrm{mm}$ and $109.30 \mathrm{~mm}$, respectively, with little difference in the degree of donuting. The bottom shows a z chip down setting of $109.23 \mathrm{~mm}$, which reduced donuting, but resulted in missing spots due to printing pins not reaching the slide surface.

\section{Figure 5. Effects of various NCode spike-in control dilutions on signal intensity.} The log-mean of median signal intensities are plotted against on-chip log-NCode spot concentration for four different spike-in concentrations. Due to Alexa Fluor 5 degradation caused by high ozone concentrations, data is from the green (Alexa Fluor 3) channel only. Since standard normalization requires both channels, data is unnormalized.

Figure 6. Schematic of the microarray layout.

Each numbered box represents a grid printed by one pin. Each grouping of eight grids is a supergrid, and each supergrid is printed six times on each microarray.

\section{Figure 7. Schematic of grid design.}

Probes were printed in columns from top to bottom, with columns on the left printed first. The set of various control spots were printed in random order in an evenly spaced pattern within each grid. The highlighted pairs of spots represent the spots used to assess carryover.

\section{Figure 8. GenePix microarray image.}

Left: Image of an entire microarray consisting of six technical replicates and spots. Along the right are close-ups of a section of the microarray showing signal from the green (experimental) channel (top); signal from the red (reference) channel (middle); and signal from both channels combined (bottom). 
Figure 9. Experion automated electrophoresis results.

Top: Results from a typical total RNA extraction, showing peaks associated with the $18 \mathrm{~S}$ and $28 \mathrm{~S}$ ribosomal fragments $[28 \mathrm{~S}: 18 \mathrm{~S}=1.92]$. Bottom: Results from a typical miRNA extraction from the same hippocampal tissue, showing depleted $18 \mathrm{~S}$ and $28 \mathrm{~S}$ ribosomal fragments and a peak associated with smaller RNA fragments.

Figure 10: Evaluation of carry-over contamination per printing pin. Top: Plot represents a typical microarray showing consistent and low carry-over $(\%)$ across all printing pins. Bottom: Plot represents a microarray with the highest proportion of carryover $(\%)$ in all grids printed by printing pin 4 .

Figure 11. Carry-over contamination (\%) across all microarrays. Carry-over contamination (\%) was computed using the formula [C-A]/[B-A] x 100 for each array and for both channels separately. The arrays are grouped according to experimental condition (LR/7, LR/14, LR/21, HR/7, HR/14, HR/21) and the arrays showing pin-specific carry over are highlighted.

Figure 12. Grid-to-grid variation for a typical microarray.

The average signal intensity for five NCode control spot concentrations are plotted as a function of grid number for both the red and green channels. Variation in signal intensity is relatively stable from top-to-bottom, but there is an approximate two-fold difference in signal intensity from left-to-right. Data are non-normalized.

\section{Figure 13. Scatterplot of median signal intensities for Alexa Fluor 3 and Alexa Fluor 5.}

The non-normalized signal intensities are relatively balanced between channels and the NCode control series (red) covers the full range of signal intensities with no gaps in the signal.

\section{Figure 14. MA plots before and after Loess normalization.}

MA plots show microarray data both before and after within-array normalization for an array that passed quality control measures and was included in the analysis (top) and an array that failed quality control measures and was excluded from analysis.

\section{Figure 15. Boxplot before and after quantile normalization.}

Each boxplot displays the intensity values for the green and red channels separately for each array. Before normalization, there is considerable variability between the arrays (top). Quantile normalization adjusted the expression values for each channel independently, reducing the variation between arrays.

Figure 16. Principal Components Analysis to identify outlier microarrays. PCA plot shows distribution of arrays on PCI versus PC3. Of the 39 microarrays included, six were identified as outliers and were excluded from subsequent analysis. 
Figure 17. Effect of hybridization date and extraction date on miRNA expression. PCA of the reference channel for all microarrays shows clear effects of both hybridization date (top) and miRNA extraction date (bottom) on miRNA expression profiles. In addition, hybridization date segregates in a temporal pattern across PC1.

Figure 18. Effect of strain and age on miRNA expression.

PCA plot shows distribution of arrays on $\mathrm{PC} 1$ versus $\mathrm{PC} 2$. PCA shows a clear effect of developmental age on miRNA expression top). However, PCA shows no obvious effect of HR/LR phenotype on miRNA expression (bottom).

Figure 19. Heat map of miRNAs differentially expressed between PND 7, 14, and 21 . 62 rat miRNAs showing significant differences in expression across postnatal days 7,14 and 21 are displayed from left to right.

Figure 20. Expression profiles for miRNAs showing significant differences between PND 7, 14, and 21.

Cluster analysis was used to classify the 62 significantly expressed genes into 12 groups showing similar expression profiles across postnatal days 7,14 , and 21 (x-axes).

Figure 21. Expression profiles for miRNAs showing significant differences between High and Low Responders across all time points.

Cluster analysis was used to classify the three significant genes into two groups showing similar expression profiles when data are combined from all timepoints. For each gene, $x$ axes show expression at PND 7, 14, and 21 for HR and LR. respectively.

Figure 22. Expression profiles for miRNAs showing significant differences between High and Low Responders at postnatal day 14.

Cluster analysis was used to classify the three significant genes into two groups showing similar expression profiles at PND 14. For each gene, $x$-axes show expression at PND 7, 14 , and 21 for HR and LR, respectively.

Figure 23. Expression profiles for miRNAs showing significant differences between High and Low Responders at postnatal day 21.

Cluster analysis was used to classify the nine significant gencs into four groups showing similar expression profiles at PND 21. For each gene, $x$-axes show expression at PND 7, 14 , and 21 for HR and LR, respectively.

Figure 24. Comparison of mRNA and miRNA expression profiles for both age and strain.

The top panel shows clear differences in both mRNA (left) and miRNA (right) expression between postnatal days 7,14 , and 21 in the hippocampus. The bottom panel shows differences in mRNA expression at postnatal day 7 and 14 (left), but no obvious differences in miRNA expression at any of the developmental time points (right). 


\section{List of Abbreviations and Acronyms}

5-HIAA - 5-hydroxyindoleacetic acid

5-HT1A - 5-hydroxytryptamine 1 A

ACTH - adrenocorticotropic hormone

AGO - Argonaute

ATP - adenosine triphosphate

BDNF - brain-derived neurotrophic factor

BSA - bovine serum albumin

CCR 4 - chemokine (C-C motif) receptor 4

CDC42 - cell division cycle 42

CNS - central nervous system

COXIV - cytochrome c oxidase

CREB - cAMP response element-binding protein

$\mathrm{CRH}$ - corticotrophin releasing hormone

CTDSP1 - CTD (carboxy-terminal domain) small phosphatase 1

CTGF - connective tissue growth factor

DCP1 - decapping protein 1

DCP2 - decapping protein 2

DDT - dithiothreitol

DECP - diethylpyrocarbonate

DOPAC - 3, 4-dihyroxy-phenylacetic acid

EDTA - ethylenediaminetetraacetic acid

eIF4E - eukaryotic translation initiation factor 4E

eIF6 - eukaryotic translation initiation factor 6

FMRP - fragile- $X$ mental retardation protein

GAL - gene array list

GILZ - glucocorticoid-induced leucine zipper

GR - glucocorticoid receptor

HPA - hypothalamic-pituitary-adrenal

HR - high responder

HVA - homovanillic acid

LC-NE - locus coeruleus-norepinephrine

Limk1 - LIM-domain kinase 1

LR - low responder

MeCP2 - methyl CpG-binding protein 2

MID - Middle (domain)

miRNA - microRNA

MR - mincralocorticoid receptor

mRNA - messenger RNA

$\mathrm{NE}$ - norepinephrine

NOT1 - negative regulator of transcription 1

$\mathrm{P}$ bodies - processing bodies

PAZ - Piwi-Argonaute-Zwille (domain)

PCA - principal components analysis

$\mathrm{PCR}$ - polymerase chain reaction 
PFC - prefrontal cortex

Pitx 3 - paired-like homeodomain transcription factor 3

Pmp 22 - peripheral myelin protein 22

PMT - photomultiplier tube

PND - postnatal day

Pre-miRNA - precursor microRNA

Pri-miRNA - primary microRNA

PVN - paraventricular nucleus

REST - RE1-silencing transcription factor

RISC - RNA-induced silencing complex

RNAi - RNA interference

RQI - RNA quality indicator

SAM - significance analysis of microarrays

SCPI - sarcoplasmic calcium-binding protein 1

SDS - sodium dodecyl sulphate

siRNA - short interfering RNA

SSC - saline sodium citrate

SSS - sensation seeking scale

TBE - tris-borate-EDTA

UTR - untranslated region

XRN1 - exoribonuclease enzyme 1 


\section{Introduction}

\subsection{Overvicw of Gene Expression and Regulation}

The genetic information contained in DNA is expressed through two stages: transcription of DNA into messenger RNA (mRNA), and translation of mRNA into protein. Transcription begins when RNA polymerase binds to a special region at the start of the gene known as the promoter. Upon binding, RNA polymerase moves along the template strand of DNA, synthesizing a complementary strand of RNA, until it reaches a terminator sequence. The initial product of transcription is called the primary transcript. which is immediately modified in the nucleus to produce mature mRNA. Following export to the cytoplasm, translation of mRNA into protein is achieved as the ribosome moves along the mRNA, reading the genetic code as a scries of codons that encode for amino acids that are added to the growing polypeptide chain (Lcwin, 2006).

The ability of organisms to produce specific types of cells in the appropriate locations at the right developmental times requires precise control of very large sets of genes. The basic principle of regulation is that gene expression is controlled by regulatory molecules that interact with specific sequences or structures in DNA or mRNA at a point prior to the synthesis of protein. For instance, RNA polymerase Il cannot initiale gene transcription without interaction with specific regulatory proteins called transcription factors. Although initiation of transcription is the first and best characterized level of gene regulation, regulation can also occur at the level of translation and protein degradation (Lewin, 2006). In addition to transcription factors, a range of regulatory molecules have been implicated in the regulation of gene expression (Carrington \& 
Ambros, 2008). Of these, a newly discovered class of small regulatory RNA molecules called microRNAs are receiving a lot of attention.

This thesis will investigate differential miRNA expression between two groups of rats exhibiting differences in stress responsivity. I will first give a general introduction to miRNAs, followed by a description of their general importance in CNS development and function, both in the normal brain and in pathology. This will be followed by a description of the specific animal model used.

\subsection{What is a MicroRNA?}

MicroRNAs are endogenous, approximately 22 nucleotide single-stranded RNA molecules that play important roles in regulating gene expression in animals and plants by targeting specific mRNAs for degradation and/or translational repression. Although their discovery was relatively recent, miRNAs make up one of the most abundant classes of gene regulatory molecules and influence the output of thousands of protein-coding genes (reviewed by Bartel, 2004).

The first miRNA was discovered in 1993 through a genelic study of the nematode, Caenorhabditis elegans. Lee et al. (1993) found that the gene lin-4 was transcribed not into a protein, but into a small single-stranded RNA molecule that controlled early larval development. This lin-4 miRNA substantially downregulated the protein lin-14, without noticeable changes in the levels of lin-14 mRNA, through interaction with multiple partially complementary sequences in the $3^{\prime}$ untranslated region (CTR) of the lin-14 mRNA (Wightman et al, 1993). This finding introduced the possibility that lin-4 may represent a novel class of non-protein coding regulatory genes that control mRNA translation through partial antisense interaction. Although this idea 
was not immediately validated, the discovery of a second miRNA, let-7, implicated in the timing of $C$. elegans development strengthened the notion of a previously undiscovered group of small regulatory RNAs (Reinhart et al, 2000). This discovery also revealed sequence conservation of these molecules across a wide range of species, as let-7 miRNA has since been detected in samples from various invertebrate and vertebrate species (Pasquinelli et al., 2000: Lagos-Quintana et al, 2001; Lau el al., 2001; Lee \& Ambros, 2001). Several other miRNAs have also been identified that are highly conserved across species, especially between more closely related animals such as mouse and human (Lagos-Quintana et al., 2001). As a result of these findings, an explosion of miRNA research has led to the discovery of hundreds of miRNA genes in animals, plants, and viruses, with more being discovered on a regular basis (Bartel, 2004; Murchison \& Hannon, 2004). To date (September, 2009), a total of 706, 547, and 286 miRNAs have been identified in the human, mouse, and rat, respectively (Griffiths-Jones et al., 2008).

\subsection{Biogenesis of MicroRNA}

An expanding body of miRNA research in the past decade has led to a growing understanding of the biogenesis and function of mammalian miRNA. MiRNA genes are located in either intergenic regions (Mallory \& Vaucheret, 2004), or inside the noncoding introns of protein-coding genes (Ying \& Lin, 2005; Lin et al., 2008). Both classes are transcribed mainly by RNA polymerase II (though a subset are transcribed by RNA polymerase III (Borchert et al, 2006)), producing long primary transcripts (pri-miRNAs) containing the mature miRNA sequence bordered by varying amounts of additional RNA necessary for downstream processing of the molecule (Cai et al., 2004; Lec et al., 2004; Zeng \& Cullen, 2005). The pri-miRNA is then cleaved by the Drosha-DGCR8 
Microprocessor complex into a shorter hairpin-shaped precursor miRNA (pre-miRNA), approximately 70 nucleotides in length (Lee et al., 2003; Denli et al., 2004; Kim, 2004; Gregory et al., 2004; Han et al., 2004; Han et al., 2006). Upon export from the nucleus to the cytoplasm by the exportin-5 transporter (Yi et al., 2003; Bohnsack et al., 2004; Lund et al., 2004), the pre-miRNA is further processed by the Dicer enzyme (Bernstein et al., 2001; Grishok et al., 2001; Hutvagner et al, 2001; Ketting et al., 2001; Knight \& Bass, 2001 ) into a short-lived double-stranded miRNA intermediate. Finally, this miRNA duplex is unwound and the strand with the highest pairing energy at the 5 end (the passenger strand) is degraded, while the other strand (the guide strand) remains as a mature 19-25 nucleotide miRNA (Schwarz et al., 2003; Bartel, 2004) This represents the functional end product of the miRVA gene.

\subsection{MicroRNA Targets Specific mRNAs to Regulate Gene Expression}

The mechanisms through which miRNA exert regulatory control of gene expression were informed by studies looking at other gene silencing mechanisms involving regulatory RNA. In the RNA interference (RNAi) pathway, short interfering RNA (siRNA) is incorporated into a complex of proteins called an RNA-induced silencing complex (RISC) that guides mRNA cleavage through perfect base complementarity between the siRNA and the target mRNA. The miRNA pathway works in a similar manner, except the miRNA-guided RISC regulates gene expression by either repressing translation or degrading $\mathrm{mRNA}$ through imperfect base complementarity between the miRNA and the target mRNA (Song \& Joshua-Tor, 2006; Peters \& Mcister, 2007. 
The mature miRN $\Lambda$ is incorporated into the RISC (Mourelatos et al., 2002; Schwarz et al., 2003; Bartel, 2004; Sonthcimer, 2005), which is often located in cytoplasmic compartments called RNA processing bodies ( $\mathrm{P}$ bodies) that act as sites of mRNA degradation and storage (Sen \& Blau, 2005). Although other proteins constitute RISC, the major components of the complex are of the Argonaute (AGO) family. These proteins are involved in the selection of the guide strand to be incorporated into the RISC and they carry out the catalytic functions of the complex. More specifically, the PiwiArgonaute-Zwille (PAZ) domain of AGO, with cooperation from the middle domain (MID), anchors short single-stranded RNA molecules into specilic binding pockets to guide the RISC to the target mRNA (Okamura et al, 2004; Song \& Joshua-Tor, 2006), and the PIWI domain confers the catalytic functions of the RISC by cleaving complementary mRNA to prevent translation. It should be noted that not all AGO proteins are active as endonucleases. For instance the cleavage-competent $\mathrm{AGO} 2$ contains a calalytic histidine residue in the PIWI domain that is replaced by arginine in the cleavage-incompetent AGOI protein (Rivas et al., 2005). These AGO protein complexes have been implicated in several different RNA silencing pathways, including the RNAi pathway and the miRNA pathway. The specific gene silencing mechanism that the AGO proteins mediate depends on both the identity of the small bound RNA and the specific mRNA being targeted. In addition, work on $D$. melanogaster suggests that different Argonaute proteins mediate the action of either siRNA or miRNA, and that there are therefore inherent differences between siRNA-RISCs and miRNA-RISCs (Okamura et al., 2004). 
Focusing specifically on the miRNA pathway, once the miRNA guide strand is loaded into the RISC, the complex identifies target mRNAs based on imperfect sequence complementarity between the integrated miRNA and sequences typically contained in the 3, UTR of the target mRNA (Chendrimada et al., 2005; Chendrimada et al., 2007). For target recognition, complementarity within a region of the miRNA located from positions 2-8 starting at the 5 ' end, termed the 'seed region', is of particular importance. The subsequent base-pairing between the miRNA and corresponding mRNA target results in one of two basic modes of action, either translational repression or mRNA degradation. The degree of complementarity between the miRNA and the mRNA target appears to be the main factor determining which of these two actions take place (Lee et al., 1993; Reinhart et al., 2000; Pasquinelli \& Ruvkun, 2002; Lee et al., 2004), though additional factors such as other RNA binding proteins or specific tissue and cell types may also play a role (Kedde et al., 2007).

The exact mechanisms for miRNA-direcled translational repression and mRNA degradation are not entirely clear. However, there are several proposed models. Translational repression can occur at both pre- and post-initiation stages, miRNAs that influence the initiation stage affect only cap-dependent translation, in which the mRNA 5 ' cap structure recruits the $40 \mathrm{~S}$ ribosomal subunit to initiate translation. $\mathrm{AGO}$ proteins contain structural similarities to eukaryotic translation initiation factor $4 \mathrm{E}$ (eIF4E), a capbinding protein that is necessary to start cap-dependent translation. Thus, competition between $\mathrm{AGO}$ and $\mathrm{EIF} 4 \mathrm{E}$ may repress translation. Another possibility is that AGO proteins recruit eukaryotic translation initiation factor 6 (eIF6), a protein that binds to the large ribosomal subunit to prevent binding of the smaller subunit, consequently inhibiting 
translation. Post-initiation mechanisms can affect both cap-dependent and capindependent translation. One model, the ribosome "drop-off" theory proposes that in the presence of miRNA-directed RISC, ribosomes involved in translation are prone to premature termination of translation, while another model suggests that the RISC may recruit proteolytic enzymes to degrade the newly synthesized polypeptide as it emerges from the ribosome. In addition to repressing translation, miRVAs can also reduce concentrations of their target mRNAs. mRNA can be sequestered in P-bodies, where RISC recruits GW182 protein, which in turn recruits deadenylase enzyme CCR4-NOT1 to remove the poly(A) tail, followed by mRNA decapping by DCP1-DCP2 enzyme and finally mRNA degradation by the XRN1 exonuclease (reviewed by Hennessy \& O'Driscoll, 2008).

MiRNAs and their targets represent extremely complex regulatory networks, given that a single miRNA is estimated to bind to and regulate the expression of potentially hundreds of different mRNA targets, while a single mRNA target is also thought to be regulated by multiple different miRNAs (Lewis et al., 2003). In fact, based on bioinformatic predictions, it has been estimated that more than one-third of human mRNAs could be controlled by the several hundred miRNAs identified so far (Lewis et al, 2005). The resulting list of potential miRNA targets is long and defining actual target genes is challenging, especially given that miRNAs bind to their targets with imperfect complementarity. However, various target prediction programs are available that predict targets based on sequence homology. This approach is complemented by studies looking for inverse relationships between miRNA expression and expression of potential targets across various in vitro and in vivo expression systems. Both of these approaches offer a 
good starting point for the identification of specific miRNA targets, which can then be validated through experimentation (Guarnieri \& Dileone. 2008; Liu, 2008).

\subsection{Cellular Functions of MicroRNA}

The recent and rapid discovery of large numbers of miRNAs has surpassed researchers' abilities to keep up with determining all of their individual functions. However, the importance of miRNA-guided gene regulation is becoming increasingly evident as more miRNAs and their targets and functions are discovered. So far, miRNAs have been shown to function in a variety of cellular processes, including developmental timing, apoptosis, differentiation, myogenesis, cardiogenesis, and glucose and lipid metabolism (reviewed by Kloosterman \& Plasterk, 2006). Other studies have reported roles for miRNAs in specific cell or tissue types, including the development of myoblasts (Naguibneva, et al., 2006), adipocytes (Esau et al., 2004), immune cells (Baltimore et al., 2008), hematopoietic stem cells (Chen et al., 2004), and neuronal stem cells (Krichevsky et al., 2006). Although this list is by no means exhaustive, it illustrates the widespread and varied functions of miRNA. Here, 1 will focus on their role in the central nervous system, with particular emphasis initially on CNS development.

\subsection{MicroRNA and Central Nervous System Development}

Based on the diversity of cellular processes in which miRNAs have been implicated and the fact that the brain exhibits the most complex mRNA expression profile in the body (Fiore \& Schratt, 2007), it is not surprising that miRNAs play a vital role in many aspects of nervous system development and function. MiRNAs have been implicated as important post-transcriptional regulators of gene expression in the nervous 
system of both primitive organisms such as C. elegans (Chang et al., 2004) and D. melanogaster ( $\mathrm{Li} \&$ Carthew, 2005; Li et al., 2006), plus higher vertebrates, including humans.

Studies on the developing mammalian nervous system using both microarrays and in situ hybridization have shown that more miRNAs are expressed in the brain than in any other tissue, the expression of many miRNAs is exclusive to the CNS, and miRNA expression in the nervous system is complex and is regulated in both a spatial and temporal manner (Miska et al., 2004; Wienholds et al., 2005; Kapsimali et al., 2007). Some miRNAs, such as miR-9 and miR-125 are distributed evenly throughout the CNS, while others, such as $m i R-/ 24$ and $m i R-128$ are preferentially expressed in neurons, and miR-24 in astrocytes (Smirnova et al., 2005). Kapsimali et al. (2007) have also reported cell-type specific expression (ie: $m i R-2 I 8 a$ in motor ncurons), as well as regionally restricted expression (ie: $m i R-222$ in the telencephalon). Widespread temporal regulation during mouse nervous system development was demonstrated by Krichevsky et al. (2003), with miR-92b showing high expression in neuronal progenitors, but not in differentiated neurons, while $m i R-29 a$ is absent in embryonic tissue, but highly expressed in the adult cortex (Landgraf et al., 2007).

One way to demonstrate the general role of miRNAs in neural development is to inhibit all miRNA biogenesis through disruption of Dicer. In zebrafish, Dicer mutants show severe defects in neural tube morphogenesis due to abnormal neural differentiation, which can be corrected by injection of mature mir-430 miRNAs (Giraldez et al., 2005). Disruption of Dicer provides less direct evidence for a developmental role in mammals, as Dicer deficiency leads to death early in development, before neurulation occurs 
(Bernstein et al., 2003). However, deletion of Dicer specifically in the mouse telencephalic region at mid-gestation results in a reduction in forebrain size likely caused by apoptosis of differentiating neurons (Makeyev et al. 2007). Similarly, postnatal Dicer inactivation in the mouse cerebellum (Schaefer et al., 2007) and midbrain dopaminergic neurons (Kim et al., 2007) results in progressive loss of miRNAs, followed by neurodegeneration. Despite the large number of mammalian miRNAs discovered to date, very few have been individually studied in any detail; however, some of the best characterized miRNAs that function in CNS development are as follows.

\section{6a miR-124}

miR-124 is expressed exclusively in neurons in both the developing and adult nervous system and is one of the most abundant miRNAs in the brain (Krichevsky et al., 2003; Miska et al., 2004; Smirnova et al., 2005; Yu et al., 2008). Its role in neural development is supported by the observation that $m i R-124$ overexpression in mouse embryonic stem cells encourages them to differentiate into neurons (Krichevsky et al., 2006), miR-124 promotes the neural stem fate by repressing non-neuronal genes (Lim $e t$ al., 2005) and inhibiting Ctdsp1/SCP1 phosphatase, a component of the REST/NRSF transcriptional repression complex that normally inhibits expression of neuronal genes (Visvanathan et al., 2007).

\section{$1.6 \mathrm{~b}$ miR-132}

Another miRNA that is enriched in neurons, $m i R-132$, promotes the growth of neuronal processes by downregulating the expression of p250GAP, a protein involved in the regulation of neuronal differentiation. $m i R-132$ expression can be induced (thus promoting neuritegenesis) by neurotrophins such as BDNF, in a CREB-dependent 
manner (Vo et al., 2005). miR-132 has also been implicated in the neurodevelopmental disorder, Rett syndrome. This disorder can result from either over- or underexpression of methyl CpG-binding protein 2 (MeCP2), demonstrating that MeCP2 levels must be kept within a narrow range for normal development to take place, miR-132-mediated downregulation of $\mathrm{MeCP} 2$ is a critical component of this regulation, helping keep protein levels within the range required for normal neuronal maturation (Klein et al., 2007).

\section{6c miR-133b}

$m i R-133 b$, a recently discovered miRNA, is specifically expressed in midbrain dopamine neurons and inhibits their maturation (Kim et al, 2007). miR-I33b is thought to regulate dopamine neuron maturation through a negative feedback circuit involving Pitx 3, a transcription factor that promotes the differentiation and survival of dopamine neurons. miR-133b suppresses differentiation of dopamine neurons by repressing Pitx 3 expression. As previously mentioned, mice deficient in Dicer in specific dopamine neurons develop a progressive loss of neurons. These animals display Parkinson's-like behaviour, suggesting that loss of miRNAs, particularly miR-133h, may be involved in the development and progression of Parkinson's disease.

\subsection{MicroRNA Functions in the Mature Central Nervous System}

In addition to their role in development, miRNAs also function in the adult brain. In particular, their role in mediating local translational control of synaptic plasticity has received much attention (Kosik, 2006). Certain mRNAs in neurons are transported from the cell body to relatively distant dendrites and synapses (Eberwine et al., 2001); it is thought that miRNAs, either transported along with the mRVA or processed from pre- 
miRNAs in the dendrite (Kosik, 2006), may inhibit the translation of these mRVAs until the neurons are exposed to a particular extra-cellular stimuli such as a neurotrophic factor or neurotransmitter release at the synapse, at which time, local translation of these previously dormant mRNAs may mediate synaptic change (Schratt es al., 2006). Experimental support for miRNA involvement in synaptic plasticity, specifically miR134, has recently been reported and described by Schratt et al. (2006).

\section{7a miR-134}

$m i R-134$ is expressed in the hippocampus, with maximal expression observed at the time of peak synaptic maturation (Kosik, 2006). miR-134 is localized in the synaptodendritic compartments of rat hippocampal neurons and negatively regulates the size of dendritic spines by inhibiting the expression of LIM-domain kinase 1 (Limk 1) mRNA, which, when normally expressed, induces spine formation by regulating actin filaments. Though the precise mechanism is unknown, $m i R-/ 34$ is thought to maintain translational repression of Limk 1 mRNA until some synaptic input overrides the silencing (Schratt et al., 2006).

\section{7b miR-30a-5p}

miR-30a-5p is a miRN $\Lambda$ that is enriched in layer III pyramidal neurons and also functions in the mature CNS. Overexpression of $m i R-30 a-5 p$ results in down-regulation of brain-derived neurotrophic factor (BDNF), a developmentally regulated protein in the prefrontal cortex (PFC), particularly in adulthood. The precise mechanism is not known, but $m i R-30 a-5 p$ likely downregulates BDNF through translational repression, since BDNF protein levels decrease with age, while BDNF mRNA levels increases with age, until levelling off in adulthood (Mellios et al, 2008). Interestingly. layer III pyramidal 
neurons of the PFC display decreased dendritic spine density and soma size (Glantz \& Lewis, 2000), as well as a reduction in BDNF levels (Pierri et al., 2001) in patients with schizophrenia, suggesting a possible role for $m i R-30 a-5 p$ in this disease.

\subsection{MicroRNAs and Neurological Disease}

Given the role of miRNAs in synaptic development, it is not surprising that a neurological disease commonly associated with miRNAs is the fragile X syndrome (FX). a form of mental retardation characterized at the neuronal level by abnormalities in the structural development of dendritic spines (Penagarikano et al., 2007). Jin et al. (2004) found an interaction between the fragile-X-mental retardation protein (FMRP), which is downregulated in fragile $\mathrm{X}$ syndrome, and components of the miRNA RISC machinery, particularly the Argonaute proteins. Recent analyses in both Drosophila and mammals indicate that FMRP and miRNAs cooperate in repressing dendritic mRNA expression; deregulation of this process is thus thought to underlie FX.

In addition to the disorders already mentioned, miRNAs have been implicated in a range of other neurological diseases, including neurodegenerative diseases such as Alzheimer's and Huntington's disease, as well as Tourette syndrome, William syndrome, spinal muscular atrophy, and cancer. Although the exact roles of miRNAs in these diseases is unclear, the discovery of the association between miRNAs and neurological diseases has generated a novel area of research, with the hopes that manipulating specific miRNA levels might represent a promising approach to restoring physiological levels of essential miRNA targets (reviewed in Fiore \& Schratt. 2007 and Barbato et al., 2008). 


\subsection{A Role for MicroRNAs in the HPA Axis Response to Stress}

miRNAs have also been implicated as potential factors in the development of stress-related disorders. In response to stress, the hypothalamic-pituitary-adrenal (HPA) axis controls the production and release of adrenal glucocorticoids, which travel through peripheral circulation to act on numerous target organs, including the brain. The brain structures involved in the HPA axis are critical to defining a stressor and determining the magnitude and duration of the response it deserves. In response to stress, the paraventricular nucleus (PVN) of the hypothalamus secretes corticotrophin-releasing hormone (CRH), which binds to receptors on the corticotrophs of the anterior pituitary to secrete pro-opiomclanocortin and release one of its active peptides, the adrenocorticotropic hormone $(\mathrm{ACTH})$ into general circulation. ACTH then binds to receptors on the adrenal gland to stimulate the production and release of glucocorticoids. Following stress-induced activation of the HPA axis, corticosterone binds to hippocampal glucocorticoid receptors (GRs) and mincralocorticoid receptors (MRs), leading to a negative feedback mechanism that restores the stimulated HPA axis to basal levels (Kabbaj, 2004).

Research on the link between miRNAs and stress responsiveness is minimal. However, one study in particular has shown promising results for a relationship between miRNA and stress. Different strains of rat have been shown to have different neuroendocrine responses to stress. For instance, Fischer 344 rats are known to consistently present exaggerated stress-induced corticosterone secretion relative to Sprague-Dawley and Lewis strains (Dhabhar et al., 1995, 1997). In an investigation of the possible involvement of miRNA in this differential stress responsiveness, Uchida et 
al., (2008) found that in the PVN, GR protein levels are lower, while miR-18a levels are higher in F344 rats compared to Sprague-Dawley controls, suggesting that miR-18a may downregulate GR translation. In addition, expression of miR- 18 and miR- $124 a$ coincides with a decrease in GR protein levels, a reduction in GR-mediated events, and impaired activation of the glucocorticoid-induced leucine zipper (GILZ) gene (Vreugdenhil et al., 2009). In light of this, these miRNAs, as well as other currently unidentified miRNAs may be involved in the regulation of the HPA axis response to stress. The fact that target sequences of miR-18a of the GR 3' UTR are well conserved among human, rat, and mouse, and the miR-18a sequence is completely conserved among these species, presents the possibility that enhanced expression of miR-18a may be a factor in the vulnerability of the development of stress-related disorder's.

It is evident that miRNAs are emerging as important regulators of gene function in the CNS. However, studies of the role of miRNAs in regulating stress responses are still in their infancy. This thesis therefore aims to characterize miRNA expression differences in hippocampal tissue of a rat model of variation in stress reactivity, namely the HR-LR model of stress reactivity.

\subsection{HR/LR Model of Stress Reactivity}

In humans, the "sensation-seeking" phenotype results in individuals that are drawn to situations that produce stress and anxiety (Bardo et al., 1996). Specifically, the "sensation-seeking" trait is characterized by: (1) thrill-secking through participation in exhilarating and risky activities; (2) the scarch for novel experiences and nonconforming lifestyles; (3) a lack of inhibition in the search for stimulation in social situations; and (4) 
vulnerability to boredom and restlessness in monotonous conditions (Dellu et al., 1992). Zuckerman and Neeb (1979) found that scores on the Sensation Seeking Scale (SSS) arc correlated with psychiatric disorders such as bipolar affective disorders, sociopathy, and drug and alcohol abuse. This "sensation-seeking" phenotype in humans is analogous to the "novclty-seeking" phenotype exhibited by some rats, making it a well established animal model of individual differences in sensation-seeking. In this model, SpragueDawley rats can be classificd as either high responders (HR) or low responders (LR) based on their locomotor response to the mild stress of a novel environment. In parallel to "sensation-seeking" humans, IIR animals show a similar predisposition for stressful and anxiogenic situations, as shown by their increased willingness over LR rats to seck out and explore aversive environments (Dellu et al., 1993). This behaviour typically initiates stress and anxiety responses that differ between HR and LR animals, which led to the adoption of this model as studies focused on stress responsiveness. When subjected to the stress of a novel environment, although high responders appear to be less anxious, they actually show greater activation of the HPA axis, leading to enhanced and prolonged secretion of corticosterone, relative to more anxious low responders (Piazza et al., 1989; Dellu et al., 1996). Thus. HR rats are more active and explore novel conditions more readily than LR rats, even though it induces in them a higher stress response. $A$ possible explanation for this differential stress response is that the mineralocorticoid receptors of HR show reduced sensitivity to noradrenaline, which has been shown to regulatc MRs independently of corticosterone fluctuations, resulting in less efficient negative feedback of corticosterone following stress (Kabbaj et al., 1996; Kabbaj et al.. 2007). In addition, HR rats self-administer corticosterone more readily than LR rats, indicating both that 
corticosterone has positively reinforcing properties, and that these properties are stronger in HRs (Piazza et al., 1993). Furthermore, this implies that HR rats seek out more stressful environments not despite the resulting elevation in corticosterone levels, but because of its rewarding properties.

In addition to differences in novelty-sceking and stress reactivity, numerous studies have reported behavioural and/or neurobiological differences between high and low responders related to vulnerability to drug and substance abuse, anxiety, emotional reactivity, and cognitive functions. I will first describe these differences in regards to behaviour, followed by neurobiological distinctions, differential gene expression, and environmental influences on the HR/LR phenotype.

\subsection{HR/LR Model of Drug Addiction}

This model has been used to examine phenomena such as sensation-seeking and stress responsiveness. However, it was originally proposed by Piazza and colleagues (1989) as a model to investigate individual differences associated with susceptibility to drug abuse. Today, many studies using the HR/LR model of individual differences have shown that high responders and low responders show substantial differences in their vulnerability to drugs of abuse. For example, HRs exhibit significantly higher locomotor reactivity to amphetamine (Exner \& Clark, 1993; Hooks et al., 1991; Piazza el al., 1989), are more likely to acquire amphetamine self-administration, and show significant sensitization to repeated amphetamine administration, compared with LRs (Klebaur et al., 2001a; Piazza et al., 1989; Pierre and Vezina, 1997; Hooks et al., 1991). Interestingly, not only do animals with a higher tendency to acquire amphetamine self- 
administration (HRs) exhibit a higher novelty-induced corticosterone secretion, but corticosterone administration to LR rats makes them behave more like HR rats by inducing amphetamine self-administration (Piazza et al., 1991). Thus, this increase in HPA activity and subsequent release of corticosterone may offer a neurobiological explanation of psychostimulant addiction. Not surprisingly, high and low responders show similar differences in their responses to cocaine, with HRs exhibiting a grcater locomotor response and a higher rate of self-administration than LRs (Hooks et al., 1991; Gong et al., 1996; Kabbaj et al., 2001). In addition, treatment with morphine (Deroche $e$ t al., 1993; Kalinichev et al., 2004) and scopolamine (Hooks et al., 1991) induces significantly stronger locomotor reactivity in HRs, and they acquire nicotine selfadministration more readily than their LR counterparts (Suto et al, 2001). HR animals also consume more ethanol and display significantly higher locomotor scores than LRs after an ethanol challenge (Hoshaw et al., 1999, 2000).

\subsection{HR/L.R Behavioural Differences}

As previously mentioned, novelty-seeking individuals appear to be drawn to stressful situations and environments that are normally avoided by others. Dellu et al. (1993) report that HR rats exhibit a strong tendency to seek novel and stressful conditions, as shown by significantly more novel-arm visits in a y-maze and 16-arm radial maze, than LR rats. HR animals also show less anxiety-like behaviour in the elevated plus-maze (Kabbaj et al., 2000; Stead et al., 2006; White et al., 2007), defensive withdrawal test (White et al., 2007), lighı/dark anxiety test (Dellu et al., 1994; Kabbaj et al., 2000; Stead et al., 2006), and the open field test (Stead et al., 2006). Surprisingly, 
while HRs place themselves in more anxiogenic environments, they are also more reactive when faced with anxiogenic stimuli. For example, in the acoustic startle-induced vocalization test, $\mathrm{HR}$ rats showed greater anxiety-like behaviour than $\mathrm{LR}$ rats, initialing vocalization more quickly and for a longer duration in response to a series of loud acoustic stimuli (White et al., 2007).

Studies on learning and memory also show differences between HR and LR animals. Learning and memory of aversive stimuli, measured by the passive avoidance test (Borta \& Schwarting, 2005), and working memory, measured by the novel object recognition test (Antoniou ef al, 2008), show impairments in HR animals. Conversely, HRs exhibit enhanced spatial learning and memory in the Morris water maze, compared with LRs (Antoniou et al., 2008).

Similar to the observation in vulnerability to drug abuse, there is significant individual variability in the severity of age-related impairments. Indeed, although both HR and LR rats perform similarly well at earlier time points, only HR rals display significant age-related memory impairments, suggesting that the novelty seeking tendency observed in young HR rats may predict cognitive impairments later in life (Dellu et al., 1994).

There are also differences between high and low responders in both basal and stress-induced sleep-wakefulness parameters. Basally, HRs sleep less and exhibit lower amounts of slow wave sleep than LR animals; however. after exposure to an acute immobilization stress, the pattern is reversed, with HR rats sleeping more and cxhibiting increases in slow wave sleep compared with LR rats (Bouyer et al., 1998). HR animals show enhanced dopamine activity in the nucleus accumbens, which increases 
wakefulness and decreases slow wave sleep, while the differential neuroendocrine response to stress between HR and LR animals likely underlies the stress-induced alterations in sleep-wakefulness.

\subsection{Neurobiological Basis of HR/LR Phenotypes}

Although the neural basis for these individual differences in response to novelty is not fully understood, the mesocorticolimbic dopamine system is thought to be involved due to its role in the reinforcing and motor cffects of psychostimulants (Kalinichev et al, 2004). Several studies have shown differences in both basal and stimulated levels of dopamine in the nucleus accumbens, striatum, and medial prefrontal cortex between IR and LR animals. As mentioned, HR rats exhibit a greater basal level of dopamine in the nucleus accumbens than LR rats and also show a greater increase in extracellular dopamine levels to an amphetamine or cocaine challenge compared to LR rats (Hooks et al., 1991a; 1992a). HR animals also exhibit reduced dopaminergic activity in the cortex and enhanced activity in the nucleus accumbens and striatum, as measured by levels of DOPAC, a metabolite of dopamine (Piazza et al., 1999). Consistent with this finding, Saigusa et al. (1999) report a novelty-induced increase in the extracellular concentration of accumbal dopamine in HR rats and Antoniou et al. (2008) found higher tissue concentrations of dopamine and homovanillic acid (HVA) in the striatum and DOPAC in the hypothalamus of HR rats compared to LR rats. In addition, tyrosine hydroxylase (the rate-limiting enzyme in dopamine synthesis), is elevated in the nucleus accumbens of HR rats compared to LR rats (Miserendino et al., 1993). High and low responding animals also react differentially to released dopamine, with considerable differences in dopamine 
receptor density. For example, a significant decrease in $\mathrm{D}_{2}$ receptor $\mathrm{mRNA}$ and dopamine binding in HR rats has been observed in the nucleus accumbens and striatum (Hooks et al., 1994; Kabbaj, 2004).

The serotonergic system also plays a role in the reinforcing properties of psychostimulants, thus it is not surprising that there are differences in serotonergic activity between HR and LR animals. High responders display lower levels of serotonin and 5-hydroxyindoleacetic acid (5-HLAA), a metabolite of serotonin, than low responders in the nucleus accumbens, striatum, and prefrontal cortex (Piazza et al., 1999). Antoniou and colleagues (2008) found similar results, with HR rats exhibiting a lower serotonin turnover ratio in the prefrontal cortex in comparison to their LR counterparts, although the serotonin turnover ratio and the tissue concentration of 5-HIAA in the striatum was found to be higher in HR rats. There are also differences in the expression of serotonin receptors, with $\mathrm{HR}$ rats exhibiting significantly lower levels of the 5-HTla receptor in the CA1 area of the hippocampus than LR rats (Kabbaj, 2004). However, this result is surprising given that 5-HT1 a knockout mice exhibit a significant decrease in cxploratory activity and an increase in anxiety-like behaviour (Ramboz et al.. 1998).

The locus coeruleus-norepinephrine (LC-NE) system also plays a role in the neurobiological differences observed between HR and LR rats. Although basal levels of $\mathrm{NE}$ in the hippocampus are not significantly different between HR and LR animals, stress-induced NE release is significantly higher in HR compared to LR rats, suggesting that both the fast and slow stress responses are similarly different between the two strains Rosario \& Abercrombie, 1999). 


\subsection{Differential Gene Expression between HR-LR Phenotypes}

Although these findings are compelling, neurotransmitter tissue concentrations alone cannot account for the differences observed between high and low responders. Using microarray technology, differences in basal and stress induced hippocampal gene expression between HR and LR animals have been identified that may be responsible in part for determining individual differences in emotional reactivity. Included in this list of differentially regulated genes are genes involved in extracellular cell signalling, neurotransmitter receptor related genes, intracellular signalling related genes, cell cycle regulator genes, transcription factors, and genes involved in biosynthesis/metabolism, ribosomal and structural functions. In addition, the majority of genes belonging to a class of genes involved in neurogenesis in the hippocampus are more abundant in LR relative to HR animals, suggesting that HR rats may have a slower rate of cell proliferation, differentiation, and transformation (Kabbaj et al., 2004). This idea is in agreement with the finding by Lemaire et al. (1999) that cell proliferation in the dentate gyrus is approximately two times lower in HR rats compared to LR rats and that cell proliferation in the dentate gyrus is negatively correlated with locomotor reactivity to novelty. Thus it appears as though neurogenesis in HR animals is significantly reduced.

High and low responders also show unique patterns of stress-related gene expression. For instance, CRH is expressed differentially between HR and LR animals, with HR rats expressing lower levels of basal CRH mRVA in the central nucleus of the amygdala than LR rats and higher levels in the PVN (Kabbaj et al., 2000). HR rats also exhibit significantly lower levels of basal glucocorticoid receptor (GR) mRNA in the CA1 field and dentate gyrus of the hippocampus than LR rats. This decrease in 
hippocampal GR may be responsible for the differential corticosterone secretion in response to novelty and may contribute to the increased novelty seeking and decreased anxiety exhibited in HR rats since infusion of RU38486, a GR antagonist, directly into the hippocampus leads to increased activity and novelty seeking in LR rats (Kabbaj et al., 2000). In addition to these basal differences, high and low responders also exhibit distinct patterns of brain activation following a stressful stimulus (Kabbaj \& Akil, 2001). After exposure to an anxiogenic stressor. HR animals show significantly higher expression of $c$-fos in the anterior olfactory nucleus, main olfactory bulb, lateral orbital cortex, cingulate cortex, caudate-putamen, and PVN, while exhibiting lower c-fos expression in the CA1 field of the hippocampus, suggesting that HR and LR animals not only start with different patterns of gene expression, but appear to respond to stressful situations distinctively as well.

\subsection{Environmental Influences on HR-LR Phenotypes}

Numerous studies have looked at behavioural and biological differences between HR and LR animals; however, there has been less research looking at what environmental factors may contribute to the development of these two phenotypes. For instance, HR and LR mothers interact differently with their young, with LR mothers generally more attentive to their pups compared to HR mothers (Clinton et al. 2007). In addition, it has been reported that DNA methylation of the GR promoter changes in response to maternal care. Mothers that exhibit increased pup licking, grooming and arched-back nursing of their young in the first week of life, produce offspring with differences in methylation of the GR promoter that remain consistent into adulthood and can be reversed with cross- 
fostering. This differential methylation results in increased histone acetylation and nerve growth factor-inducible-A (NGFI-A) transcription factor binding to the GR promoter, resulting in changes in GR expression and subsequent HPA axis responses to stress (Weaver et al., 2004). Thus, maternal care has an impact on gene expression in offspring and the development of the brain and HPA stress axis, possibly contributing to the differences observed between HR and LR animals. Environmental factors also likely act to modulate existing HR and LR phenotypes. For instance, chronic social defeat delays acquisition of cocaine self-administration in HRs and enhances self-administration in LRs (Kabbaj et al., 2000), while one week of social isolation inhibits IR's novelty-seeking behaviour, making them more like LR rats (Kabbaj et al., 2001).

\subsection{Selective Breeding for Divergence in Novelty-Seeking Traits}

The majority of studies using the HR-LR model have used outbred SpragueDawley rats classified as either high responders or low responders based on their adult behavioural response to a novel environment. Since the novelty-seeking trait is defined based on behaviour observed in adult animals, it has been impossible up until this point to study the development of these phenotypic differences. Based on this, and on issues of trait stability and heritability, Stead et al. (2006) have applied a selective breeding paradigm to enrich for the HR and LR traits in Sprague-Dawley rats, making developmental and genetic factors that play a role in variation in the stressresponsiveness of adults open to examination. After just one generation of selective breeding, a rapid response to selcetion for HR and LR traits was reported, with phenotypic divergence between selected lines increasing with almost every consecutive generation to a maximum divergence at generation S7, with locomotor responses to 
novelty in HR-bred males and females $123 \%$ and $145 \%$ higher than LR-bred rats, respectively. This breeding paradigm was also successful in its goal of being able to predict whether an animal would display the HR or LR phenotype at early developmental stages, with over $99 \%$ of all IIR animals from HR parents and $98 \%$ of all LR animals from LR parents by the fifth generation.

\subsection{Differential mRIA Expression in Developing HR-LR Rats}

A recent study investigating differences between fourth generation selectivelybred adult HR $(n=6)$ and LR $(n=6)$ rats used Affymetrix GeneChip RAE230A microarray analysis to identify mRN $\mathrm{A}$ differences in the hippocampus, hypothalamus, and frontal cortex. After false discovery rate correction, no genes were significantly differentially expressed between the two strains of rat (Stead \& Akil, unpublished data). While this is in an apparent contradiction to the data from Kabbaj et al. (2004), differences between the two studies included analysis of selectively-bred vs. non-sclectively bred rats, plus differences in the stringency of false discovery rate correction between the studies. To determine if gene expression differences did arise between these strains earlier in devclopment. mRNA expression was again analyzed by microarray between selectivelybred (generation F8) HR and LRs during development in the hippocampus, due to its role in the stress response, and the nucleus accumbens, due to its role in addictive behaviours. Microarray analysis at three early postnatal time-points (P7, P14, and P21) revealed no differences in the nucleus accumbens, but hundreds of significantly different genes between HR and LRs in the hippocampus at PND 7 and 14. Figure 1 shows a principal components analysis of the microarray data, with each spot representing one microarray 
slide and the distances between the spots representing the degree of similarity between each array (Stead, Clinton \& Akil, unpublished data). This shows that although developmental age produces the biggest differences in mRNA expression, differences between the two strains are apparent in the hippocampus at P7 and P14.

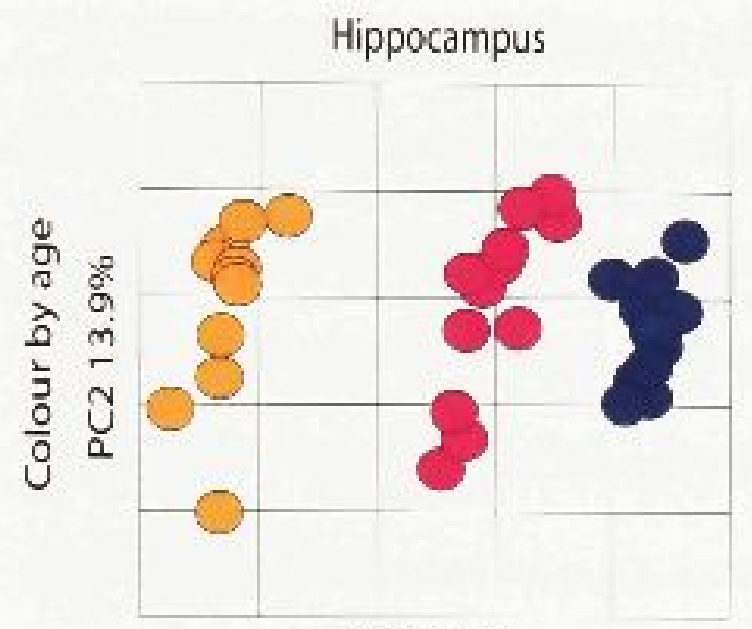

$P C 137.3 \%$

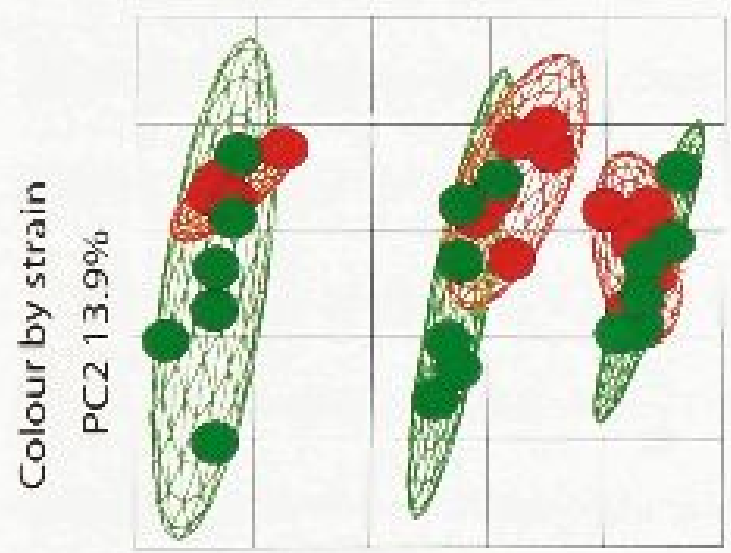

PC1 $37.3 \%$

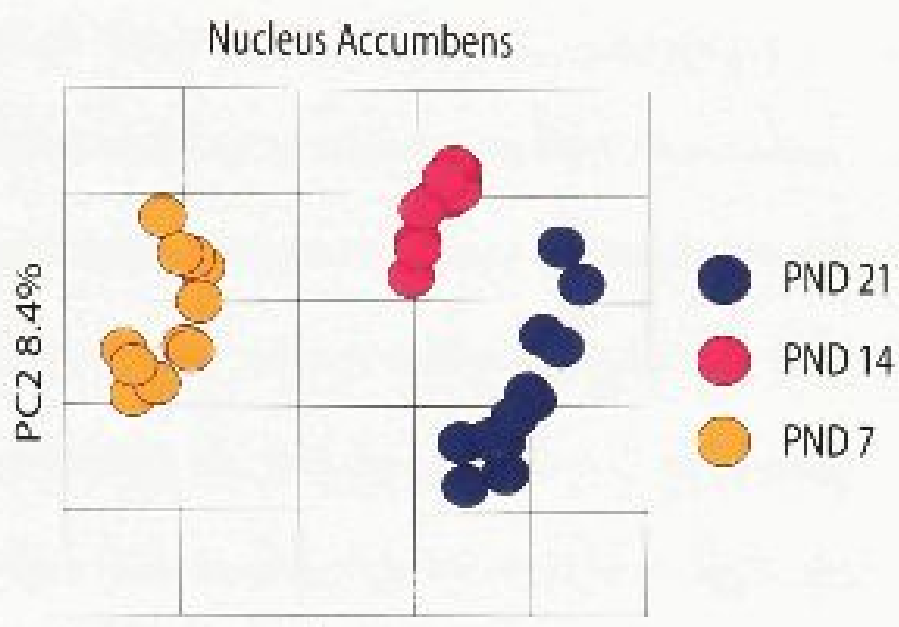

PC1 48.9\%

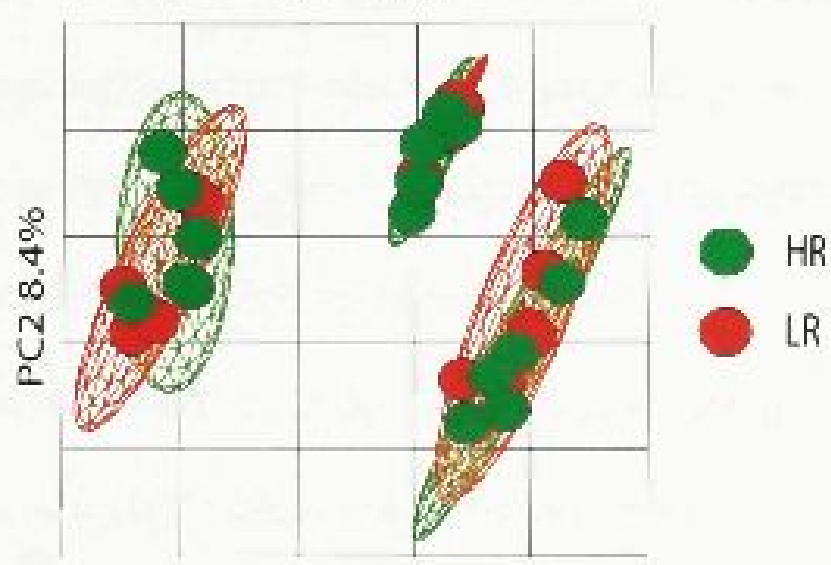

PC1 48.9\%

Figure 1: mRNA expression differences at P7, 14 and 21 in IRs and LRs. The top panel shows clear differences in mRNA expression between postnatal days 7,14 , and 21 for both the hippocampus and nucleus accumbens. The hottom panel shows differences in mRNA expression at postnatal day 7 and 14 in the hippocampus only. 


\subsection{Proposal}

As mentioned, the behavioural test used to identify the HR and LR phenotypes is conducted on adult animals. Therefore, in order to determine the genetic cause of these unique profiles it is important to identify early differences in gene expression that may serve as precursors to the differences observed later in life. By identifying differences in gene expression early on, it may give insight into the developmental factors that predispose individuals to respond differentially to stressful environments and situations.

The purpose of this thesis is twofold. The primary objective is to develop a custom miRNA microarray platform printed in-house to evaluate miRNA expression across various conditions. This will require the evaluation of various microarray printing parameters, the design of microarrays incorporating various within-chip controls, the assessment of labelling and hybridization procedures, and the evaluation of microarray quality assessment and data analysis options. The second objective will be to apply this platform to test the hypothesis that differences in miRNA expression between HR and LR rats will be present in the developing hippocampus at P7 and P14, but not P21, in at manner analogous to mRNA expression profiles, In addition, I hypothesize that miRNA expression differences may underlic some of the mRNA expression differences previously observed in these rats. To test this, I will be using microarray technology to identify a subset of differentially expressed miRNAs between selectively bred (generation S18) high responders and low responders at three different developmental time points, postnatal days 7,14 and 21 . Thus, there will be six experimental groups ( $\mathrm{n}=6$ ): (1) HR at PND 7; (2) LR at PND 7; (3) HR at PND 14; (4) LR at PND 14; (5) HR at PND 21; and (6) LR at PND 21. 
I will be looking at the hippocampus for several important reasons, specifically because HR and LR rats: (1) show differential mRNA expression in the hippocampus early in development (Stead, Clinton \& Akil, unpublished data); (2) show differential HPA axis activation in response to stress, with the hippocampus being an integral part of this system; (3) differ in basal hippocampal expression of glucocorticoid receptors (Kabbaj et al., 2000), (4) differ in hippocampal expression of $5 \mathrm{HTl}$ a serotonergic receptors (Kabbaj, 2004), (5) show differential hippocampal c-fos expression in response to an anxiogenic stressor (Kabbaj \& Akil, 2001), (6) exhibit differential neurogenesis in the hippocampus (Lemaire et al., 1999; Kabbaj et al., 2004), and (7) show differences in basal and stress induced hippocampal gene expression (Kabbaj et al., 2004). 


\section{Materials and Methods}

\subsection{Animals}

The animals used for this study were Sprague-Dawley rats selectively bred to enrich for the HR and LR traits. They were bred, behaviourally tested, and euthanized at the University of Michigan according to the University's Animal Ethics Commillee guidelines, which follow the procedures outlined in the Guide for the Care and Lse of Laboratory Animals (National Research Council, 1996).

The initial population was made up of 60 male and 60 female Sprague-Dawley rats from three different breeding colonies purchased from Charles River Laboratories (Kingston NY, Portage MI, and Saint-Constant QC). Rats were housed 2-3 per cage with other animals from the same colony and were allowed to acclimatize to their housing for two weeks before beginning behavioural testing. Males and females werc housed in separate rooms with males on a 12:12 light-dark cycle and females on a 14:10 light-dark cycle (lights on at $7 \mathrm{am}$ ). All animals had ad libitum access to food and water.

\subsection{Selective Brecding of HR and I.R A nimals}

From the initial population, males and females with locomotor scores in the top $20 \%$ were bred together to generate the High Responder line and males and females with locomotor scores in the bottom $20 \%$ were bred together to generate the Low Responder line. For both lines, 12 litters were raised at each generation. Locomotor responsc to a novel environment was examined by placing them in a standard size $(43 \times 21.5 \times 24.5)$ clear acrylic cage in a different room from where they had been housed. Locomotor activity was monitored for one hour by two panels of photocells connected to a computer, with final locomotion scores determined by summing horizontal and rearing activities. 
Behavioural testing was performed on adult animals between postnatal days 60 and 75 and rats were bred for the following generation between the age of 80 and 90 days. The male and female with the "best" score from within each litter was used for breeding into the next generation. The breeding colony is managed by S. Clinton, Lniversity of Michigan.

\subsection{Sample Collection}

Animals were sacrificed by decapitation at postnatal days 7,14 , and 21 . The brains were immediately removed and the hippocampus was dissected on ice, fast frozen on dry ice, and stored at $-80^{\circ} \mathrm{C}$ until ready for future processing. Sample collection was performed by S. Clinton, Lniversity of Michigan.

\subsection{Overview of Microarray Technology}

Microarray experiments characterize expression levels of potentially thousands of genes using a single array. The arrays used in this study were printed in-house with the NCode Multi-Species miRNA Microarray Probe Set V2 (Invitrogen), consisting of 1140 oligonucleotides complementary to known and predicted miRNA sequences for human (553), mouse (427), rat (261), D. Melanogaster (85), C. Elegans (115), and Zebrafish (371). A two-colour reference design was used in which all experimental samples were hybridized along with a common reference sample of pooled miRNA (Knapen et al., 2009). The experimental sample was labelled with Alexa Fluor 3 (green), the reference sample was labelled with Alexa Fluor 5 (red), and both were hybridized to the same array. Printing custom microarrays required the evaluation of numerous factors to 
determine optimal printing parameters and microarray design, which will be discussed in detail.

Following this, miRNA was isolated from the hippocampus of both High and Low Responders at postnatal days 7, 14, and 21. Following evaluation of RNA quality, the miRNA was labelled with fluorescent Alexa Fluor dyes and hybridized to the arrays. The arrays were scanned to generate images that were analyzed to measure relative fluorescence intensities, or expression levels, for each gene. Given the complexity of this technique, the various steps are outlined in Figure 2. and will be described in greater detail below. 


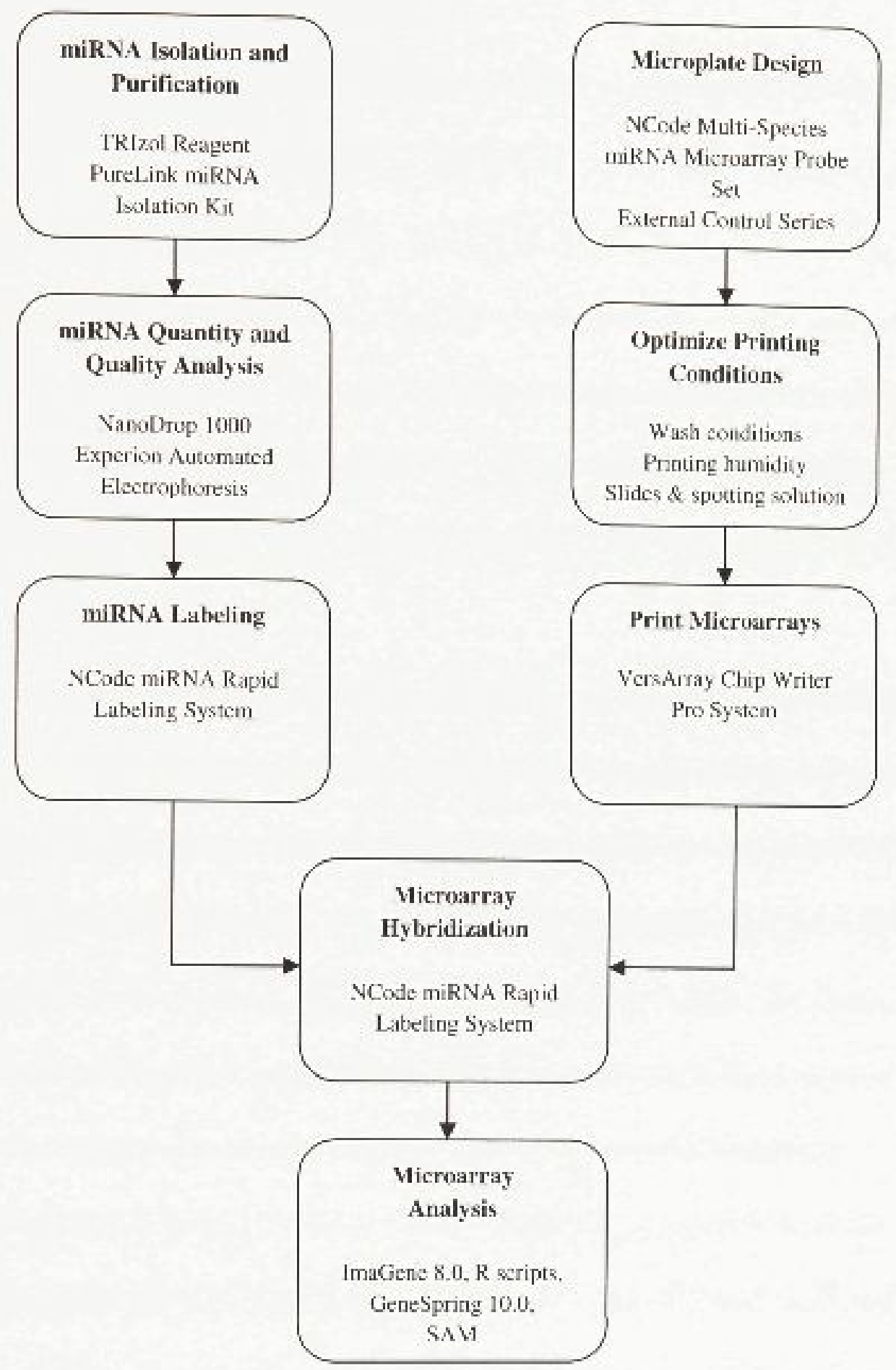

Figure 2: Overview of microarray experimental procedure. The left branch consists of all steps associated with isolating. quantifying, and labelling miRNA samples. while the right branch consists of all steps associated with designing and printing the microarrays. Both branches converge at the hybridization stage. 


\subsection{Microarray Printing Optimization}

All microarrays were printed using the VersArray ChipWriter Pro (Bio Rad). The microarraying process begins by loading oligonucleotide samples from a source plate into robotically controlled printing pins. Excess sample is blotted onto a glass microscope slide and then spotted onto a series of epoxide-coated slides (Corning). After each sample, the pins are washed in $10 \%$ ethanol (prepared from distilled water and $100 \%$ ethanol) and air-dried to minimize carry-over conlamination between samples. Sonication in another $10 \%$ ethanol water bath can also be added to the washing process for a more thorough pin cleaning.

A series of test microarrays were produced to evaluate a range of variables. Factors such as slide chemistry, spotting solution, pin washing conditions, and printing environment humidity, were altered to optimize print quality as determined by spot size and morphology and the extent of carry-over contamination between spots. Five oligonucleotides were chosen as probes to print on these test chips. The first is complementary to a synthetic miRNA sequence designed as a positive control for use with the NCode Multi-Species miRNA Microarray system. The remaining oligonucleotides were chosen based on varying expected expression in the rat hippocampus, with miR- $125 b$ highly expressed in the brain, miR-222 moderately expressed in the brain, $m i R-122 a$ not expressed in the brain, and $m i R$-let $7 b$ expressed ubiquitously (Miska et al., 2004). Oligonucleotide sequences are listed in Table 1. Unless otherwise stated, all oligonucleotides were suspended in Pronto! epoxide spotting solution (Corning) and printed on Corning epoxide-coated slides. All arrays were scanned using the GenePix 4000B microarray scanner (Axon Instruments). The following sections 
describe in detail which variables were optimized. The full details of the final methodology will be provided later.

Table 1: Oligonucleotide sequences used for microarray printing optimization.

\section{Oligonucleotide}

Name

NCode Control

miR-222

mik-125b

$\operatorname{miR}-122 \mathrm{a}$

let $-7 \mathrm{~b}$

\section{Olisonucleotide Seguence}

CTGTCATTGCTCCGGACACACTGTCATTGCTCCGGACACA

AGACCCAGTAGCCAGATGTAGAGACCCAGTAGCCAGATGTAG

TCACAAGTTAGGGTCTCAGGGTCACAAGTTAGGGTCTCAGGG

ACAAACACCATTGTCACACTCCACAAACACCATTGTCACACTCC

AACCACACAACCTACTACCTC AАCCACACAACCTACTACCTCA

\section{5a Ethidium Bromide and SYBR Green II Test Chips}

Initial test chips were printed and stained with ethidium bromide to assess spot morphology and carry-over (Gupta et al.. 2007). Chips were printed with the five test oligonucleotides, as well as extracted total RNA suspended in either Pronto! epoxide spotting solution or $0.1 \%$ diethyl pyrocarbonate (DEPC)-treated $\mathrm{H}_{2} \mathrm{O}$ (conc, $0.5 \mu \mathrm{g} / \mu \mathrm{l}$ ). Buffer-only spots and DEPC-treated water spots were also included as negative controls. After printing, all slides were stained with a 1:10,000 dilution of ethidium bromide (50 $\mathrm{mg} / \mathrm{ml}$ ) and $0.5 \mathrm{X}$ tris-borate-EDTA (TBE) buffer. Staining was followed by three 5 minute washes in $0.5 \mathrm{X}$ TBE buffer and three 2 minute washes in MilliQ water at room temperature. The chips were dried by centrifugation at $2,000 \mathrm{rpm}$ for one minute (Protocol modified from Gupta et al., 2007). Ethidium bromide is designed to stain 
double stranded DNA, thus, staining was highly variable between probes (assumed to be the result of variability in secondary structure between different single stranded oligonucleotide probes). Therefore, at an early stage of printing optimization, ethidium bromide was replaced with SYBR Green II, which specifically binds to single stranded DNA.

Test chips stained with SYBR Green II were printed with dilution series of the same five test oligonucleotides $(0.39 \mu \mathrm{M}$ to $100 \mu \mathrm{M})$, as well as buffer-only spots and a dilution series of random hexamers $(0.39 \mu \mathrm{M}$ to $30 \mu \mathrm{M})$ (Qiagen) for negative controls. Arrays were stained following the same procedure outlined above, with ethidium bromide replaced with SYBR Green II (Protocol modified from Gupta et al., 2007).

\section{Determining Optimal Printing Humidity}

Corning recommends that their epoxide-coated slides be printed in an environment with relative humidity between $55 \%$ and $70 \%$. Therefore, four chips were printed at $55 \%, 60 \%, 65 \%$ and $70 \%$ relative humidity to evaluate the effect of printing humidity on spot size and morphology. A relative humidily of $65 \%$ produced the best spots in terms of consistency, sizc, shape, and minimal "donuting", which was consistent when replicated (data not shown).

\section{Determining Optimal Slides and Spotting Solution}

In addition to Corning's products, the performance of epoxide-coated slides and spotting solutions from TeleChem and FullMoon Biosystems was evaluated.

Oligonucleotides $m i R-222$ and $m i R-125 b$ were suspended in all three spotting solutions to a final concentration of $50 \mu \mathrm{M}$ and printed on all three slides at $55 \%, 60 \%$, and $65 \%$ relative humidity. Results indicated that oligonucleotides suspended in Corning epoxide 
spotting solution printed on Corning epoxide-coated slides performed best, with the most favourable spot size and morphology, as well as the highest signal intensitics (data not shown).

\section{Reducing Carry-Over Contamination}

After washing and sonication, the printing pins are dried by a series of air holes, one for each pin. Upon recommendation from the manufacturer, since only 8 out of 48 possible pins were used to print the arrays, the air holes not being used were covered with electrical tape in order to force air to come only from the holes aligned with active pins. In addition, default wash settings were modified to increase the number of washes from three to five and add 60 seconds of sonication between loading new probes. This resulted in more effective pin drying and eliminated virtually all detectable carry-over between samples (Figure 3). 

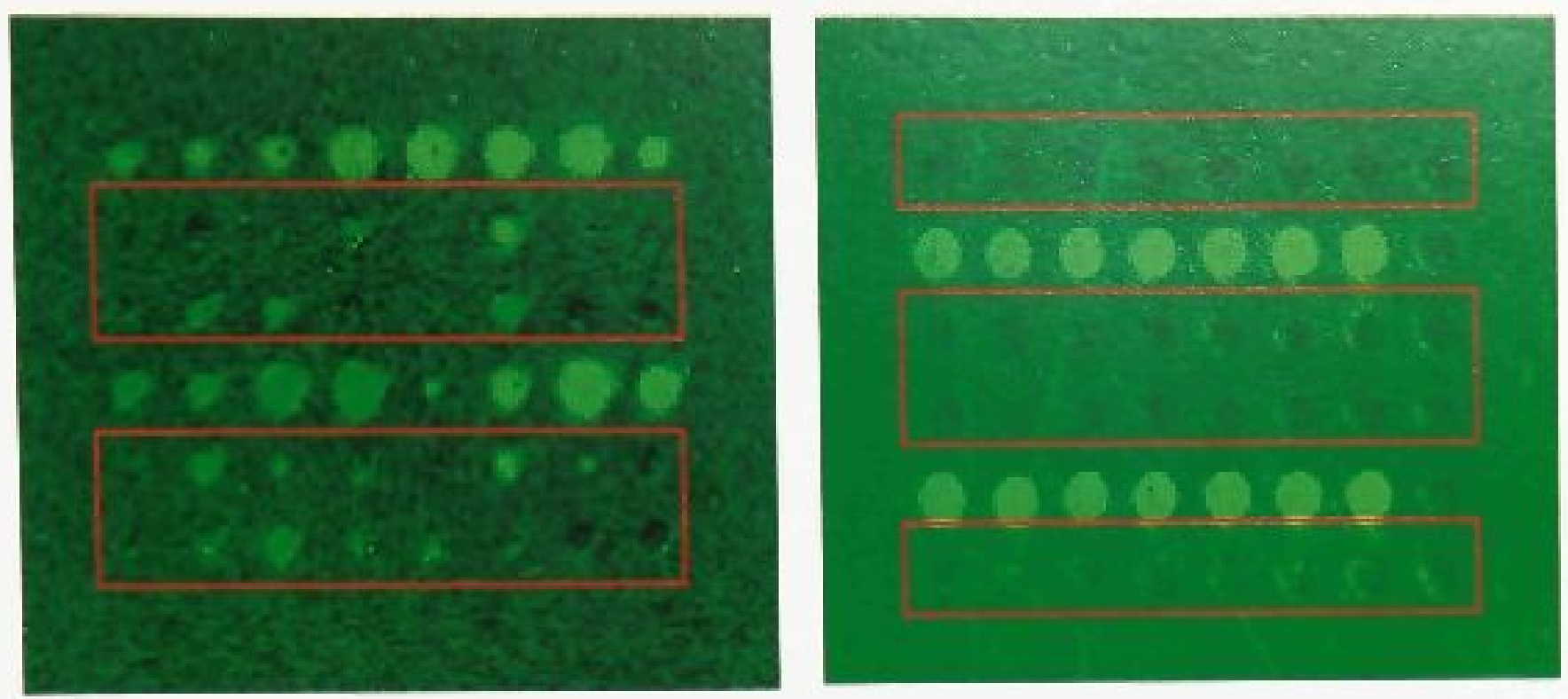

Figure 3: Reducing carry-over contamination. Probes were printed in columns from top to bottom, with columns on the left printed first. Highlighted areas show buffer-only spots, Left: Signal from buffer-only spots indicates observable carry-over. Right: Carryover has been virtually eliminated after increasing pin washing and sonication and covering unused air-holes.

\section{Reducing Spot "Donuting"}

Spot donuting occurs when the solution is either not loaded evenly onto the slide, or it dries in a non-uniform manner. If the pin contacts the slide for too long, the probe may dry around the edge of the spot before the pin has lifted, encouraging the solution to spread to the spot edges. To counteract this phenomenon, printing environment humidity was increased and the dwell time of the pin on the slide was reduced. Although these measures helped, they did not totally eliminate donuting. Ideally, if the printing pins travelled downwards just enough to touch the surface of the slide, spot donuting would be minimized. However, due to slight variations in the thickness of the slides, this is not realistic and the pins must travel downwards to a point slightly below the surface. Three test chips were printed with varying "z chip down" settings $(109.58 \mathrm{~mm}, 109.30 \mathrm{~mm}$, and 
$109.23 \mathrm{~mm}$ ) to evaluate the effect on spot donuting. The smallest distance travelled (109.23 mm) resulted in reduced donuting, but some spots were missing. There were no clear differences between the other two positions, with both showing a similar degree of donuting, particularly in the three control spot serics (NCode, $m i R-125 b$, and $m i R-222$ ) at low concentrations $(<6.25 \mu \mathrm{M})$ (Figure 4$)$.
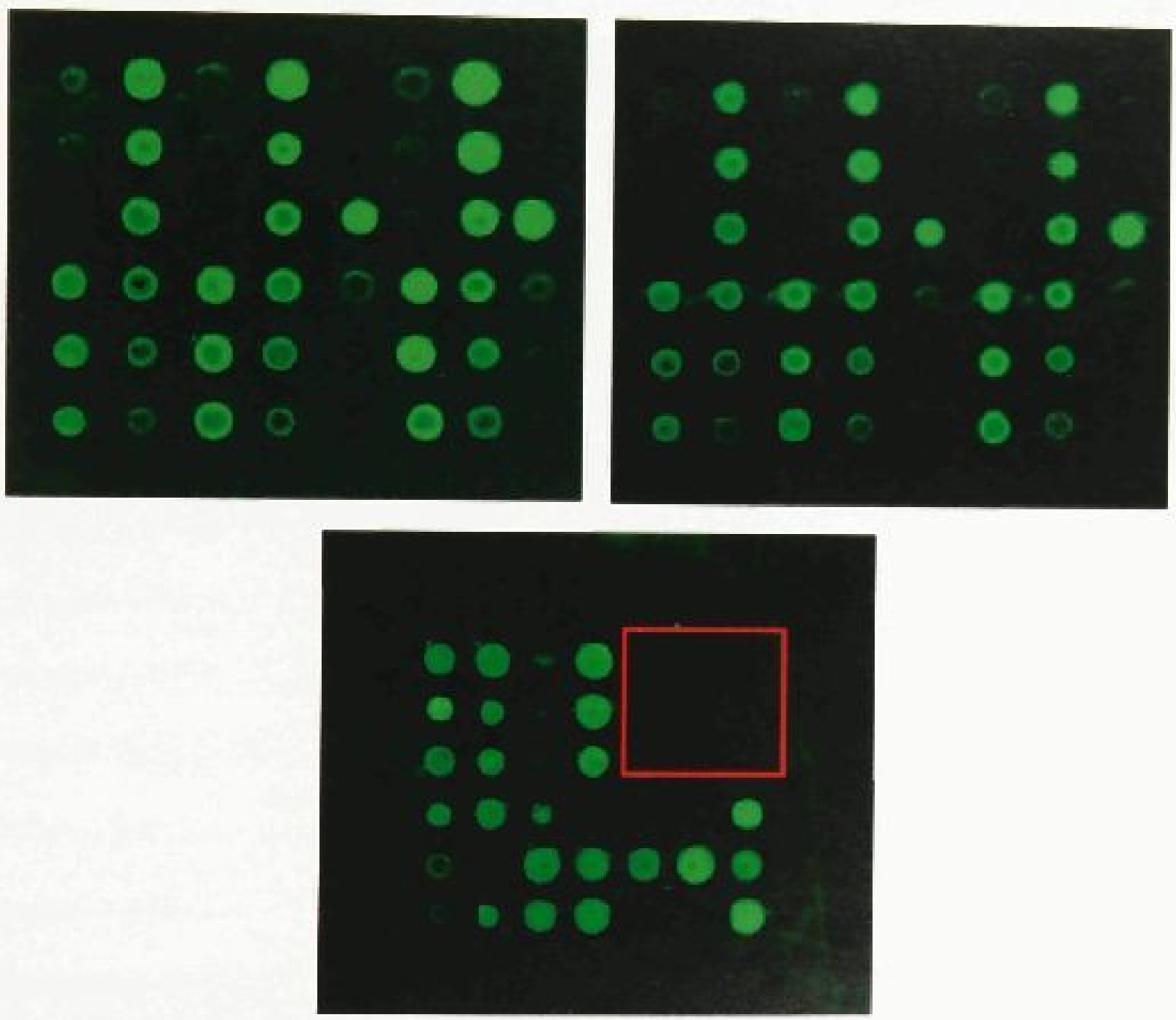

Figure 4: Evaluating spot donuting. The distance the pins travel downward towards the slides was manipulated to evaluate the effect on spot donuting. The top panel shows z chip down settings of $109.58 \mathrm{~mm}$ and $109.30 \mathrm{~mm}$, respectively, with little difference in the degree of donuting. The bottom shows a z chip down sctting of $109.23 \mathrm{~mm}$, which reduced donuting. but missing spots due to printing pins not reaching the slide surface. 


\section{5b NCode MicroRNA Labeling System Test Chips}

Although SYBR Green II proved to be effective for cvaluating printing conditions at low cost, it was also necessary to evaluate, and if necessary, optimize procedures for miRNA labelling and hybridization, as well as other factors that may impact the integrity of the system. To this end, a final group of microarrays were printed and hybridized with labelled miRNA samples. Dilution series of the five test oligonucleotides $(0.39 \mu \mathrm{M}$ to $100 \mu \mathrm{M}$ ) were printed on the arrays rather than the probes from the NCode Multi-Species miRNA Microarray Probe Set because results from these test chips werc used to inform the design of the actual microarrays and thus how to create the probe source plates.

All test arrays were hybridized with two identical pooled miRNA samples cone labelled with Alexa Fluor 3 and the other with Alexa Fluor 5) using the NCode miRNA Labcling System (see MicroRNA Labeling and Hybridization for procedure). Using a single pool for all labels meant that any differences between the test chips (and between dyes on a single chip) could be explained by technical variability as opposed to R.VA variability. Furthermore, all labelled samples included an NCode spike-in control (1:400 dilution in DEPC-treated water, as recommended by manufacturer) to hybridize against spotted dilutions $(0.000015$ to $100 \mu \mathrm{M})$ of a complementary oligonucleotide. All test microarrays also consisted of buffer-only spots and random hexamers (Qiagen) as negative controls.

\section{Evaluation of IIybridization Chambers}

Invitrogen's NCode Rapid miRNA Labeling System was designed for use with Corning hybridization chambers, which are stationary during the hybridization period. Agilent hybridization chambers on the other hand are assembled into a constantly moving 
rotisseric. The Agilent chambers were appealing because constant circulation of the hybridization mix may increase the likelihood of miRNAs encountering their complementary probes, thus increasing hybridization and signal intensity. However. Agilent chambers are designed for a significantly larger volume of hybridization mix compared to Corning ( $400 \mu \mathrm{l}$ versus $60 \mu \mathrm{l})$. The performance of both chambers was compared with $60 \mu \mathrm{l}$ of hybridization mix. Although both arrays looked nice, much greater signal was observed with the Agilent chambers. However, some unevenness in signal intensity was observed, which may have been due to the reduced volume. The hybridization protocol was modified to increase the volume of hybridization mix as much as the kit contents allowed $(273 \mu \mathrm{l})$, resulting in even hybridization and no decrease in overall signal intensity.

\section{Evaluation of NCode Control Spike-In Concentration}

The NCode control spike-in ( $2 \mathrm{pmol} / \mu \mathrm{l})$ was initially diluted 1:400 in DEPCtreated water as recommended by Invitrogen. However, the maximum signal intensity using this concentration only reached approximately 3000 units, whereas the microarray signal saturates at 65,535 units. As will be described later, signals from the NCode control dilution series will be used in data analysis to normalize the microarrays. However, during this normalization stage, reliable results can only be expected for intensities within the range covered by the spike-in (Yauk et al., 2006: Sarkar et al., 2008). For this reason, a dilution of NCode control spike-in was desired, that when hybridized to the printed NCode dilution series, covered the full range of possible intensities. To determine the optimal NCode spike-in dilution, four microarrays were hybridized with miRNA samples consisting of varying concentrations of the NCode 
spike-in, namely $0.9 \mathrm{X}, 9 \mathrm{X}, 90 \mathrm{X}$ and $900 \mathrm{X}$ dilutions (Figure 5). Based on these data, optimal spike-in concentration (where only the most concentrated probe spots reach saturation) was estimated to be at a $7 \mathrm{X}$ dilution. However, subsequent modifications of the labelling and hybridization procedures designed to minimize the adverse effects of high ozone levels on Alexa Fluor stability led to a general increase in signal intensity (see Array Wash Procedure). Based on quantification of this general increase, an NCode spike-in concentration of $50 \mathrm{X}$ was chosen for all subsequent microarrays. Figure 5 also shows a clear increase in mean signal intensity as spike-in concentration is increased. Furthermore, for spots printed at a concentration between 0.39 and $25 \mu \mathrm{M}$, an increase in probe concentration leads to an observable increase in signal intensity.

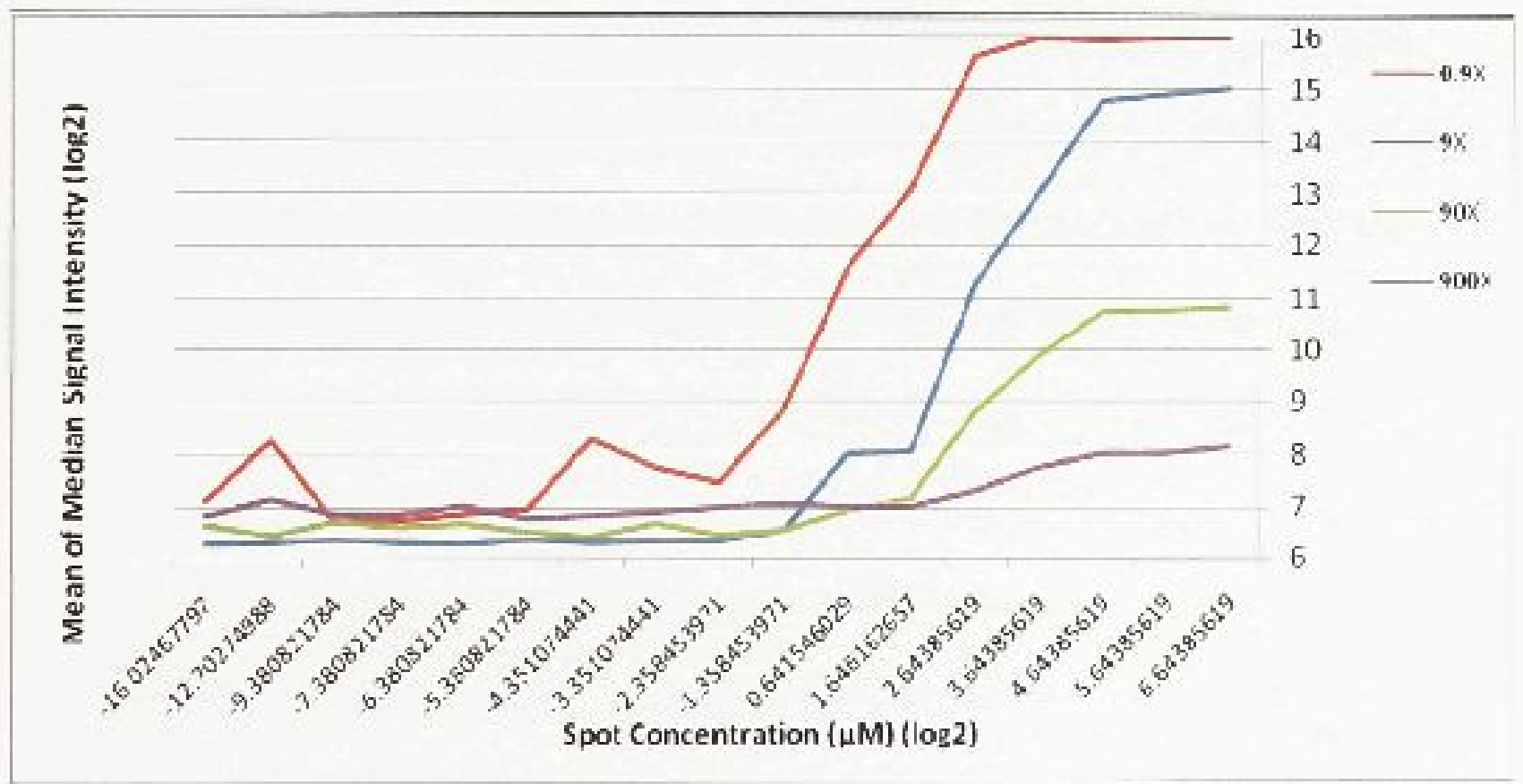

Figure 5: Effects of various NCode spike-in control dilutions on signal intensity. The log-mean of median signal intensities are plotted against on-chip log- VCode spot concentration for four different spike-in concentrations. Due to Alexa Fluor 5 degradation caused by high ozone concentrations, data is from the green (Alexa Fluor 3 ) channel only. Since standard normalization requires both channels, data is unnormalized. 


\subsection{Printing the Experimental Microarrays}

\section{6a Description and Positioning of miRNA Probes and Control Spots}

The collection of spots on a microarray printed by each individual pin is termed a grid. The collection of grids printed by all pins ( 8 pins were used to print the arrays) that encompass the entire set of probes and controls is termed a supergrid. In this experiment, each grid consisted of 240 spots ( 16 rows by 15 columns), each supergrid consisted of eight grids (1920 spots), and each supergrid was replicated six times per array, for a total of 11,520 spots (Figure 6).

The oligonucleotides from the NCode Multi-Species miRNA Microarray Probe Set were printed on the arrays at a concentration of $30 \mu \mathrm{M}$. In addition, various external controls were also incorporated into the arrays. A $2 X$ control dilution series $(0.000015$ to $100 \mu \mathrm{M}$ ) using the synthetic NCode sequence complementary to the NCode spike-in control was spotted in duplicate per grid. A $4 \mathrm{X}$ control dilution series $(0.006$ to $100 \mu \mathrm{M})$ of the two test oligonucleotides that showed high (miR-125a) and medium (miR-222) expression in the brain were also spotted in duplicate per grid. Dilutions from these control serics were printed in random order in an evenly spaced pattern within cach grid, among the miRNA probes. Negative controls including buffer-only spots and random hexamers $(4.5 \mu \mathrm{M})$ were also included within each grid to assess non-specific hybridization. In addition, a specific pattern of buffer-only spots were included within each grid to assess carry-over from spot-to-spot during the printing process (Figure 7). The amount of carry-over was assessed by comparing the median signal of buffer-only spots that were printed immediately after a $100 \mu \mathrm{M}$ NCode external control spot to the 
median signal of buffer-only spots printed immediatcly after another buffer-only spot, in a manner similar to that described by Yauk et al., (2006).

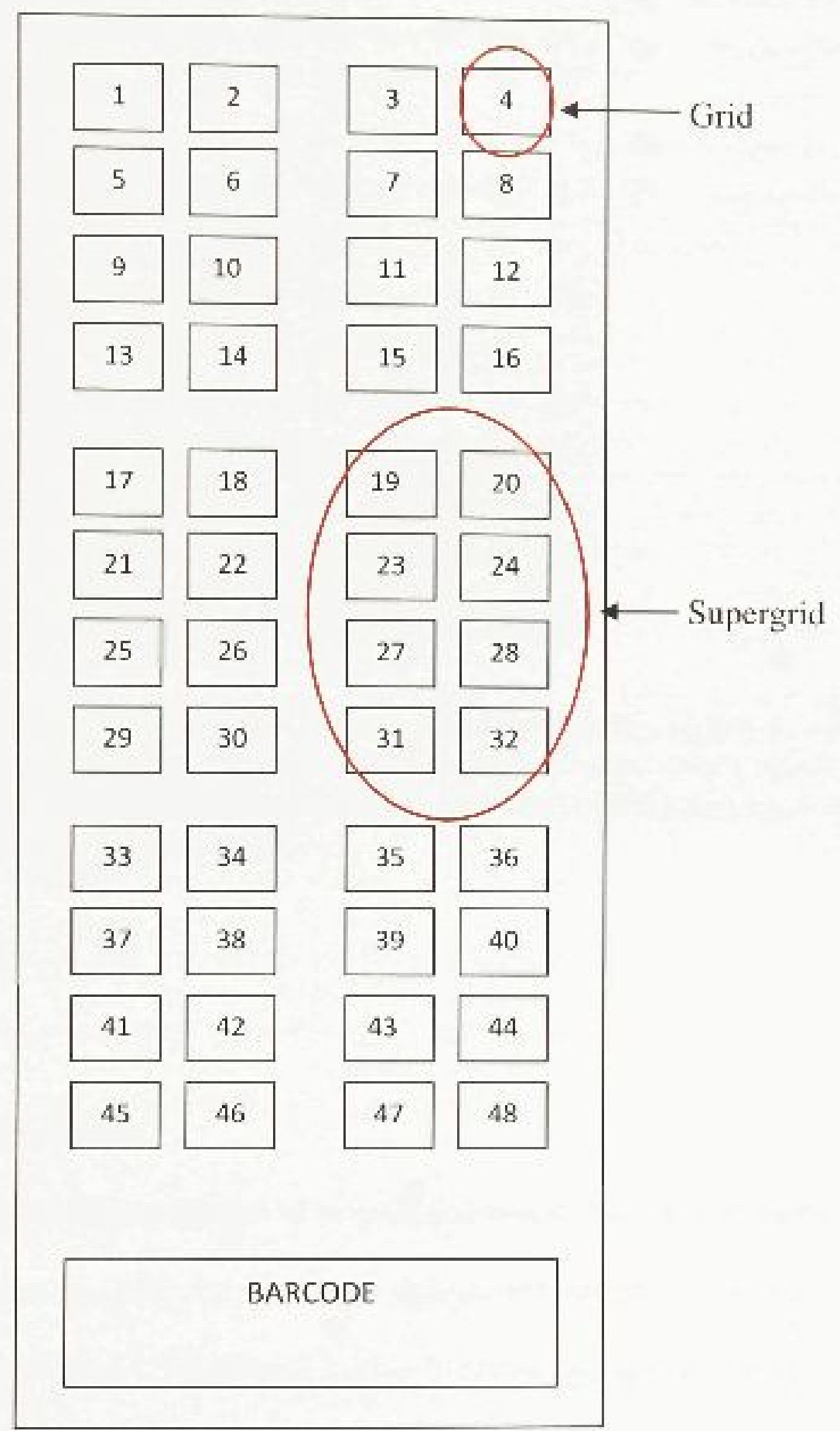

Figure 6: Schematic of the microarray layout. Each numbered box represents a grid printed by one pin. Each grouping of eight grids is a supergrid, and each supergrid is printed six times on cach microarray. 


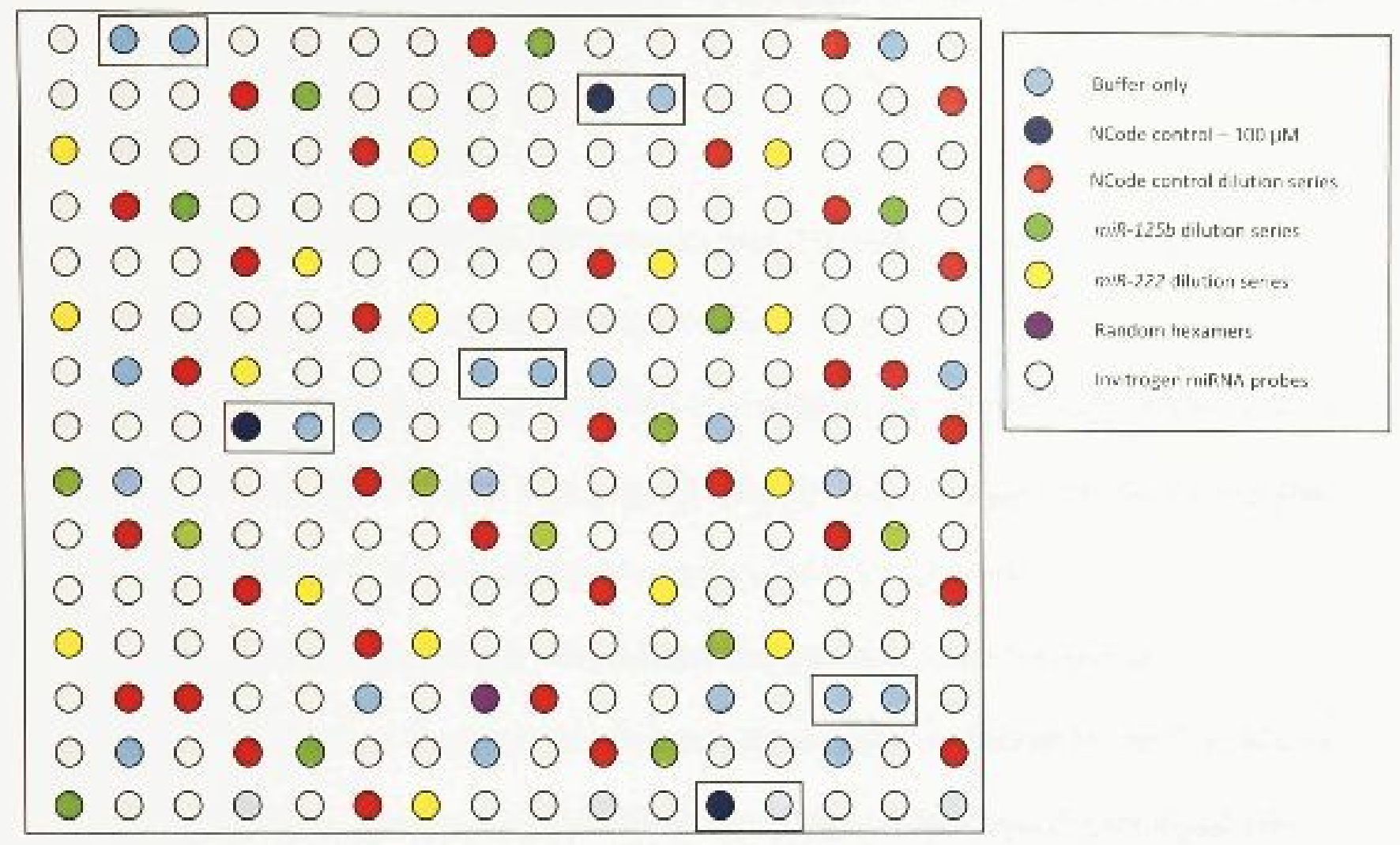

Figure 7: Schematic of grid design. Probes were printed in columns from top to bottom, with columns on the left printed first. The set of various control spots were printed in random order in an evenly spaced pattern within each grid. The highlighted pairs of spots represent the spots used to assess carry-over.

\section{6b Creating the Source Plates}

In order to print the miRNA probes at a concentration of $30 \mu \mathrm{M}, 500$ pmoles of lyophilized miRNA probes from the NCode Multi-Species Microarray Probe Set were reconstituted with $15 \mu 1$ of Pronto: Epoxide-Spotting Solution and transferred to five new source plates already containing the three external control series (Ncode, $m i R-12.5 \mathrm{~h}$, and $m i R-222$ ), the negative controls (buffer-only spots and random hexamers), and the carry- 
over controls. The five final source plates were sealed and stored at $-20^{\circ} \mathrm{C}$ until ready for printing the microarrays.

\section{6c Printing the Microarrays}

Based on test chip results, the experimental microarrays were printed under the following conditions: ambient temperature between 20 and $25^{\circ} \mathrm{C}$, relative printing humidity of $65 \%, 5$ washes and 60 seconds of sonication between loading probes, and a z chip down setting of $109.5 \mathrm{~mm}$. The pins reloaded the same sample from the source plate after every 15 slides to ensure sufficient sample to spot on all arrays.

A total of 45 microarrays were printed continuously over a period of approximately 35 hours. Each source plate was removed from storage at $-20^{\circ} \mathrm{C}$ as nceded and allowed to thaw at room temperature for 20 minutes. After centrilugation at 2,000 rpm for one minute, cach plate was placed in the ChipWriter and allowed to acclimatize to the humidity for 10 minutes before printing. After printing, all microarrays were incubated in the ChipWriter at $70 \%$ relative humidity for 12 hours, after which, they were dried at room temperature for 30 minutes and stored in microarray holders sealed in storage pouches until ready for hybridization. The arrays can be stored this way for up to six months. SYBR Green II staining of selected microarrays confirmed that arrays were printed successfully and appropriate for use with the hybridization procedure.

\subsection{MicroRNA and Total RNA Isolation}

Both miRNA and total RNA were extracted from hippocampal lissuc samples. Although total RNA will not be analyzed in this thesis, it was extracted for possible mRNA expression analyses at a later date. 


\section{7a MicroRNA Isolation}

Invitrogen's TRIzol reagent and PureLink miRNA Isolation Kit were used to isolate miRNA according to the manufacturer's instructions. Unless otherwise stated, all centrifugations were at $12,000 \mathrm{xg}$ and both centrifugations and incubations were at room temperature. Tissue samples were homogenized for 15 seconds at medium speed in $1 \mathrm{ml}$ of TRlzol Reagent using a PowerGen 125 tissue homogenizer (Fisher Scientific) and incubated for five minutes to allow complete dissociation of nucleoprotein complexes. $200 \mu 1$ of molecular grade chloroform (Sigma) was added to the lysate and the mixture was vigorously shaken, incubated, and centrifuged at $4^{\circ} \mathrm{C}$ to separate the mixture into a lower red phenol-chloroform phase, an interphase, and a colourless aqueous phase containing total RNA. The upper phase was transferred to a fresh tube and $215 \mu \mathrm{l}$ of $100 \%$ ethanol was added to obtain a final concentration of $35 \%$ ethanol. The solution was transferred to spin cartridges pre-inserted into collection tubes and centrifuged. At this point, the flow through contained the small RNA and the larger total RNA was bound to the membrane of the spin cartridges. The spin cartridges containing the total RNA were placed into new microcentrifuge tubes containing $10 \mu \mathrm{l}$ of Wash Buffer I from the PureLink Micro-to-Midi Total RNA Purification System and stored at $4^{\circ} \mathrm{C}$ until ready for total RNA recovery. To continue with the miRNA isolation, $720 \mu \mathrm{l}$ of $100 \%$ ethanol was added to the flow through to oblain a final concentration of $70 \%$ ethanol and the solution was transferred to fresh spin cartridges in collection tubes and centrifuged. The miRNA, bound to the spin cartridge membrane, was washed twice with $500 \mu \mathrm{l}$ of wash buffer and centrifuged at maximum speed to remove any residual wash buffer. The spin cartridges were placed into clean recovery tubes and $50 \mu 1$ of sterile, RNase-free water was added 
and centrifuged at maximum speed to collect the purified small RNA molecules. The miRNA was stored at $-80^{\circ} \mathrm{C}$ until ready for downstream applications.

\section{7b Total RNA Isolation}

Total RNA was isolated from the same samples using Invitrogen's PureLink Micro-to-Midi Total RNA Purification System according to the manufacturer's instructions. The spin cartridges containing bound total RNA were removed from $4^{\circ} \mathrm{C}$ storage and washed once with $700 \mu \mathrm{l}$ of wash buffer I and twice with $500 \mu \mathrm{l}$ of wash buffer II. To collect the purified total RNA, $60 \mu \mathrm{l}$ of RNase-free water was added to the spin cartridges inserted in new recovery tubes, incubated, and centrifuged to collect the contents. Total RNA was stored at $-80^{\circ} \mathrm{C}$ for future quality assessment.

\subsection{Assessment of RN $\Lambda$ Quality and Quantity}

The NanoDrop 1000 Spectrophotometer (Thermo Scientific) was used to determine sample concentration and assess RNA purity. A ratio of absorbances at 260 and $280 \mathrm{~nm}$ wavelengths $\left(\mathrm{A}_{26 n}: \mathrm{A}_{280}\right)$ of approximately 1.8 is generally considered "pure" for RNA samples.

The Experion Automated Electrophoresis Station (Bio Rad) was used according to manufacturer's instructions to determinc sample concentration and the degree of RNA degradation, which decreases the reliability of results obtained in downstream applications such as microarray analysis and real-time PCR. The Experion software generates a ratio of the two major ribosomal RNA fragments, namely the $28 \mathrm{~S}$ and $18 \mathrm{~S}$ fragments, which is expected to be approximately 2.0 and remain constant across tissues. Degraded samples will exhibit greater depletion of the larger ribosomal molecules 
compared with the smaller molecules, thus greater degradation will be indicated by a lower $28 \mathrm{~S}$ : $18 \mathrm{~S}$ ratio. The RNA Quality Index (RQI) was also used to assess quality, with 1 indicating that the sample is completely degraded and 10 indicating that the sample is perfectly intact. This index can be used to assess the appropriateness of using the sample for downstream applications. For instance, in order to perform future microarray work, the RQI of the sample should be at least 7 or 8 and to perform real time-PCR the RQI should be at least 5 or 6 . To date, Experion does not offer a kit to assess quality of small RNA molecules. Therefore, total RNA quality was used to infer quality of the isolated miRNA.

\subsection{Pre-Soaking and Pre-hybridizing the Microarrays}

Immediately before the labelling procedure, the arrays were removed from storage and pre-soaked to reduce background fluorescence that can develop over time. The arrays were immersed in a 1:100 dilution of liquid borohydride and pre-soak solution from the Corning Background Reduction Kit, at $42^{\circ} \mathrm{C}$ for 20 minutes. The arrays were washed twice briefly in $0.1 \mathrm{X}$ saline-sodium citrate (SSC) at room temperature and dried by centrifugation at $2,500 \mathrm{rpm}$ for two minutes.

Following the pre-soaking procedure, the microarrays were pre-hybridized to remove loosely bound probe DNA and prevent hybridization from occurring on unprinted regions of the slide. The arrays were immersed in $42^{\circ} \mathrm{C}$ pre-hybridization solution consisting of $5 \mathrm{X}$ SSC, $0.1 \%$ sodium dodecyl sulphate (SDS), and $0.1 \mathrm{mg} / \mathrm{mL}$ bovine serum albumin (BSA), followed by three 5 minute washes in $0.1 \mathrm{X} \mathrm{SSC}$ at room temperaturc. After a brief wash in $0.1 \%$ DEPC-treated water, the arrays were dried by 
centrifugation at 2,500 rpm for two minutes and stored in slide holders sealed in microarray storage pouches. The arrays must be hybridized within a few hours of the presoak and pre-hybridization procedures.

\subsection{Overview of the Labelling Procedure}

All miRNA samples were labelled using Invitrogen's NCode Rapid miRNA Labeling System according to the manufacturer's instructions. The first step in the labelling procedure is the addition of a poly(A) tail to the $3^{\prime}$ end of the miRNA molecule. Next, using an oligo(dT) bridge, the experimental sample is labelled with Alexa Fluor 3 , while the universal miRVA reference sample is labelled with Alexa Fluor 5. Both samples are then hybridized to the same microarray and loaded into the hybridization oven for overnight incubation. The next day, the microarray is thoroughly washed and immediately scanned using the GenePix 4000B Microartay Scanner. This procedure is explained in greater detail below.

\subsection{0a Polyadenylation of miRNA}

The quantity of miRNA used in the labelling procedure was $320 \mathrm{ng}$ dissolved in $0.1 \%$ DEPC-treated water $(35.5 \mathrm{ng} / \mu \mathrm{l})$, as recommended by Invitrogen. $1 \mu \mathrm{l}$ of $50 \mathrm{X}$ diluted NCode spike-in control ( $2 \mathrm{pmol} / \mu \mathrm{l})$ was added to each sample to hybridize the NCode external control series printed on the arrays. To add a poly(A) tail to the miRNA molecules, $1.5 \mu \mathrm{l}$ of $10 \mathrm{X}$ miRNA reaction buffer, $1.5 \mu \mathrm{l}$ of $25 \mathrm{mM} \mathrm{MnCl}, 1 \mu \mathrm{l}$ of diluted $\mathrm{ATP}$, and $1 \mu \mathrm{l}$ of Poly A Polymerase were added and the solution was incubated at $37^{\circ} \mathrm{C}$ for 15 minutes.

\subsection{0b Ligation of Alexa Flour Dye Molecules}


From this point on, all procedures were performed in low light conditions to minimize photobleaching of the Alexa Fluor dye molecules. To ligate the DNA polymer containing the Alexa Fluor dye molecules to the recently added poly (A) tail, $4 \mu \mathrm{l}$ of Alexa Fluor 3 Rapid Ligation Mix was added to each experimental sample and $4 \mu \mathrm{l}$ of Alexa Fluor 5 Rapid Ligation Mix was added to each reference sample, along with $2 \mu 1$ of T4 DNA Ligase. Since samples were hybridized to arrays printed in-house, $1 \mu \mathrm{l}$ of DEPC-treated water was added to each sample to replace the Dye Normalization Control, which is supplied with the kit and designed to detect probes on Invitrogen's commercial miRNA microarrays. After incubation at room temperaturc for 30 minutes, the ligation reaction was stopped by adding $2.5 \mu l$ of Stop Solution supplied with the kit.

\subsection{0c Hybridization Procedure}

To perform dual-colour hybridization, the two differentially labelled samples were combined into one tube. The volumes of BSA and $2 X$ Enhanced Hybridization Buffer were increased to $22,7 \mu \mathrm{l}$ and $200 \mu \mathrm{l}$, respectively, to increase the hybridization mix volume. The resulting mix was incubated at $65^{\circ} \mathrm{C}$ for 10 minutes. For cach sample, a gasket slide was placed in the Agilent hybridisation chamber and the hybridization mix was pipetted down the center of the gasket slide. The printed microarray was placed active side down, on top of the gasket slide, and the hybridization chamber was assembled and tightly sealed. A randomized block design was used to 1) ensure that each batch of arrays were hybridized with samples from different treatment groups and 2) to pair miRNA samples and microarrays printed at different locations within the ChipWriter for hybridization. The chamber was rotated vertically to wet the gasket slide and ensure 
proper bubble formation and then loaded into the hybridization oven. The rotisserie was set at $20 \mathrm{rpm}$ and the array was left to incubate overnight $(9.5$ hours $)$ at $52^{\circ} \mathrm{C}$.

\subsection{0d Array Wash Procedure}

After hybridization, the array was removed from the hybridization oven and washed in $52^{\circ} \mathrm{C}$ Wash Solution 1 ( $2 X$ SSX, $0.2 \%$ SDS, $0.1 \mathrm{mM}$ DDT) for a total of 20 minutes with gentle agitation $(200 \mathrm{rpm})$ using a magnetic stirrer and stir plate. After 10 minutes, the Wash Solution was refreshed and the arrays were flipped to ensurc even washing. The array was washed in the same manner with Wash Solution 2 (2X SSC, 0.1 $\mathrm{mM})$ and again with Wash Solution $3(0.2 \mathrm{X} \mathrm{SSC}, 0.1 \mathrm{mM}$ DDT $)$. The array was dried by centrifugation at $2,500 \mathrm{rpm}$ for two minutes in a centrifuge tube containing $20 \mu \mathrm{l}$ of 2 mercaptoethanol and then quickly transferred to a new tube, also containing $20 \mu$ l of 2 . mercaptoethanol, until ready to be scanned. Note that the dithiothreitol (DDT) in the wash solutions, plus storage of slides in tubes containing 2-mercaploethanol, were custom modifications designed to create a reducing environment to combat the effects of ozone. Alexa Fluor dyes, especially Alexa Fluor 5, have been shown to be highly susceptible to degradation when exposed to elevated ozone levels (Fare et al., 2003). In particular, the Alexa Flour dyes appear to be especially vulnerable during the washing and scanning procedures. In addition to the use of DDT and 2-mercaptoethanol, labelling and hybridization was avoided on days above approximately $25^{\circ} \mathrm{C}$ and the washing and scanning procedures were done early in the morning (between 5:30:am and 8:30am) when daily ozone levels are typically at their lowest. To ensure ozone levels were not negatively affecting the arrays, atmospheric ozone concentrations were recorded throughout the procedure and evaluated in subsequent analysis. Furthermore, the water 
tank supplying the MilliQ cleaning system was emptied and allowed to refill before preparing the wash solutions in an effort to avoid using water exposed to high levels of ozone and the GenePix 4000B Microarray Scanner was moved to an office environment, as lab equipment may increase ambient ozone levels (Genisphere Incorporated, 2004).

\subsection{0e Microarray Scanning}

The GenePix 4000B scanner simultaneously scans microarray slides at two wavelengths using a dual laser scanning system (532 $\mathrm{nm}$ and $635 \mathrm{~nm}$ lasers) and detects emitted fluorescent light using a pair of high-sensitivity photomultiplier tubes (PMTs). By default, both PMTs are set at $600 \mathrm{v}$. However, in order to optimize signal and balance the overall intensity from both the red and green channels, these PMT seltings can be changed. Each microarray was first scanned at PMT settings of 660 and 620 for the red and green channels, respectively. A ratio of the overall signal intensity from both channels was generated from this initial scan. Based on this, the PMT settings were adjusted, and the arrays were scanned a second time to obtain a balanced image. All images used in subsequent data analyses were obtained from cither the first or second scan, with a count ratio between 0.85 and 1.15 . Figure 8 shows a typical microarray image generated using the GenePix 4000B scanner and software package. 

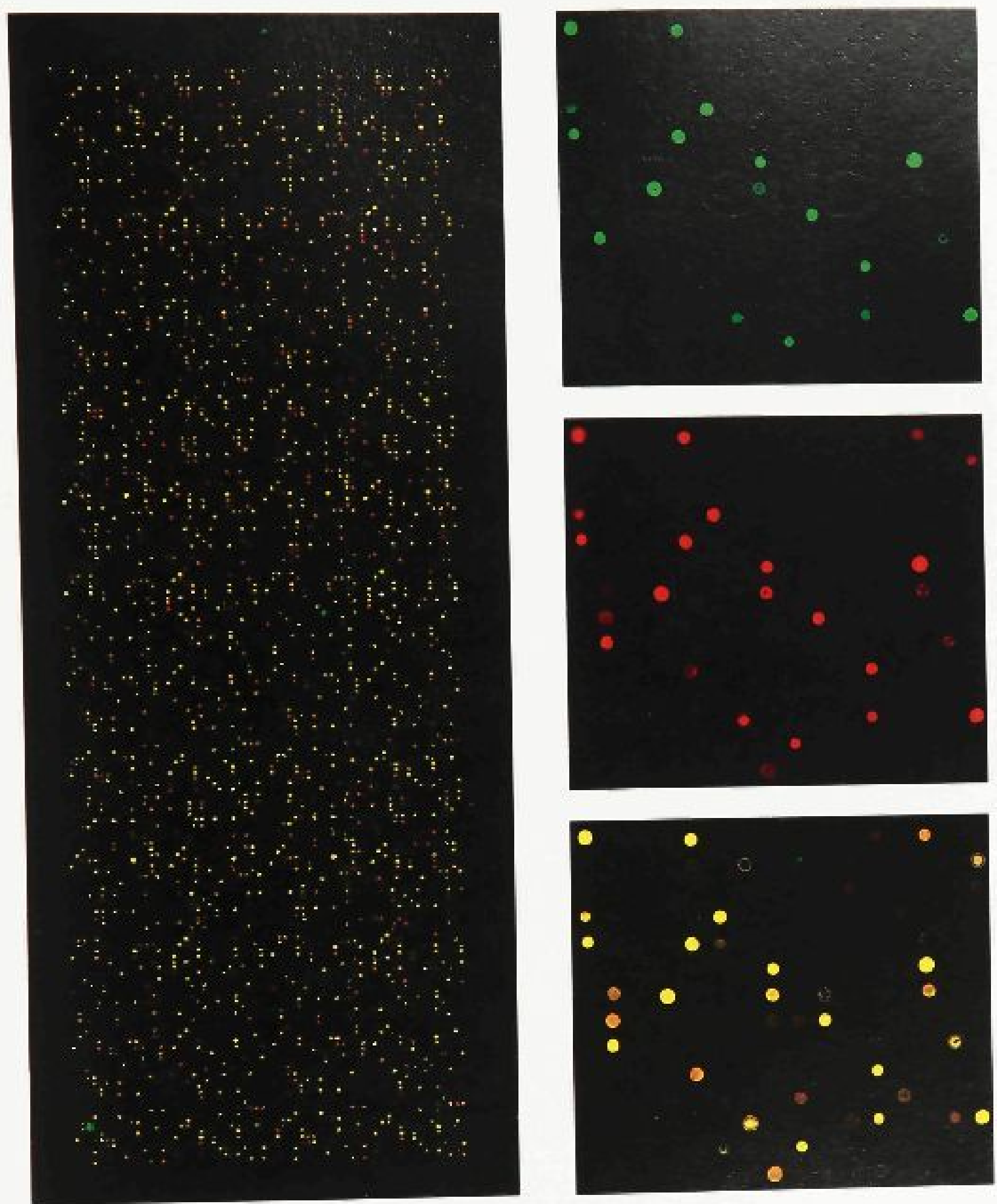

Figure 8: GenePix microarray image. Left: Image of an entire microarray consisting of six technical replicates and spots. Along the right arc close-ups of a section of the microarray showing signal from the green (experimental) channel (top); signal from the red (reference) channel (middle); and signal from both channels combined (bottom). 


\subsection{Image and Statistical Analyses}

\subsection{1a Overview of Analyses}

ImaGene 8.0 was used to determine median signal intensity for each spot and data from controls printed within each grid were used to evaluate the quality of each array. A custom algorithm written in R scripts by Andrew Williams (IIealth Canada) was used to perform within-array normalization using a method called Loess normalization, while GeneSpring 10.0 was used to perform between-arTay normalization using a lechnique called quantile normalization. Partek was then used to perform Principal Components Analysis (PCA) to identify arrays that did not behave in a consistent manner and to screen for (and if necessary eliminate) effects due to variables other than strain and age. Testing for statistical significance was performed using Significance Analysis of Microarrays (SAM) (Tusher et al., 2001). Finally, cluster analysis was performed to identify groups of genes with similar expression profiles using the self-organizing map algorithm in GeneSpring 10.0.

\subsection{1b ImaGene Image Analysis}

The microarray images from GenePix $4000 \mathrm{~B}$ were loaded into ImaGene 8.0. along with the corresponding Gene Array List (GAL) file that contains the ID information for every spot organized in a grid format. Each grid was aligned individually to account for any misalignment due to uneven slide arrangement in the ChipWriter or warping of the printing medium. Next, spots were automatically adjusted four times to ensure that the grid lined up properly with the image. Where necessary, further adjustments of individual spots were made manually.

Within ImaGene 8.0 there are various parameters which control virtually all aspects of the array image analysis. Spot finding involves the localization of the array 
signal as printed on the array medium. Duc to warping of the slide surface or slide misalignment, spots and sometimes entire grids require spot finding in order to properly determine the location of the signal. Spot finding settings were left at default with the exception that grid flexibility was increased to allow greater deformation of the grid to match any misaligned spots. Segmentation is the differentiation of signal and background values within the image and constitutes one of the most imporlant aspects of array image analysis. Automatic scgmentation was used with a background buffer of 9 pixels and a background width of 15 pixels. In addition, $20 \%$ of the lowest pixel signals were filtered out to exclude pixels in the center of "donuts". All other parameters were left at default settings, resulting in non-background subtracted, and non-normalized median signal intensitics for each spot.

\subsection{1c Evaluating Grid-to-Grid Variation}

By printing the NCode external control dilution series within each grid, the design allowed for the assessment of grid-10-grid variation in signal intensity caused from differential array pre-soaking or pre-hybridization, uneven hybridization, irregularities in array washing, or printing and pin number. Average signal intensities from the $100 \mu \mathrm{M}$, $12.5 \mu \mathrm{M}, 6.25 \mu \mathrm{M}, 3.13 \mu \mathrm{M}$ and $1.56 \mu \mathrm{M}$ NCode control spots were evaluated as a function of grid number to identify any top-to-bottom or left-to-right variation in signal intensity and to ensure consistency across various probe concentrations, in a manner similar to that described by Yauk el al. (2006).

\subsection{1d Determining Presence/Absence of Signal}

In order to determine the presence or absence of signal from each miRNA probe, an algorithm written in R scripts by Andrew Williams (Hcalth Canada) generated a 
threshold in which all probes exhibiting a median signal greater than three standard deviations above the mean of all buffer-only spots (excluding buffer-only spots printed immediately after $100 \mu \mathrm{M}$ NCode control spots) were considered present. All probes with median signals below this threshold were determined absent.

\subsection{0e Microarray Data Normalization}

In microarray experiments, there are various sources of systematic variation which affect the measured gene expression levels. Normalization is the process in which such variation is removed. The arrays were normalized independently to correct for variation within each single array (within-array normalization) and as a set to make the data comparable between arrays (between-array normalization).

\section{Within-Array Normalization}

An algorithm was written in R scripts by Andrew Williams (Health Canada) to normalize the data within each microarray using Loess normalization. In experiments such as this, where two fluorescent dyes are used, the different dyes do not get incorporated equally well in the labelling procedure, resulting in an intensity difference between samples which is attributable to the dyes, not to differential gene expression. This is referred to as dye bias and may introduce false variations in the data if not corrected (Dobbin et al., 2005). Loess normalization, or locally weighted linear regression analysis, is a technique used to remove variation related to dye bias (Smyth \& Speed, 2003). Loess normalization fits simple linear models to localized subsets of the data to build up a function, point by point, that describes the variation in the entire dataset. (Cleveland, 1979; Cleveland \& Devlin, 1988). The Loess normalization used here was based on the NCode controls series only. Thus, for each NCode data point, a locally 
weighted linear regression was fit to $10 \%$ of the data from the entire control series that was closest to the point in question. The polynomial was fit giving more weight to array elements near the data point whose response was being estimated and less weight to elements further away. The value of the regression function for the point was obtained by evaluating the local polynomial and the data point was adjusted to balance the intensity from both the red and green channels. This was done for every NCode data point until regression function values were computed for every point in the NCode control series and a system for correcting the data at each data point for both channcls was generated. This correction was then applied to all other data. Upon completion of the within-chip normalization, the normalized data was output in $\log 2$ format.

\section{Between-Array Normalization}

After Loess normalization, the red and green distributions within each array were essentially the same. However, considerable variation between arrays was expected due to incvitable differences in array processing such as minor variations in the concentration of miRNA, the number of scans, and atmospheric ozone concentrations. Between-array normalization corrects for these systematic differences and allows direct array-10-array comparisons. GeneSpring 10.0 was used to perform quantile normalization, which has been shown to be a robust method for miRNA data (Bolstud et al., 2003; Rao et al., 2008; Pradervand et al., 2009). This non-parametric approach assumes that there is an underlying common distribution of intensities across all chips (Smyth \& Speed, 2003). The algorithm divides the ordered signal intensities for each array into four equally-sized subsets, or quartiles. The mean intensity at the $1^{\text {st }}, 2^{\text {nd }}$ (median), and $3^{\text {rd }}$ quantile is calculated using data from the entire set of microarrays. The arrays are then normalized 
by converting the mean signal at each quantile to the mean signal across all chips and scaling the intensities of each spot by this overall mean value. This effectively makes the distribution of expression values the same for each array (Pevsner, 2009).

Following normalization, the output data was entered into Excel and the six technical replicates were manually collapsed to give a single median intensity value for every probe. Within each array, if $50 \%$ of the replicates were flagged as being absent, the probe was not included in subsequent analysis.

\subsection{0f Principal Components Analysis}

Principal Components Analysis is an exploratory technique that transforms a large number of possibly correlated variables into a smaller number of uncorrelated variables called principal components. These new variables are ordered by the amount of variance explained, such that the first principal component accounts for as much of the variability in the data as possible and becomes the $\mathrm{X}$ axis, the second principal component accounts for most of the remaining variability and becomes the $\mathrm{Y}$ axis, and so on until all the variation in the data is explained. Converting the original variables into a smaller number of principal components reduces a complex data set into a lower-dimensional picture that may unveil hidden structures or patterns in the data (Shlens, 2009).

\section{Identifying Outliers}

PCA was performed in Parlek to identify any outlier arrays resulting from technical problems. Since the reference channel used pooled miRNA samples that were expected to be identical for all arrays, decisions to exclude specific arrays were based on PCA of the reference channel only. A correlation dispersion matrix with normalized 
eigenvector scaling was used to standardize the data to a mean of zero and a standard deviation of one.

\section{Evaluating Batch Effects}

PCA was also used to screen for effects due to variables other than strain and age, such as date of miRNA extraction and date of hybridization. PCA showed clcar effects of miRNA hybridization date on miRNA expression. This elfect of hybridization date was therefore subtracted from the data using the "remove batch eflect" algorithm in Partek.

\subsection{1g Significance Testing}

Before significance testing, all genes that were never expressed to delectable levels were removed to decrease the number of hypothesis tests and thus reduce the falsc discovery rate correction. A probe was defined as present if it was flagged as present in at least three out of five animals (using experimental channel data only) within at least one treatment group. Anything that failed this filter was excluded from subsequent analysis. Similarly, any genes that were annotated to detect exclusively non-rat miRNAs were excluded, leaving a total of 206 genes for analysis.

Significance testing was performed using Significance Analysis of Microarrays (SAM), a non-parametric statistical technique for identifying significant genes in a set of microarray experiments (Tusher et al., 2001). The independent variables were defined separately as strain and age, as SAM only allows analysis of one variable at a time. SAM computes a statistic (d) for each gene that measures the strength of the relationship between gene expression and the independent variables(s), based on the change in gene expression relative to the standard deviation of repeated measurements. SAM uses repeated permutations of the data, 5000 in this case, to estimatc the likelihood of such 
genes being identified by chance (false discovery rate) and then determines if the expression of any gene is significant in relation to the independent variable. The significance threshold is determined by a user-defined parameter termed delta that is based on the false positive rate. In this study, the delta value was adjusted to report significant genes with a median false positive rate of 0 . This does not mean that there are no false positives, but rather that on at least $50 \%$ of the data permutations, there were no false positives, and thus we can have high levels of confidence in the genes considered significant.

\subsection{1h Clustering Algorithms}

Microarray experiments generate overwhelmingly large amounts of data. Cluster analysis is a widely used tool that helps make sense of this data by identifying groups of genes with similar patterns of expression. These groupings can be used to classify genes according to potential functionality and can be interpreted with respect to possible biological pathways (Shannon, Culverhouse, \& Duncan, 2003). Cluster analysis was performed using the self-organizing map algorithm in GeneSpring 10.0 . 


\section{Results}

\subsection{MicroRNA Quality}

An $\mathrm{A}_{260}: \mathrm{A}_{280}$ absorbances ratio of 1.8 for RNA is generally considered "pure". These samples showed a mean $\mathrm{A}_{260}: \mathrm{A}_{280}$ of 1.99 , with a minimum ratio of 1.88 and a maximum ratio of 2.06 , demonstrating a high level of purity for all miRNA samples.

Similarly, Experion analysis gave an RQI index of at least $9.8 / 10$ (with $8 / 10$ or higher being sufficient for microarray application), indicating that RNA quality was more than sufficient for all downstream applications. Furthermore, comparison between total RNA and small RNA fractions showed no small RNA in the total RNA fraction, with a peak corresponding to small RNA fragments and depleted larger RNA fragments in the small RNA fraction, demonstrating that the small RNA was separated successfully from the total RNA (Figure 9). 

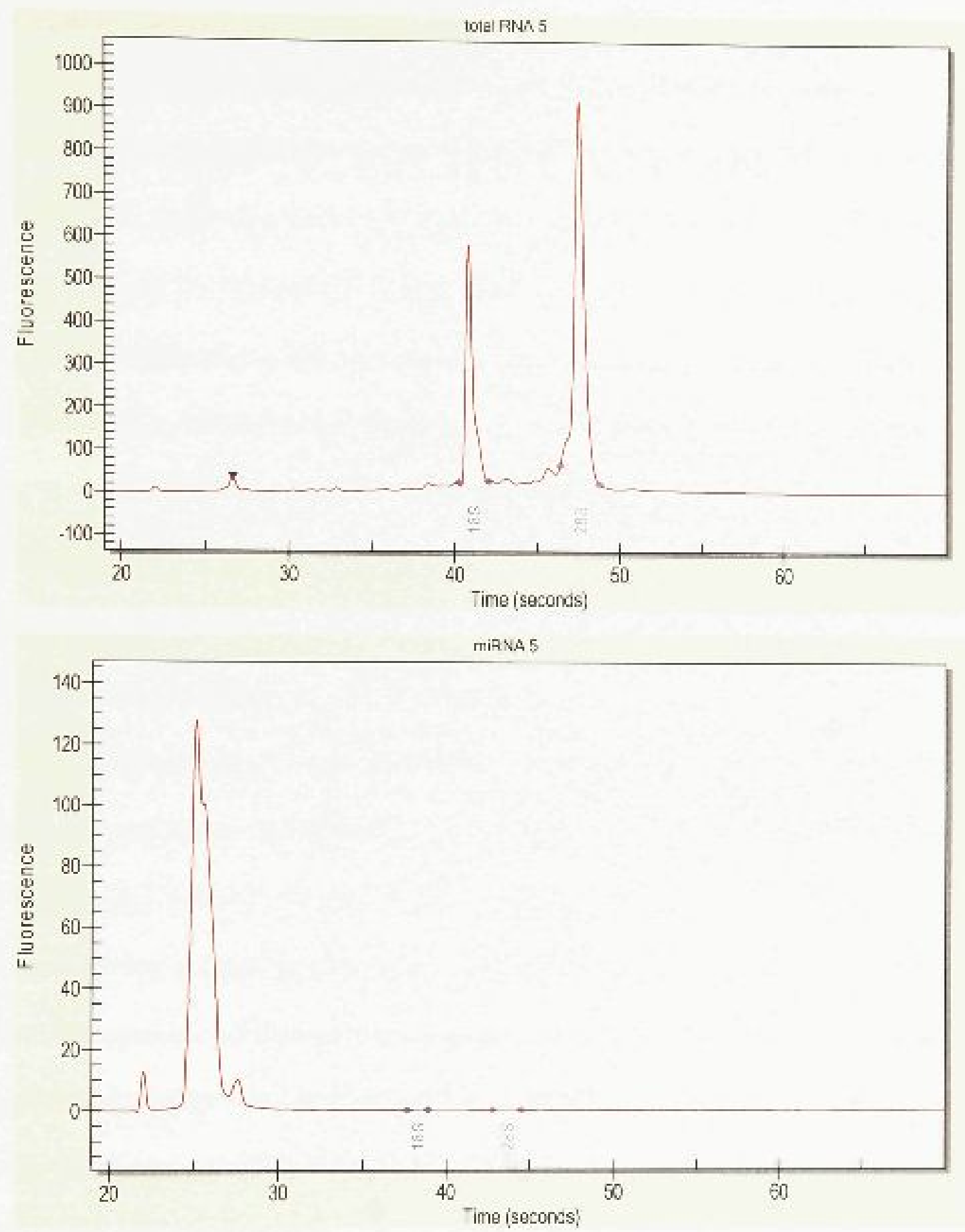

Figure 9: Experion automated electrophoresis results. Top: Results from a typical total RNA extraction, showing peaks associated with the $18 \mathrm{~S}$ and $28 \mathrm{~S}$ ribosomal fragments [28S: $18 \mathrm{~S}=1.92]$. Bottom: Results from a typical miRNA extraction from the same hippocampal tissuc, showing depleted $18 \mathrm{~S}$ and $28 \mathrm{~S}$ ribosomal fragments and a peak associated with smaller RNA fragments. 


\subsection{Evaluating Carry-Over Contamination}

Each grid included six negative control spots used to assess carry-over contamination from the printing process. Three buffer-only spots (Blank C) were printed immediately after a high signal intensity spot $(100 \mu \mathrm{M}$ NCode control spot, termed Spot B) and three (Blank A) were printed immediately after a buffer-only spot. The percent cross-spot contamination was calculated by subtracting the mean signal of the Blank A spots from the mean of the Blank C spots, divided by the mean signal of the $100 \mu \mathrm{M}$ NCode external control spots (Spot B) minus the mean signal of the Blank A spols (i.e., [C-A $/[\mathrm{B}-\mathrm{A}] \mathrm{x}$ 100) (Yauk et al., 2006). Using this measure. the average cross-spot contamination across all arrays was $0.18 \%( \pm 0.02$ standard error) for Alexa Fluor 5 and $0.25 \%( \pm 0.02$ standard error $)$ for Alexa Fluor 3 .

Of the 30 microarrays, exactly half showed consistent and low levels of carryover contamination across all eight printing pins. while the other half showed a higher proportion of carry-over for one printing pin in particular (Figure 10). The cross-pin carry-over observed in grids printed by pin 4 fluctuated between approximately $0.60 \%$ and $1.5 \%$. The majority of these arrays were grouped together and all were among the first half of arrays printed within the ChipWriter. Since a randomized block design was used to randomly assign miRNA samples to arrays for hybridization, the microarrays showing a higher pin-specific carry-over contamination were evenly distributed among each of the six experimental groups (LR/7:3; LR/14: $2 ; \mathrm{LR} / 21: 2 ; \mathrm{HR} / 7: 2 ; \mathrm{HR} / 14: 3$; HR/21:2) (Figure 11). 

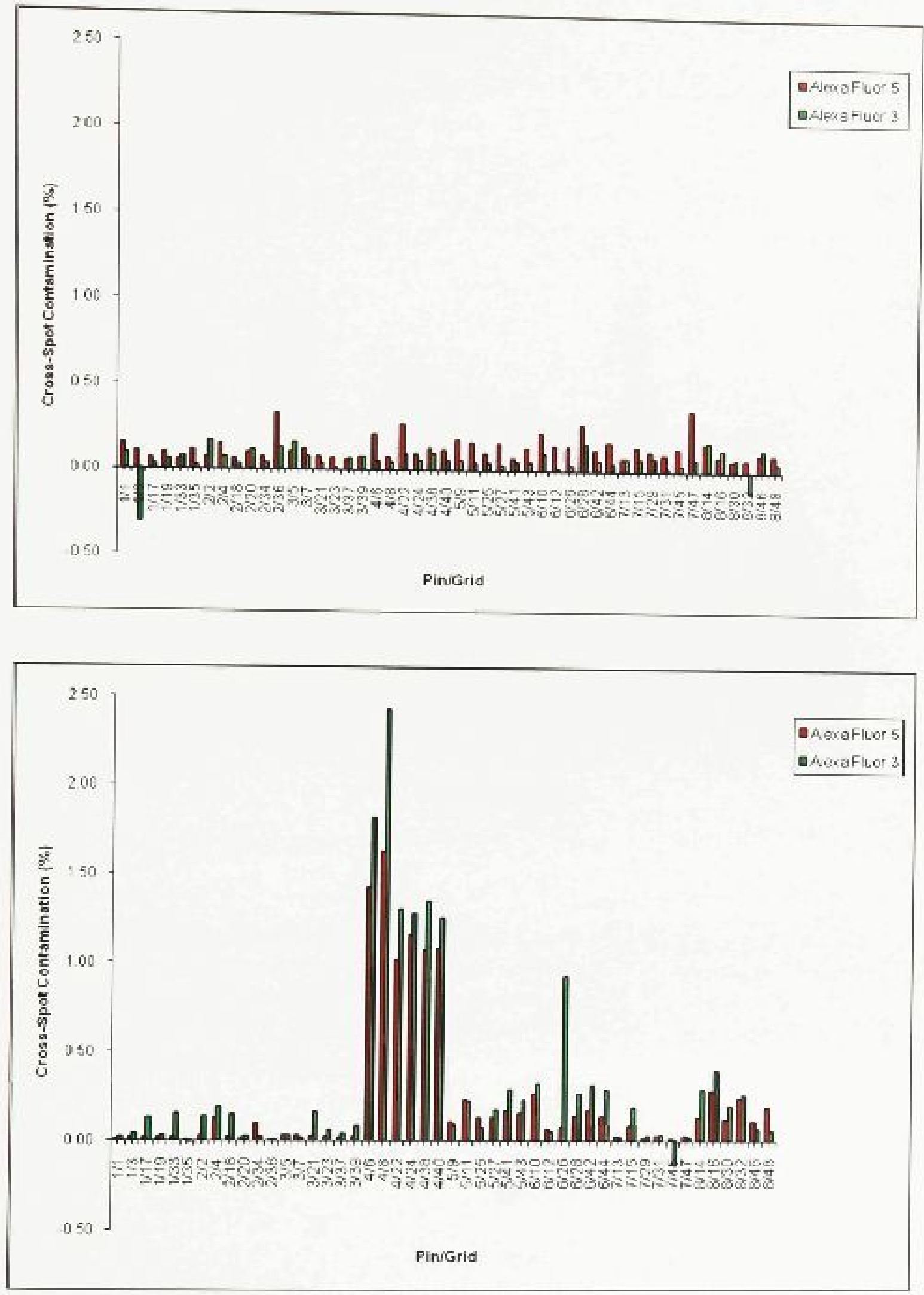

Figure 10: Evaluation of carry-over contamination per printing pin. Top: Plot represents a typical microarray showing consistent and low carry-over $(\%)$ across all printing pins. Bottom: Plot represents a microarray with the highest proportion of carryover $(\%)$ in all grids printed by printing pin 4 . 


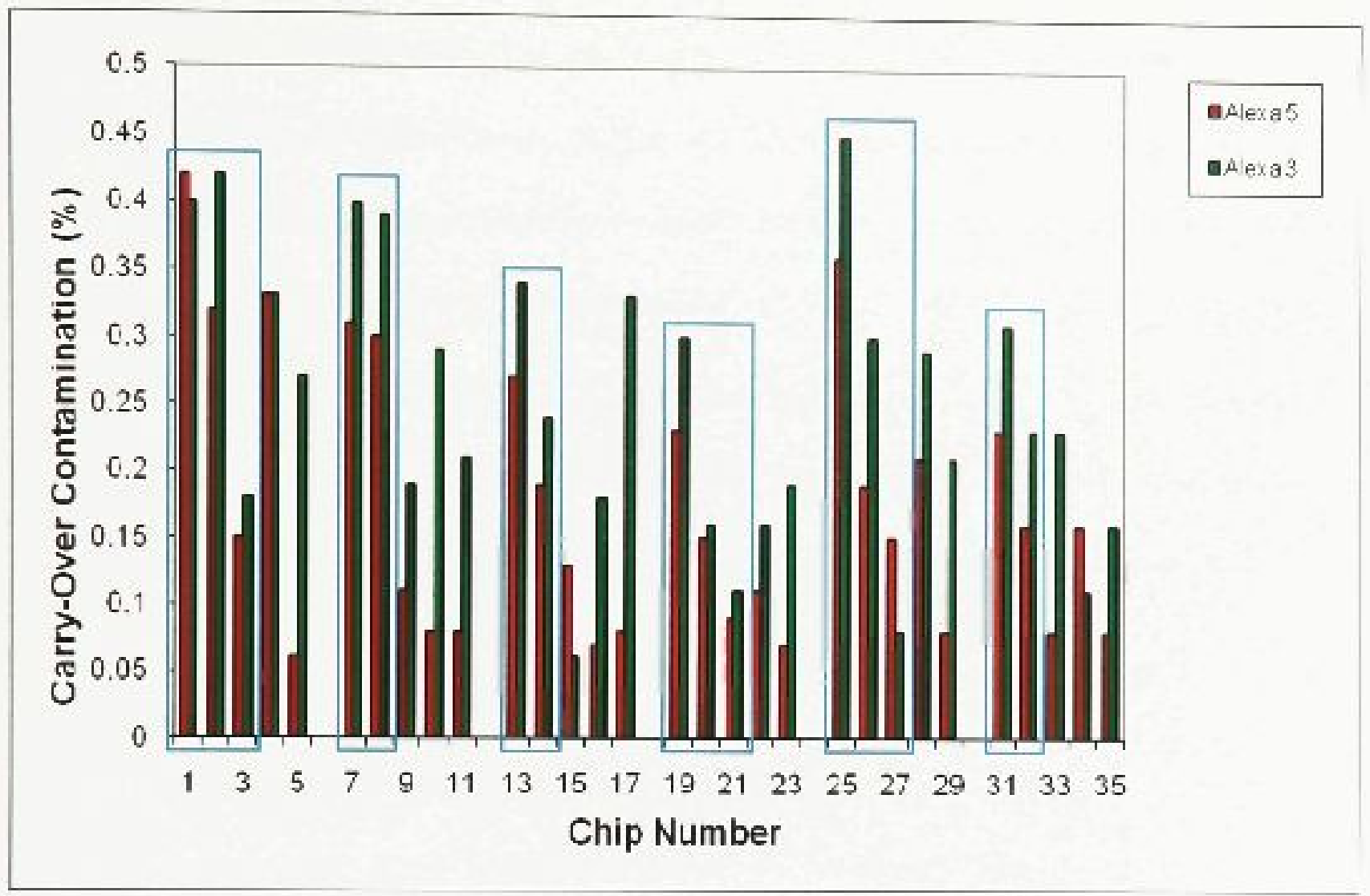

Figure 11: Carry-over contamination (\%) across all microarrays. Carry-over contamination (\%) was computed using the formula $[\mathrm{C}-\mathrm{A}] /[\mathrm{B}-\mathrm{A}] \times 100$ for each array and for both channels separately. The arrays are grouped according to experimental condition (L.R/7, LR/14, LR/21, HR/7, HR/14, HR/21) and the arrays showing pinspecific carry over are highlighted. 


\subsection{Evaluating Grid-to-Grid Variability}

Figure 12 shows the grid-to-grid variation in signal intensity of a typical microarray, with grids numbered across four columns and grid number increasing towards the bottom of the array (see microarray layout in Figure 6). This figure covers the full range of signal intensities, as probes with intensities below that observed for the $1.56 \mu \mathrm{M}$ probes were typicatly flagged as absent. Analysis of non-normalized data shows relatively stable signal intensity from top-to-bottom of the array. However, the signal for the first grid in every row typically drops, indicating an approximate two-fold increase in intensity from left-to-right that is observed for all arrays. Figure 12 also shows that gridto-grid variation is consistent across the series of spot concentrations and variation in signal is similar for both channels.

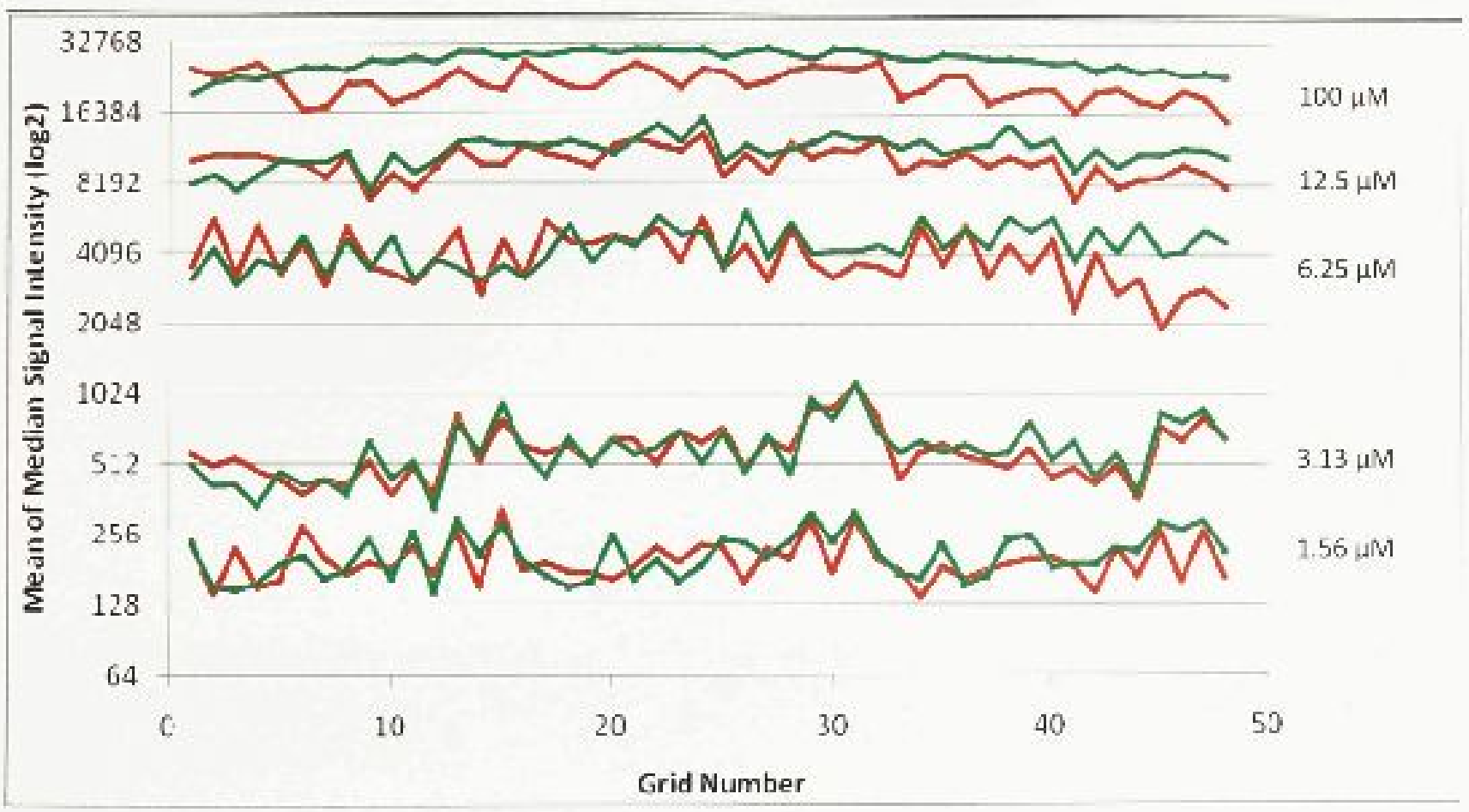

Figure 12: Grid-to-grid variation for a typical microarray. The average signal inlensity for five NCode control spot concentrations are plotted as a function of grid number for both the red and green channels. Variation in signal intensity is relatively stable from top-lo-bottom, but there is an approximate two-fold difference in signal intensity from left-to-right. Data are non-normalized. 


\subsection{Microarray Data Normalization}

A scatterplot of non-normalized data comparing the median signal intensily from both channels confirms that the NCode control series covers the full range of signal intensities with no breaks in the signal, making the series appropriate for use in normalization procedures (Figure 13).

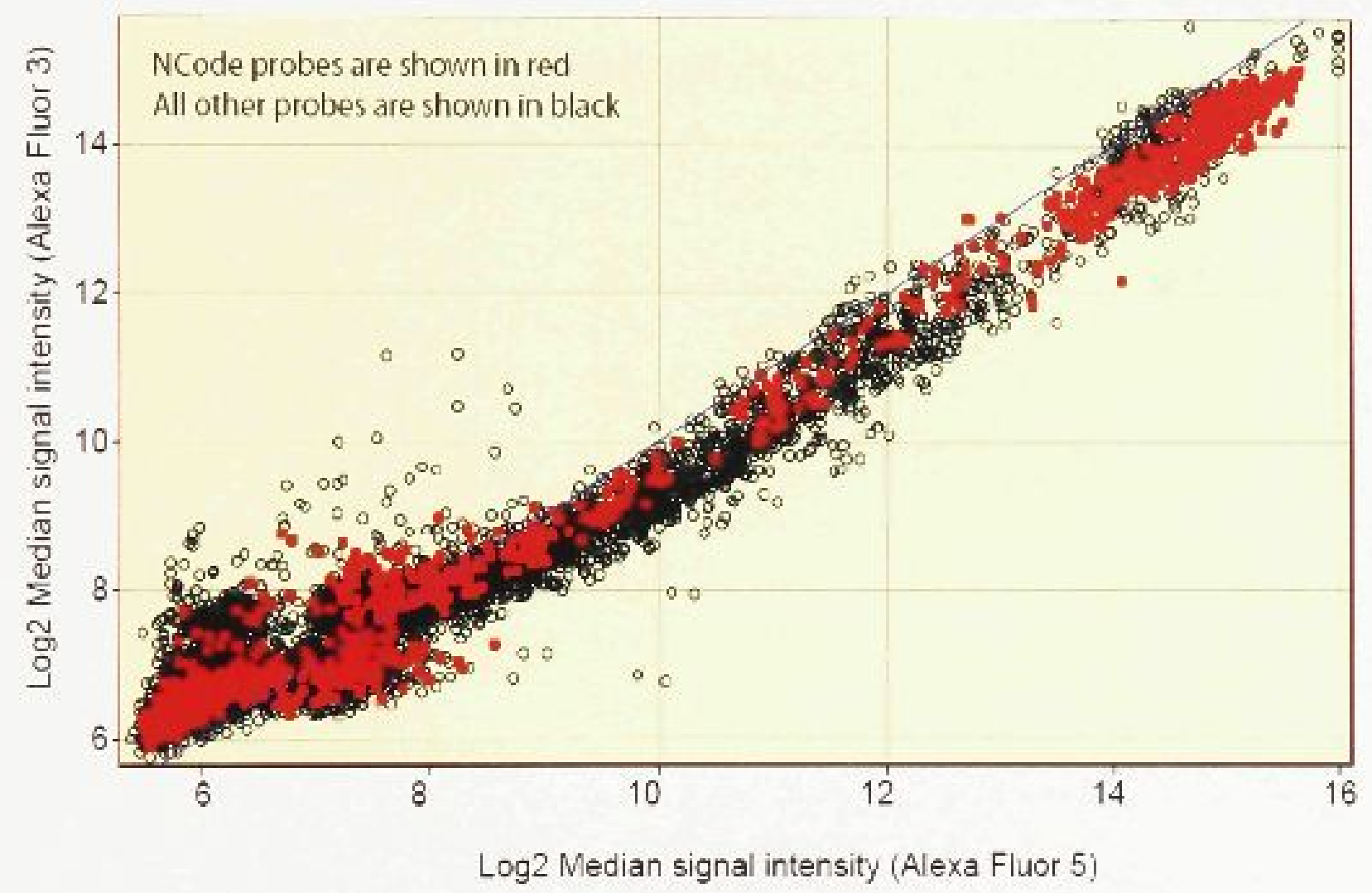

Figure 13: Scatterplot of median signal intensities for Alexa Fluor 3 and Alexa Fluor 5. The non-normalized signal intensities are relatively balanced between channels and the NCode control series (red) covers the full range of signal intensities with no gaps in the signal. 
MA plots were generated to compare intensities from the red and green channels, where $\mathrm{M}$ is the log-ratio of the expression intensities and $\mathrm{A}$ is the average log-expression of intensities. Figure 14 shows MA plots for a microarray included in the analysis and an array later identified as an outlier. For an array included in the analysis, Loess normalization produced a relatively minor adjustment of the data. However, for an outlier array excluded from analysis, dramatic differences in signal intensities between the two channels prior to normalization resulted in a much larger adjustment and therefore, less confidence in the normalized data. Quantile normalization of the entire set of microarrays adjusted the distribution of expression values for each array, dramatically reducing variation between arrays (Figure 15). 

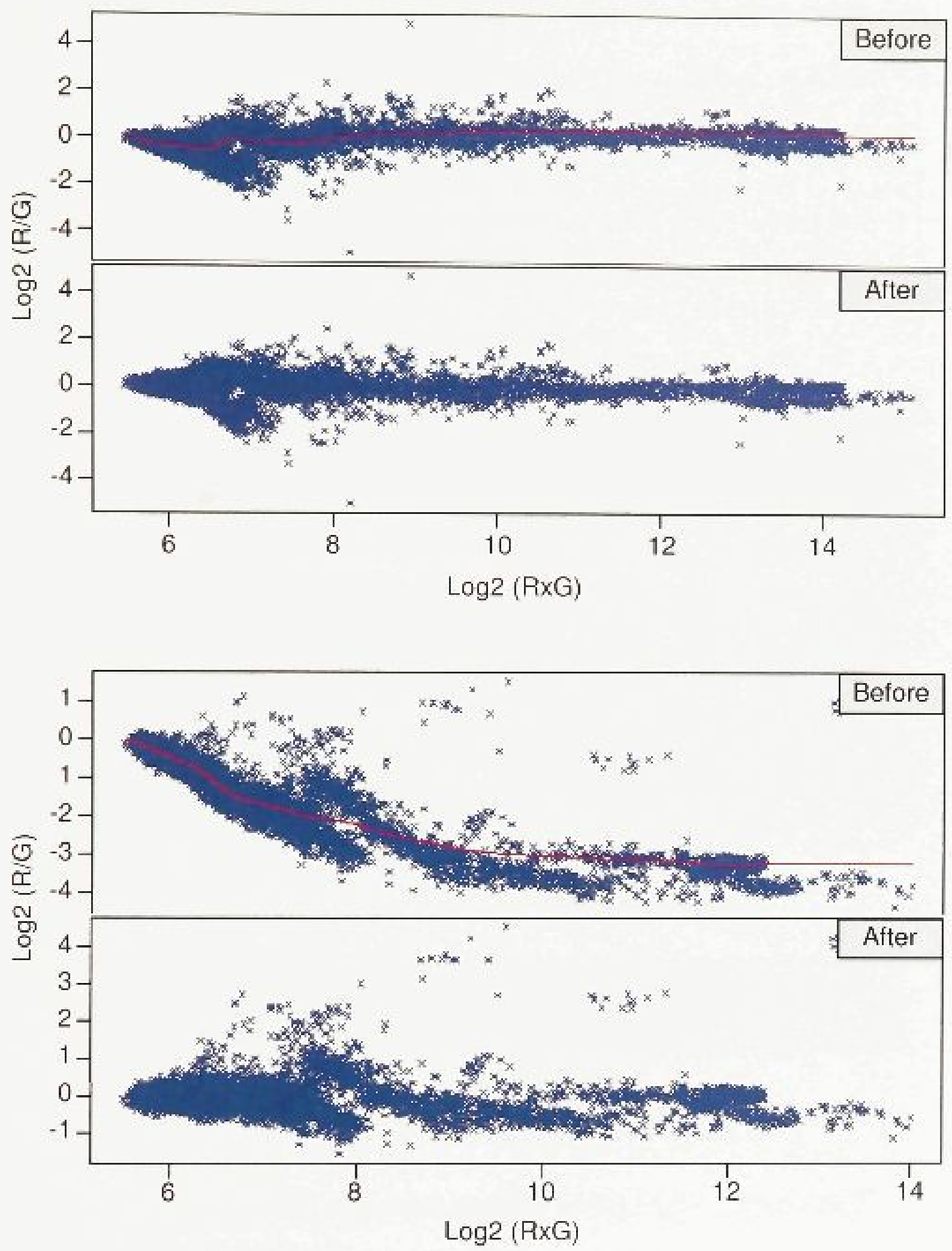

Figure 14: MA plots before and after Loess normalization. MA plots show microarray data both before and after within-array normalization for an array that passed quality control measures and was included in the analysis (top) and an array that failed quality control measures and was excluded from analysis. 

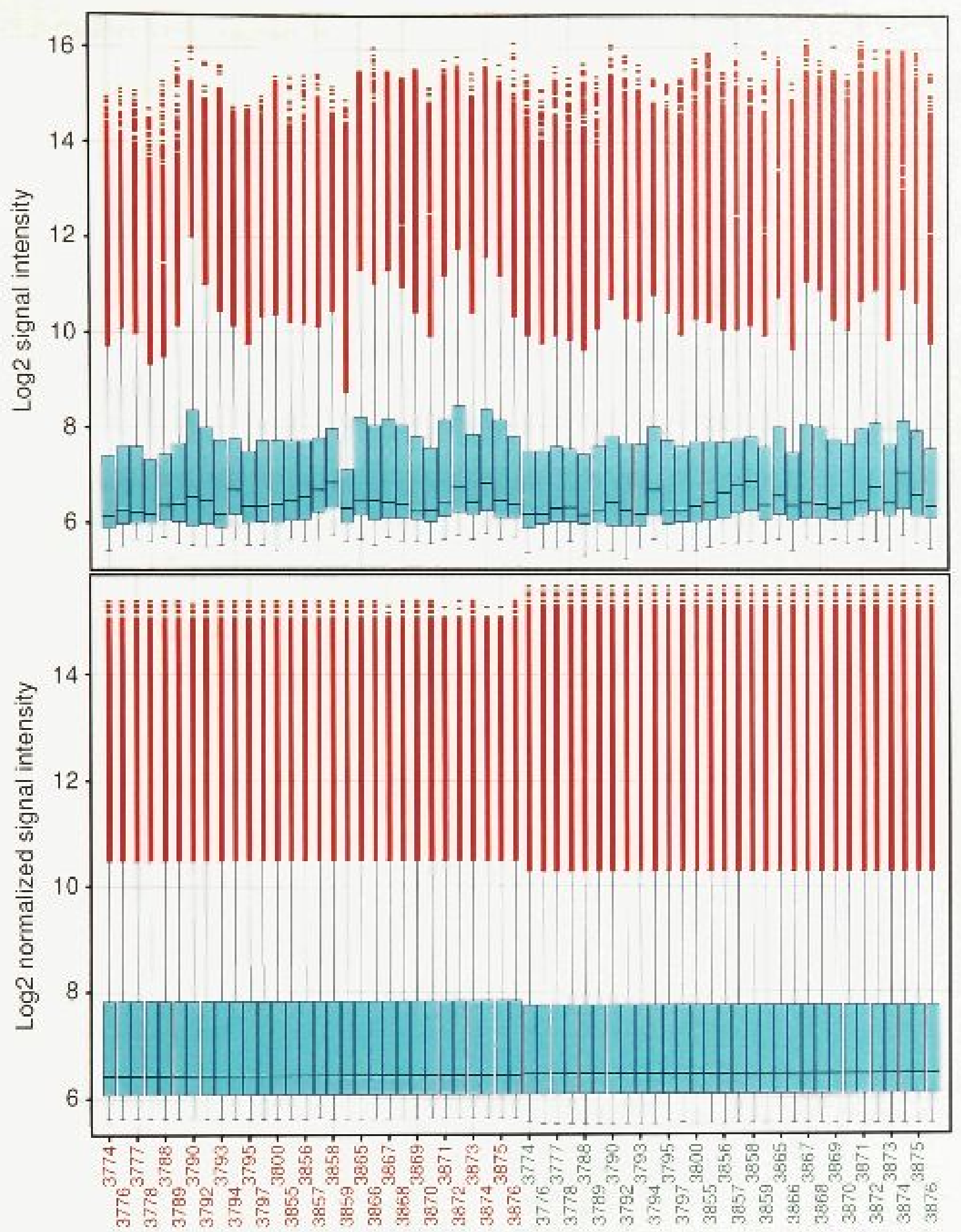

Array barcode reference number (red and green channels)

Figure 15: Boxplot before and after quantile normalization. Each boxplot displays the intensity values for the green and red channels separately for each array. Beforc normalization, there is considerable variability between the arrays (top). Quantile normalization adjusted the expression values for each channel independently, reducing the variation between arrays. 


\subsection{Outlier Determination}

Decisions to exclude specific microarrays were based on Principal Components Analysis of the reference channel. PCA of all 39 microarrays (a total of 36 plus 3 duplicated arrays) identified six outliers (Figure 16). Exclusion of these six microarrays and re-analysis by PCA led to minimal evidence of any remaining outliers. In order to generate $n=5$ in each experimental group, three additional microarrays were excluded from analyses. Given that hybridization date had an effect on miRNA expression, microarrays that led to the removal of an entire hybridization batch were excluded and all subsequent analysis was on a total of 30 microarrays.

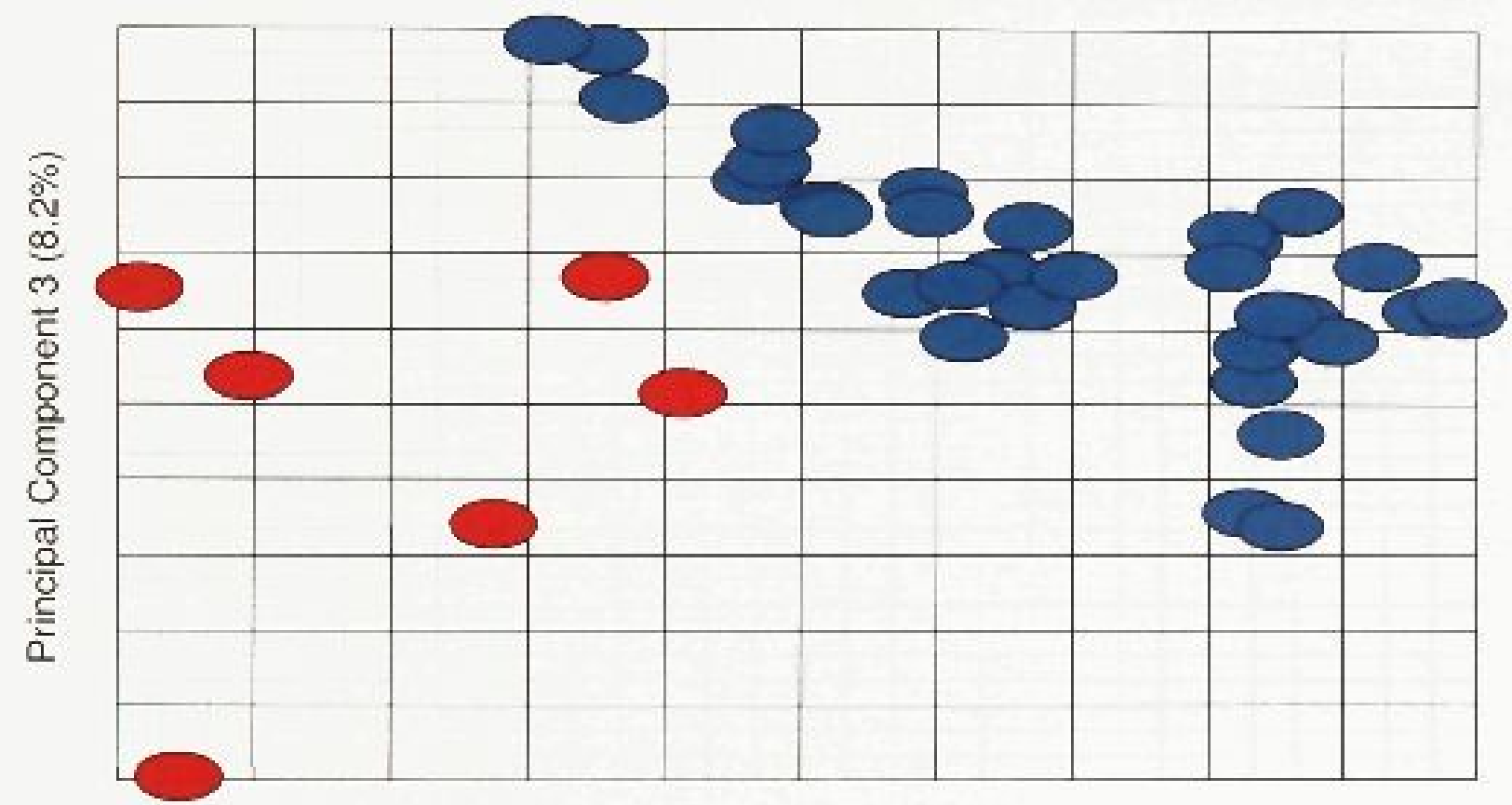

Principal Component $1(18.4 \%)$

Excluded as outlier

Included in subsequent analysis

Figure 16: Principal Components Analysis to identify outlier microarrays. PCA plot shows distribution of arrays on PCl versus PC3. Of the 39 microarrays included, six were identified as outliers and were excluded from subsequent analysis. 


\subsection{Removing Batch Effects}

The presence of batch effects was assessed by PCA on the reference channel (Figure 17). Interestingly, the actual date of hybridization segregates in a progressive manner along the $\mathrm{PCl}$ axis, so that the more recent the hybridization, the further to the right the array is on the axis. This suggests that something is systematically changing over the course of time that hybridization was being performed. PCA on the experimental channel shows similar effects of hybridization date and miRNA extraction date, although slightly less pronounced (data not shown). Since both factors are interrelated due to the experimental design, and hybridization date appears to have an additional effect on miRNA expression within groups distinguished by extraction date, Partek was used to remove the hybridization date batch effect only. Re-analysis by PCA demonstrated that the effect attributable to both hybridization date and extraction date had been dramatically reduced for both the reference and experimental channels. 


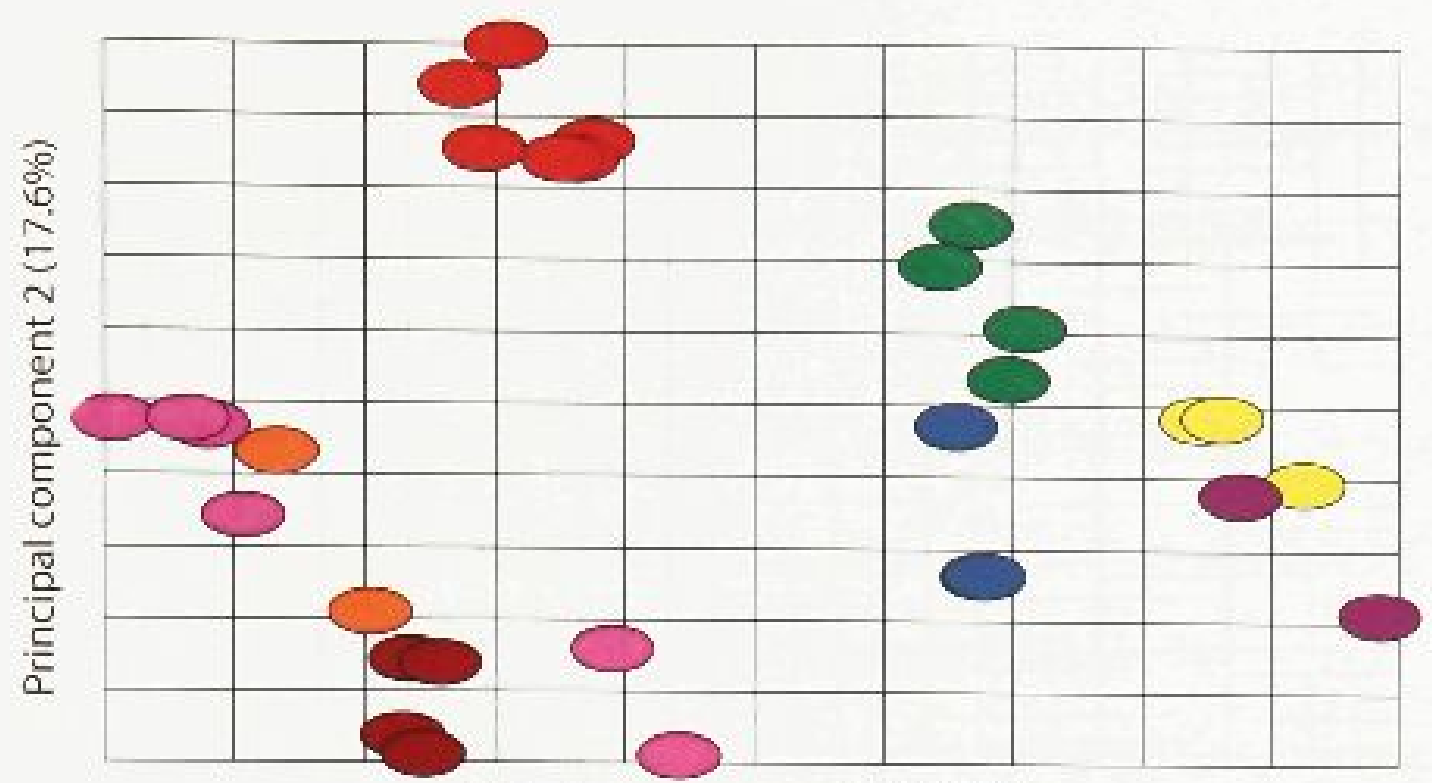

Principal component $1(22.8 \%)$

$\begin{aligned} \text { Hybridization } & \text { July } 22009 \\ \text { date } & \text { July } 32009 \\ \text { July } 82009 & \text { July } 112009\end{aligned}$

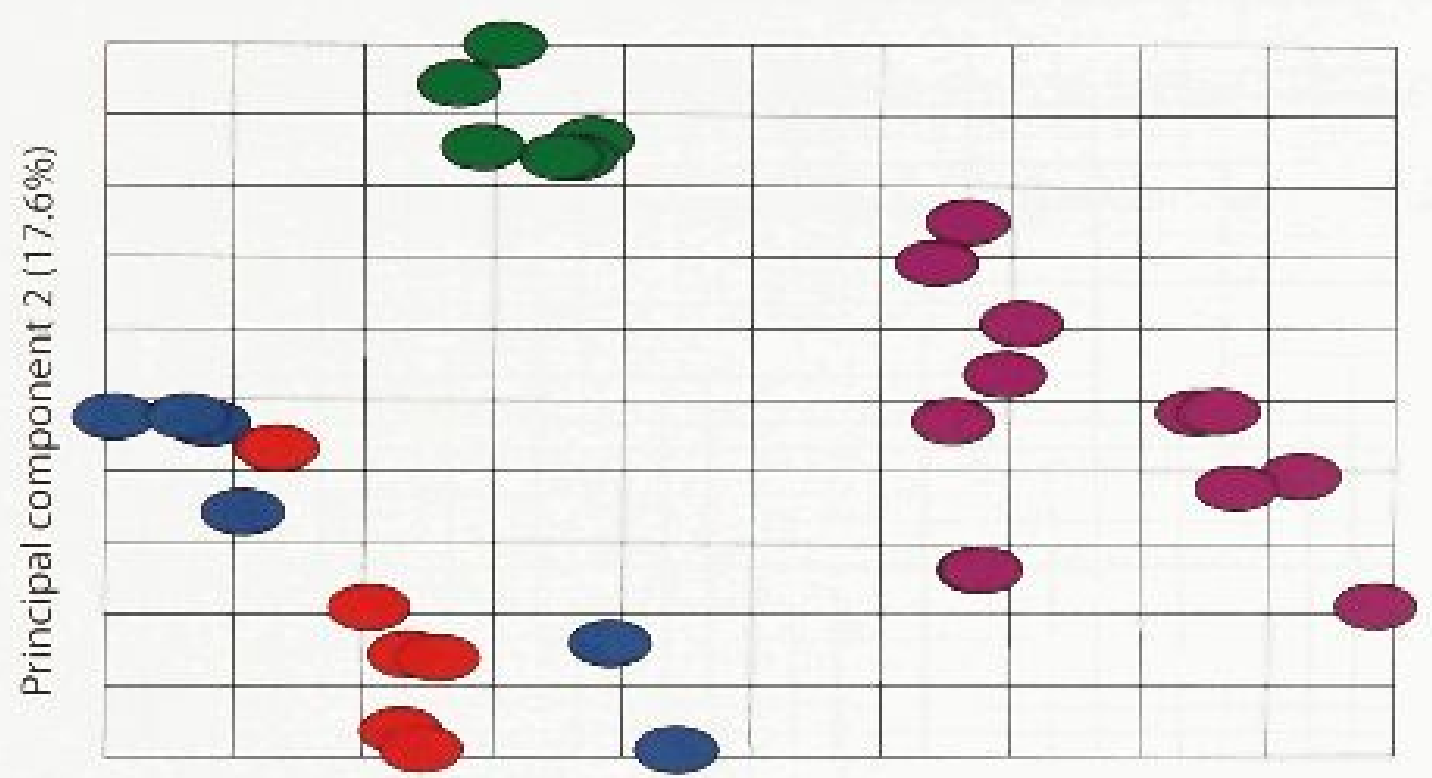

Principal component $1(22.8 \%)$

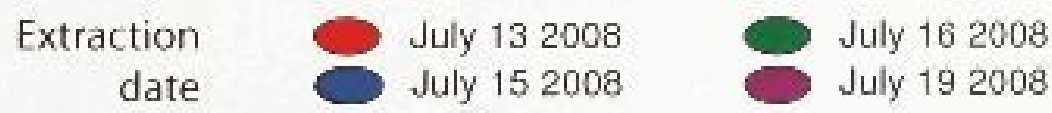

Figure 17: Effect of hybridization date and extraction date on miRNA expression. PCA of the reference channel for all microarrays shows clear effects of both hybridization date (top) and miRNA extraction date (bottom) on miRNA expression profiles. In addition, hybridization date segregates in a temporal pattern across $\mathrm{PCl}$. 


\subsection{Differences in MicroRNA Expression}

PCA was performed to test the hypothesis that there would be differences in miRNA expression between postnatal days 7, 14, and 21 and between HR and LR rats at P7 and P14, but not P21, as was observed for mRNA expression profiles (Figure 1). Contrary to the hypothesis, there was no indication of segregation by strain. However, age segregated along PCl (the largest single component of variance), revealing an obvious effect of developmental age on miRNA expression (Figure 18).

Significance analysis of microarrays (SAM) revealed that $78.9 \%$ of the 261 rat miRNA probes included on the chip were expressed at detectable levels. The threshold of significance was adjusted to the point where the median number of false positives was 0 . At this threshold, there were 62 genes that different by age. The expression patterns of these genes across the three developmental timepoints are graphically represented in Figure 19. A self-organizing map algorithm was also used to classify these 62 genes into

12 groups based on similarities in expression profiles across postnatal days 7,14 , and 21 (Figure 20). 


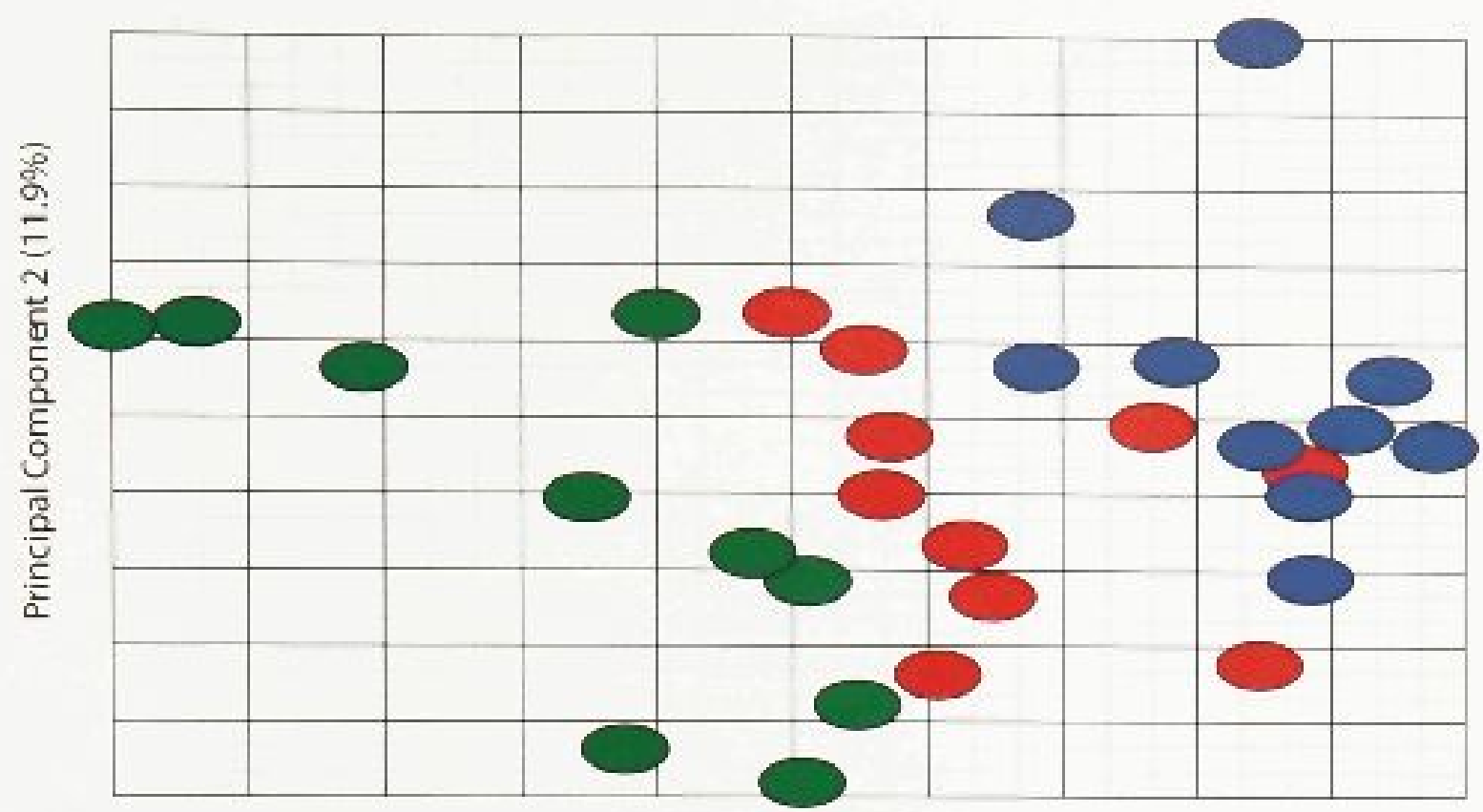

Principal Component $1(19.5 \%)$

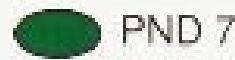

PND 14

PND 21

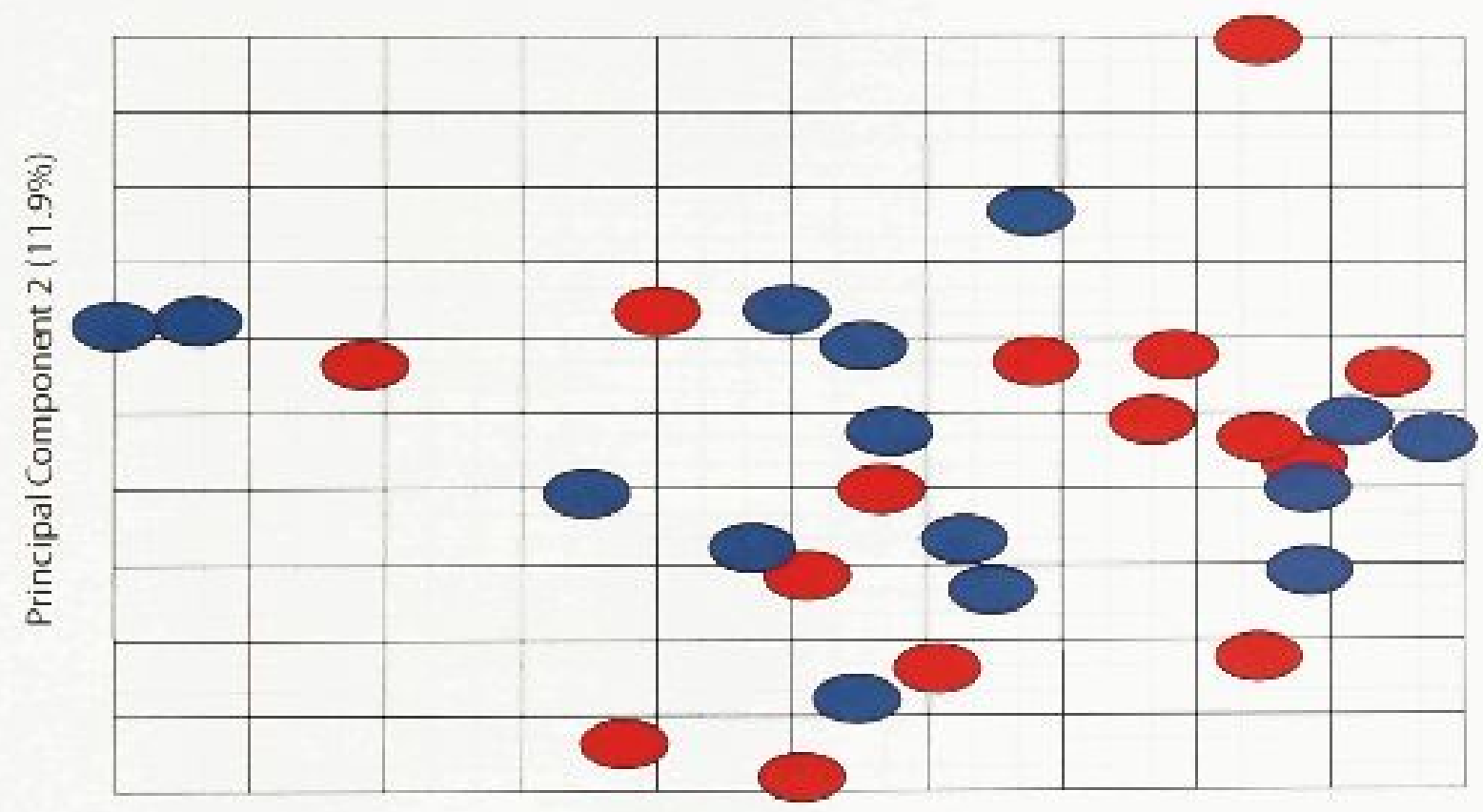

Principal Component $1(19.5 \%)$

Figure 18: Effect of strain and age on miRNA expression. PCA plot shows distribution of arrays on PC1 versus PC2. PCA shows a clear effect of developmental age on miRNA expression top). However, PCA shows no obvious effect of HR/LR phenotype on miRNA expression (bottom). 


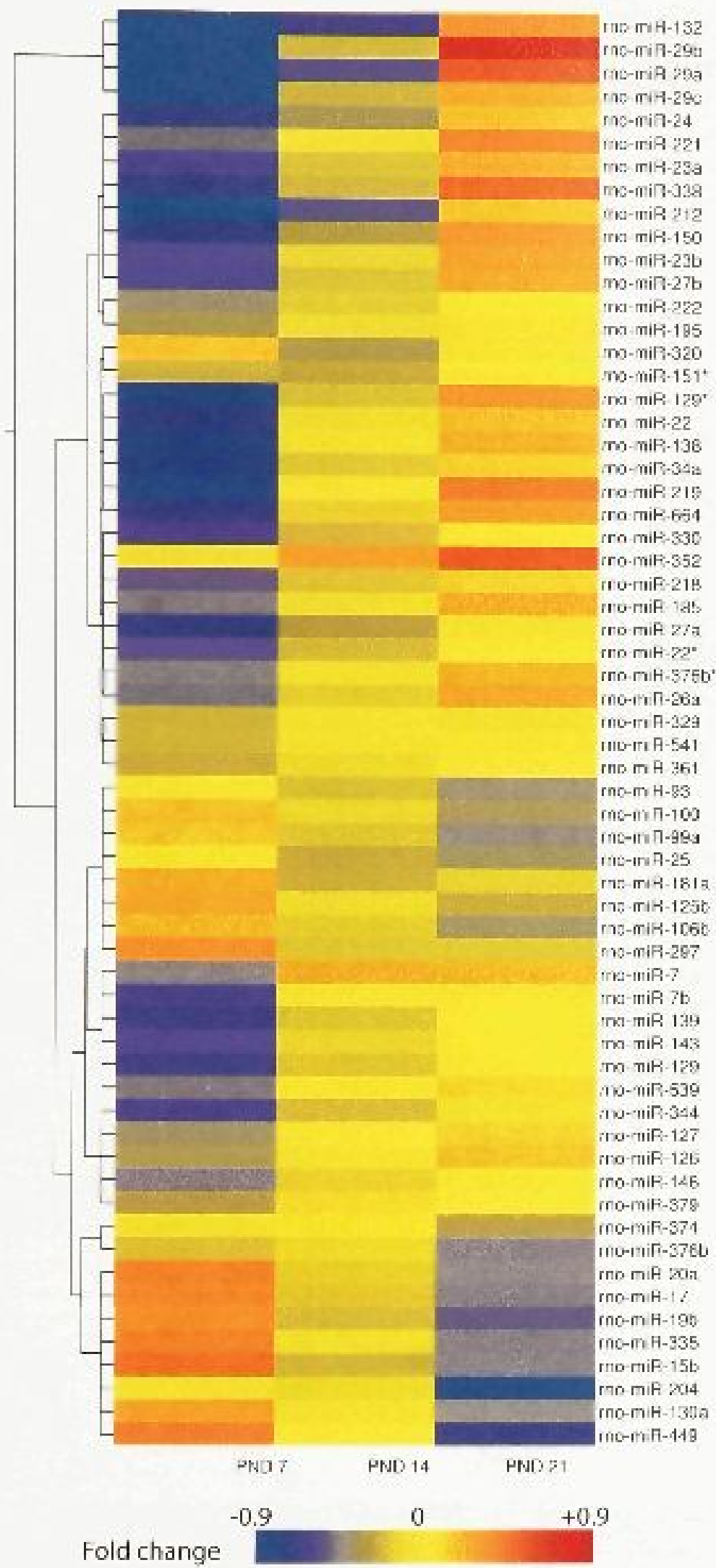

Figure 19: Heat map of miRNAs differentially expressed between P'ND 7, 14, and 21 . 62 rat miRNAs showing significant differences in expression across postnatal days 7, 14 and 21 are displayed from left to right. 

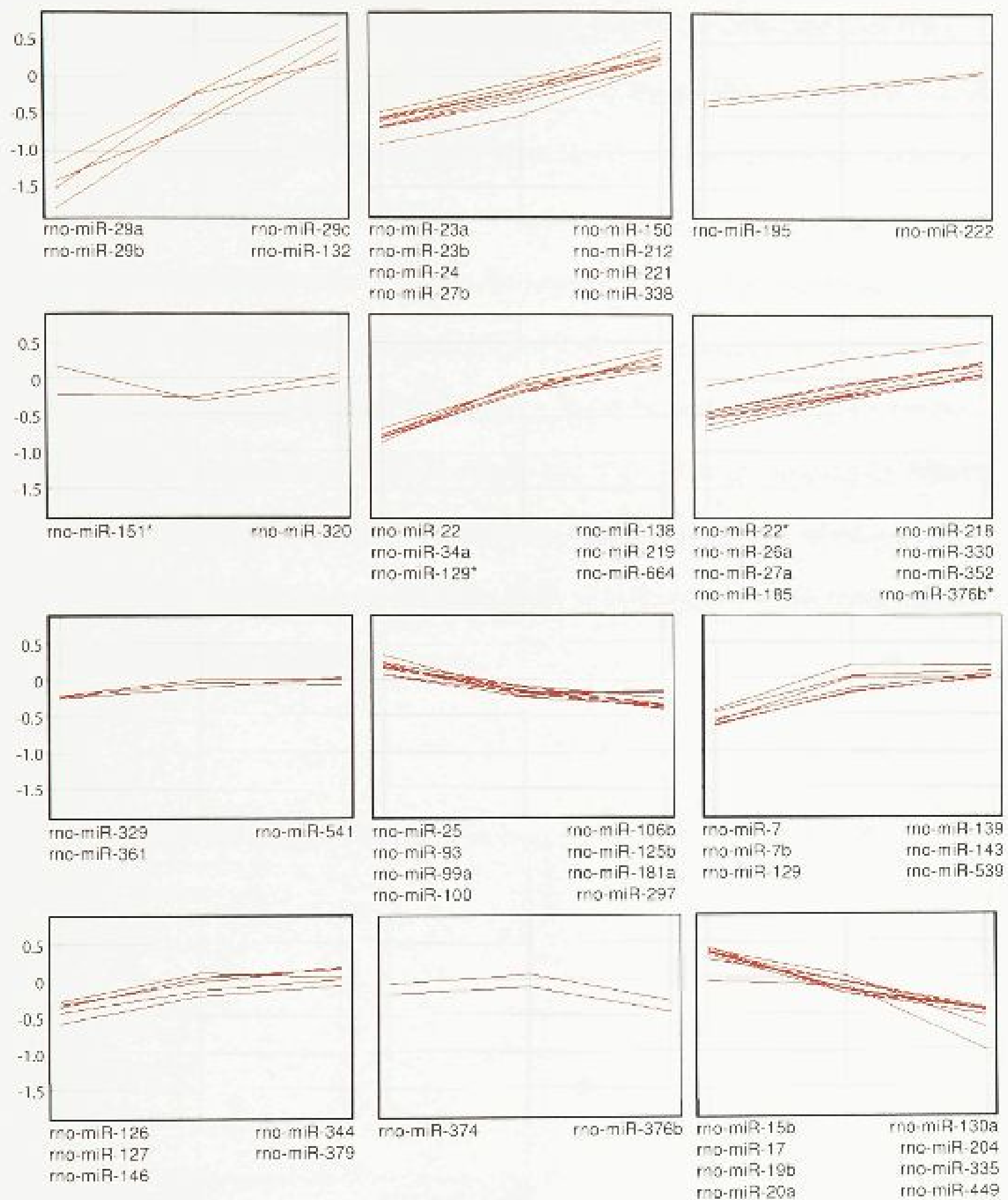

Figure 20: Expression profiles for miRNAs showing significant differences between PND 7, 14, and 21. Cluster analysis was used to classify the 62 significantly expressed genes into 12 groups showing similar expression profiles across postnatal days 7,14 , and 21 (x-axes). 
Although PCA showed no obvious effect of the IIR/LR phenotype on miRNA expression, SAM revealed three genes displaying significantly highcr expression in High Responders compared to Low Responders when data from all timepoints are combined (Figure 21). In addition, SAM was used to explore the interaction between age and strain to identify any differences in gene expression between High Responders and Low Responders within each developmental time point. Results revealed nine genes that are significantly upregulated in High Responders at PND 14 (Figure 22) and three that are significantly downregulated at PND 21 (Figure 23). There were no significantly different genes between the strains at PND 7. As expected, significance analysis of microarrays performed on the reference channel for the effects of both age and strain, confirmed no significant differences in gene expression.
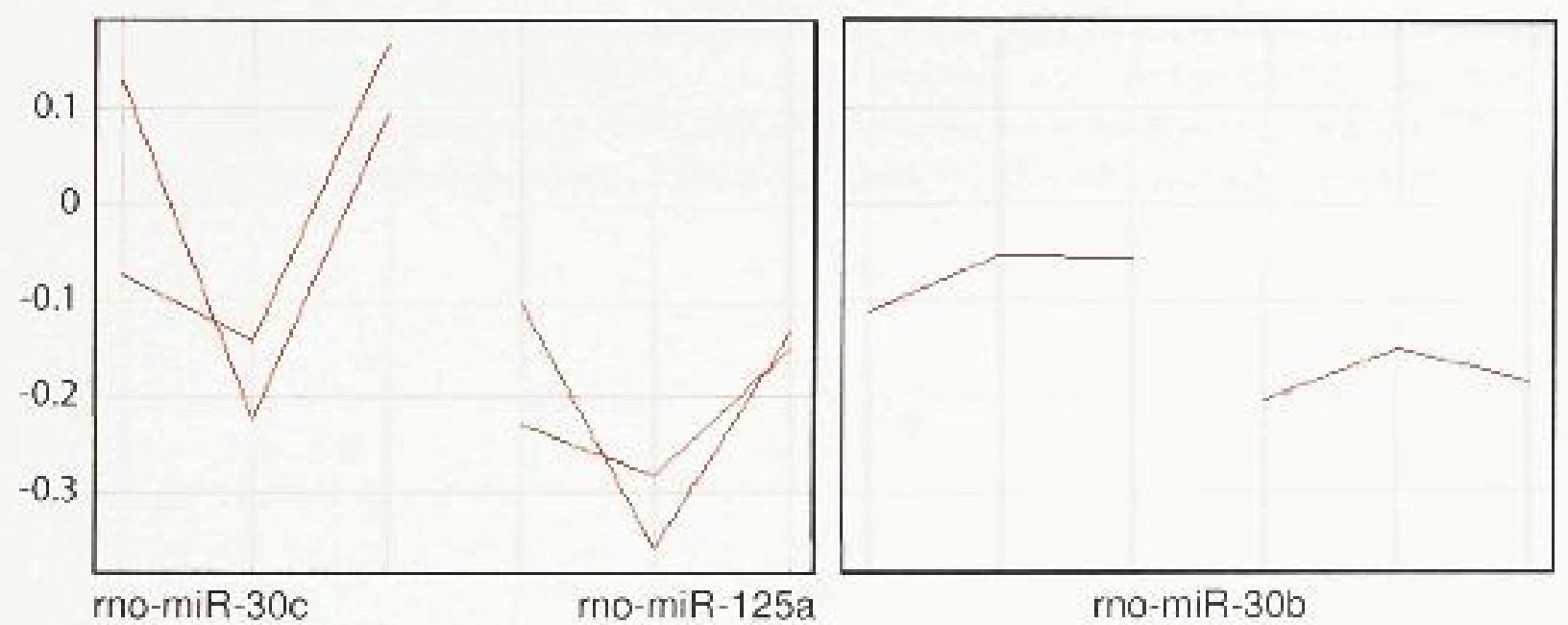

mo-miR-30b

Figure 21: Expression profiles for miRNAs showing significant differences between High and Low Responders across all time points. Cluster analysis was used to classify the three significant genes into two groups showing similar expression profiles when data are combined from all timepoints. For each gene, x-axcs show expression at PND 7, 14, and $2 I$ for $H R$ and LR, respectively. 


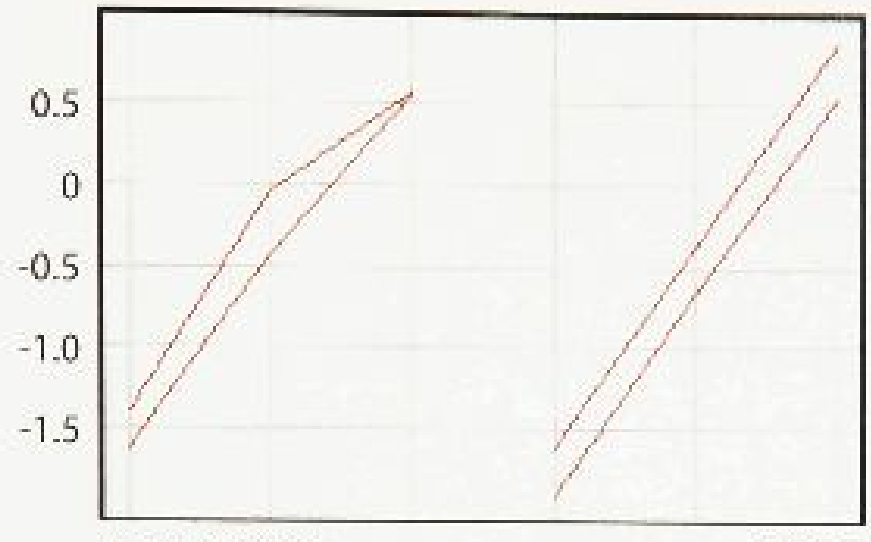

rno-miR-29a

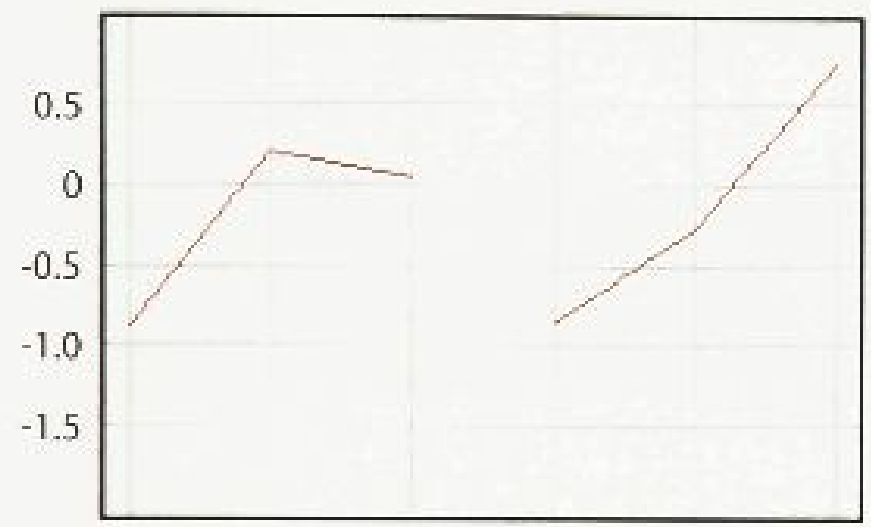

rno-miR-219
rno-miR-29b

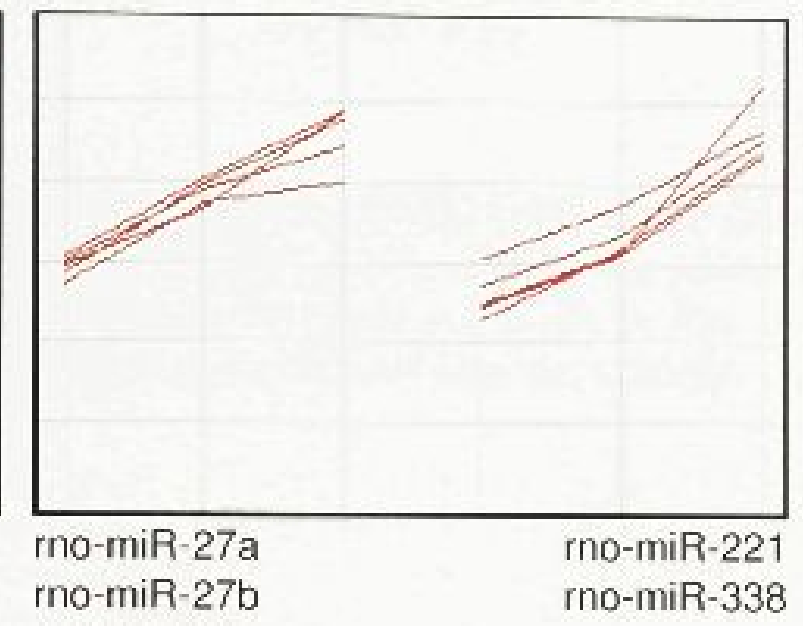

mo-miR-150

Figure 22: Expression profïles for miRNAs showing significant differences between High and Low Responders at PND 14. Cluster analysis was used to classify the three significant genes into two groups showing similar expression profiles at PND 14. For each gene, $x$-axes show expression at PND 7, 14, and 21 for HR and LR, respectively. 

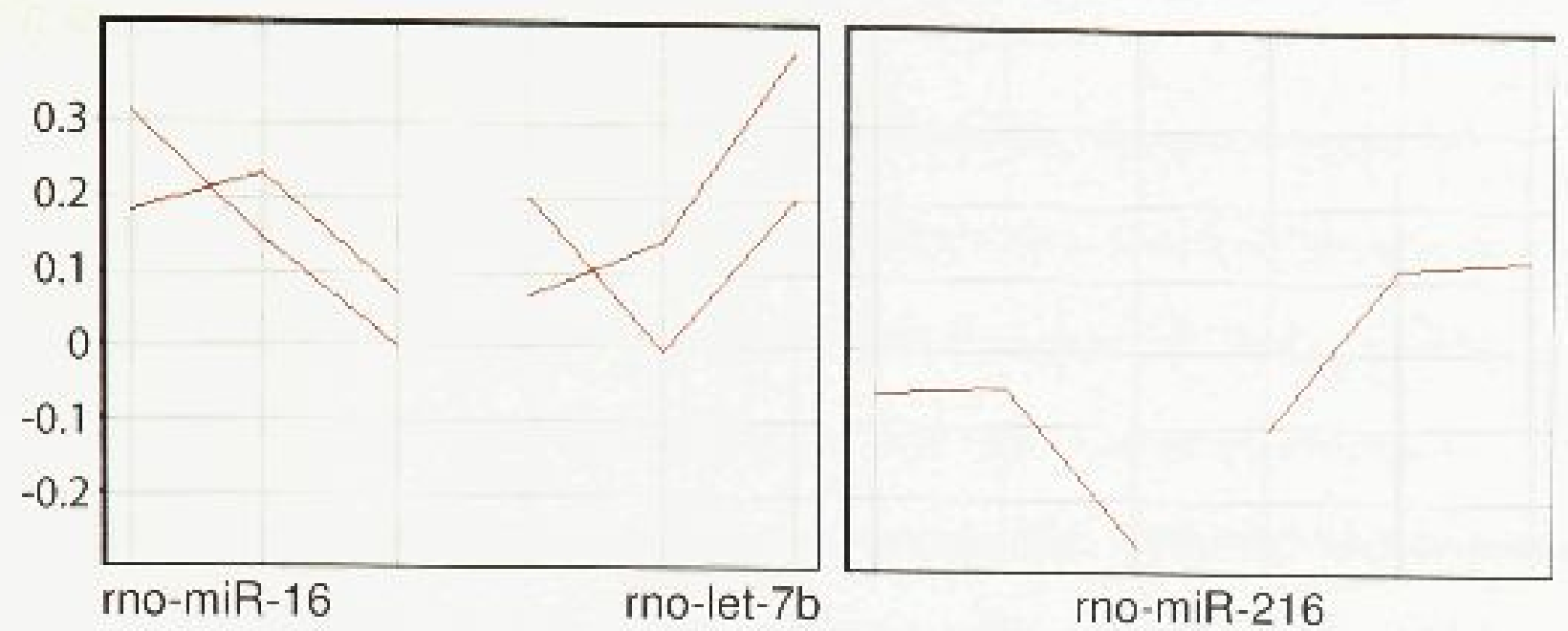

Figure 23: Expression profiles for miRNAs showing significant differences between High and Low Responders at PND 21. Cluster analysis was used to classify the nine significant genes into four groups showing similar expression profiles at PND 21. For each gene, $x$-axes show expression at PND 7,14 , and 21 for IIR and I.R, respectively.

Since a higher proportion of carry-over was observed for grids printed with pin 4 on half of the microarrays, genes showing significant expression were analyzed for possible print-tip carryover artefacts. Of the 62 significant genes, eight were located within grids printed by this pin. Iowever, none of these probes were printed in positions likcly to have been affected by carry-over effects, as all were printed immediately after either buffer-only spots or probes showing very low relative expressions. 


\section{Discussion}

In humans, "sensation-seekers" are individuals that are drawn to stress- or anxiety-causing situations (Bardo et al., 1996) and are more likely to suffer from stressrelated disorders such as bipolar affective disorder, depression, and drug and alcohol abuse (Zuckerman \& Neeb, 1979). In order to better understand the genetic factors underlying susceptibility to stress-related disorders, the High Responder-Low Responder model was used to identify differences in miRNA profiles between these two phenotypes in the developing hippocampus, a brain region that plays an important role in the HPA axis response to stress. miRNAs are involved in central nervous system development and function and have been implicated as potential factors in the development of stressrelated disorders (Uchida et al, 2008). By identifying differences in gene expression early on, it may give insight into the developmental factors that predispose individuals to respond differentially to stressful environments and situations.

\subsection{Creating a Custom MicroRNA Microarray Platform}

These data demonstrate that the custom miRNA platform established within this thesis is able to accurately detect differences in miRNA expression. While these data must be confirmed by complementary techniques such as real-time PCR, clear differences in expression profiles between different age groups are observed. Furthermore, differences between groups are as expected based on previous studies (Stead et al., 2006) as differences between P7 and P14 appear to be greater than differences between P14 and P21 (Figure 24). Similarly, the difference in expression profiles is greatest when comparing $\mathrm{P} 7$ to $\mathrm{P} 21$. 


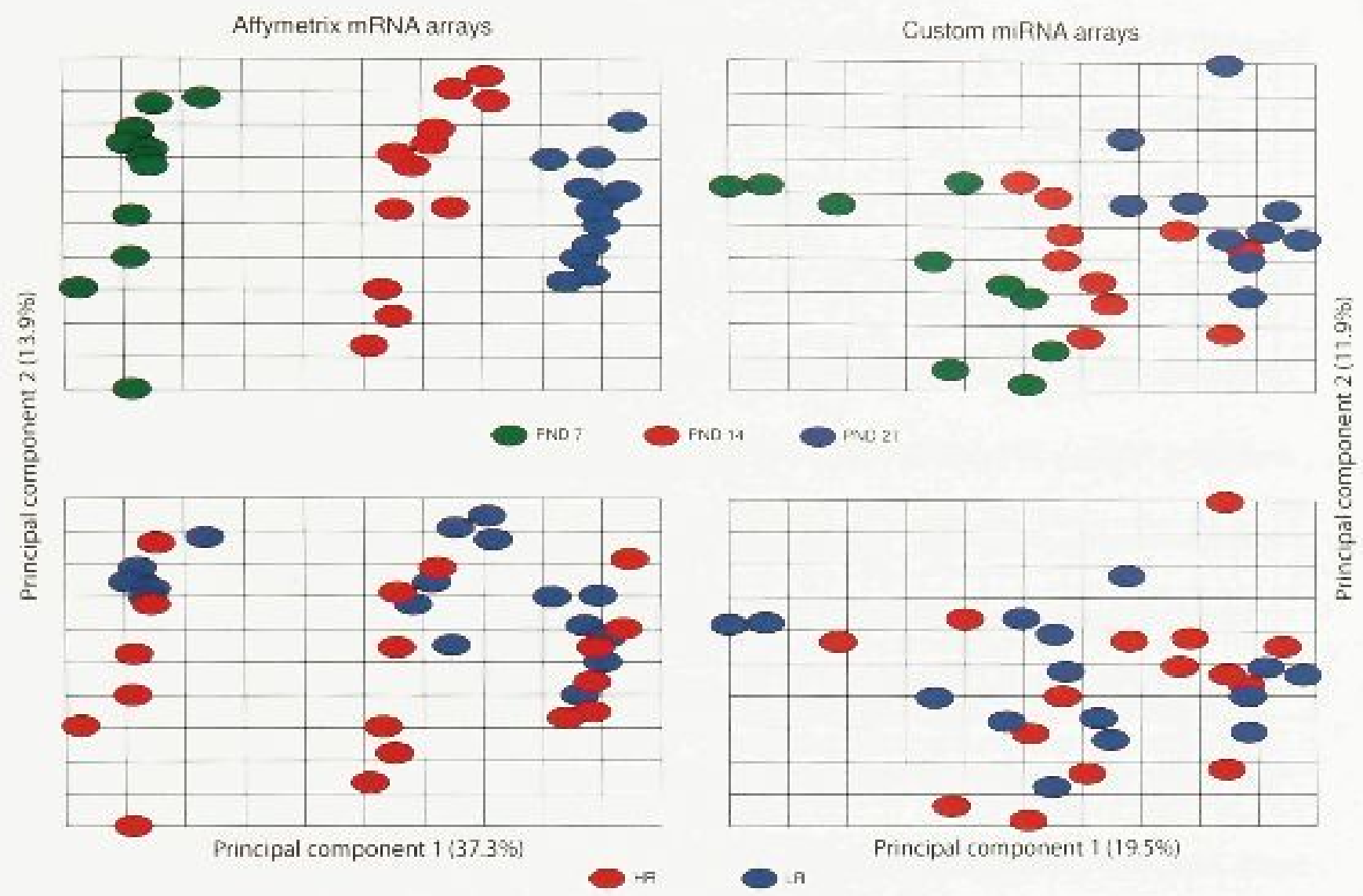

Figure 24: Comparison of mRNA and miRNA expression profiles for both age and strain. The top panel shows clear differences in both mRNA (left) and miRNA (right) expression between postnatal days 7, 14, and 21 in the hippocampus. The bottom panel shows differences in mRNA expression at postnatal day 7 and 14 (left), but no obvious differences in miRNA expression at any of the developmental time points (right).

Nomenclature of miRNAs follows a set of specific rules. New miRNAs are assigned sequential numerical identifiers as discovered, Sequences whose mature miRNAs differ at only one or two nucleotides are assigned the same number. but different lettered suffixes, constituting a family of miRNAs that may share similar functions (Griffiths-Jones et al., 2006). It is therefore notable that within this study, families of miRNAs that differ by only one or two nucleotides (mik-29a, b. \& $c$; mik-23a 
$\& b$; miR-7 \& miR-7b) displayed similar expression patterns between postnatal days 7 , 14, and 21 (Figure 20). Related miRNAs also showed similar expression profiles between the two different strains. For example, two of the three genes that were significantly upregulated in High Responders across all three time points were $m i R-30 b$ and $m i R-30 c$ (Figure 21). Furthermore, at postnatal day $14, m i R-27 a$ and $m i R-27 b$, as well as $m i R-29 a$ and $m i R-29 b$, were upregulated in HRs compared to LRs (Figure 22). This suggests that the microarray platform is able to differentially detect these structurally similar miRNAs. Although Invitrogen's miRNA probes are designed to provide maximum specificity for discerning between closely related miRNAs, it is also possible that cross-hybridization occurred, in which only one miRNA was actually changing, but was being detected by both probes. For instance, miR-29a might have been the only miRNA changing, but the probes for both $m i R-29 a$ and $m i R-29 b$ were detecting this change. If this is the case, these isoform probes can essentially be viewed as technical replicates of each other, acting as two independent sets of probes that detect the same miRNA. The fact that these sets of probes give the same results demonstrates consistency within arrays and is evidence that each probe is giving an authentic signal.

\section{1a Designing and Printing the Microarrays}

Although miRNA microarrays are becoming a common tool for exploring the profiles of hundreds of genes simultaneously, standard control measures have not been established to ensure the quality of arrays before analyzing and interpreting results (Pradervand et al., 2009). A major goal of this study was to design a microarray that allowed for quality assurance measures at various stages of the process. Consequently. the various controls incorporated into the design are a key strength of this custom 
platform. For instance, the three dilution series (NCode, miR-125a, and miR-222), the carry over controls, and the random hexamers are all features of these arrays that are not included in Invitrogen's commercial arrays. Furthermore, additional technical replicates (six) were printed on each slide, compared to pre-printed slides available from Invitrogen (three).

Printing six tcchnical replicates per array increases the likelihood of obtaining accurate results. It is common to use only two or three replicates per array. However, a variety of problems can occur in the hybridisation process, which can affect the signal intensities for individual spots or for entire regions of the array, and the fewer replicates, the more inaccurate the resulting expression levels can be. It should be noted that taking the median signal from six replicates does not automatically guarantec better quality data. For example, if arrays consistently showed strong top-to-bottom variation in signal intensity, the median signal would always equal the difference between spots in the two supergrids in the middle of the array. This would essentially lead to consistent use of datit from only two of the six replicate spots. Fortunatcly, for these data there were no dramatic and consistent grid-to-grid variations in signal intensity, so this limitation was not an issuc.

Carry-over contamination between different probes on the amay can result in increased signal intensity due to a previously printed, highly expressed probe. Surprisingly, many microarray studies do not address this issue. Evaluating carry-over contamination ensured that high signal intensity was in fact due to increased expression and not carry-over artefacts. Although the carry-over contamination (\%) was considerably higher for pin 4 for a subset of the arrays (Figure 10), careful inspection 
showed that this was due only to the last of the three buffer-only spots used in the carryover calculation. This spot consistently showed high signal, while the first two bufferonly spots showed signals comparable to background levels. This phenomenon was observed for all microarrays printed before the first re-dip. After the re-dip, the problem disappeared for several slides, but returned partway through the printing cycle. There is no clear explanation for this observation. However, it does suggest that significantly expressed miRNAs should be screened for higher intensity in the subset of arrays showing this pattern.

The inclusion of the NCode control spike-in for hybridization to the NCode dilution series had several benefits. Having a series of spots within each grid with intensities that are independent of the miRNA sample (and thus expected to be identical in intensity between arrays), allowed for the uniform evaluation of carry-over contamination and grid-to-grid variability in signal intensity. The NCode control series was also used to demonstrate that a more intense signal is achieved with more probetarget interactions (Figure 5). Furthermore, the NCode control series was used to normalize the data within each array.

Measurable signal intensities from the NCode control spots confirmed that the labelling procedure worked appropriately. However, it did not confirm that the quality or quantity of endogenous labelled miRNA was appropriate for the labelling procedure, nor that concentration-dependent data would be obtained from endogenous miRNA. For this reason, $m i R-222$ and $m i R-125 a$ dilution series were included in the design and showed an increase in signal intensity with probe concentration similar to the NCode series (data not shown). However, these control series cannot be used for normalization, as that would 
require the assumption that expression levels of these miRNAs are constant between samples, which would have to be determined empirically in advance of each experiment.

\section{1b Reference Design}

Two-colour microarrays were generated using a reference design. This design incorporates a common reference sample on every array against which all other samples are initially compared (Knapen et al., 2009) and has several advantages. First, it allows for the evaluation of technical variability between arrays and identification of batch effects. Furthermore, significance testing of the reference channel increases the reliability of results revealed on the experimental channel. Analysis of the reference channel will also be used to compare expression data between different normalization approaches.

\section{1c Image and Statistical Analysis}

\section{Normalization Techniques}

To date, well-established normalization techniques designed for mRNA arrays have been applied to miRNA arrays, even though there are important differences between miRNA and mRNA data sets. For instance, mRNA microarrays typically evaluate the expression of tens of thousands of genes simultancously, while miRNA microarrays evaluate the expression of hundreds of genes. In addition, the majority of miRNAs are either not expressed or are expressed at low levels, and consequently, most spots on the arrays cannot be used for normalization. For these reasons, normalization methods used for mRNA expression arrays may not be appropriate for miRNA arrays (Sarkar $e t$ al., 2008; Pradervand et al., 2009).

Typical normalization approaches assume that most genes will not change. However, for arrays with small sets of genes in which a large proportion may exhibit 
differential expression, this assumption may not hold true. To address this issue, Yauk et al. (2006) incorporated an external control dilution series with a Loess normalization to improve the detection of differential mRNA cxpression in an array focusing on a subset of mRNAs relevant for toxicological studies. Results demonstrated that Loess normalization incorporating this control series improved detection over Loess normalization on its own. Since our custom microarrays share similar characteristics, Loess normalization based on the NCode control series was used for within-array normalization. To the best of my knowledge, this is the first study using this approach with miRNA data. Thus, the performance of Loess normalization with and without the NCode control series will be evaluated in the future. In addition to intensity-dependent dye bias, there are other types of biases that can be removed through within-array normalization. Spatial patterns in the data can occur due to variability in printing pins (pin bias) or through the use of several different source plates (plate bias). The intensity for each spot also contains a contribution from the background fluorescence (background bias) (Khojasteh et al., 2005). Spatial normalization methods include scaling each printtip group or plate group by the mean intensity of that group or scaling spots within a predefined collection of spots by the mean intensity of that collection. Background bias can be removed by subtracting an estimate of the background intensity from each spot. Evidence suggests that multi-step normalization procedures addressing all of these sources of variability outperform conventional single step methods (Khojasteh et al., 2005). This suggests that in the future, multiple systematic variations should be considered when normalizing microarray data. 
Some of the first between-array normalization methods used with miRNA array data were centering to median values (Sun et al., 2004; Castoldi et al., 2006) or scaling based on total array intensities (Miska et al., 2004; Tian et al., 2008). Variance Stabilizing Normalization (VSN) and quantile normalization have more recently been used with miRNA data (Laurent et al., 2008; Pan et al., 2008). Perhaps surprisingly, some researchers do not use any normalization procedures at all (Baskerville \& Bartel, 2005; Liang et al., 2005; Wang et al., 2007). All of these various approaches to normalization (or lack thereof) have been used on miRNA microarray data, despite the fact that there is virtually no evidence supporting the appropriateness of their use. Several recent studies have compared the performance of various normalization approaches used with miRVA expression data and although there is no clear consensus, results suggest that quantile normalization works at least as well as other methods, if not better ( Bolstad et al., 2003; Rao et al., 2008; Pradervand et al., 2009).

Loess within-array and quantile between-array normalizations were chosen for this study based on existing literature. However, a comparison of various normalization procedures will be assessed to determine the most appropriate method for these particular data.

\section{Evaluating Batch Effects}

The effect of hybridization date on miRNA expression may not be surprising, given that various factors may change from date-to-date, such as atmospheric ozone concentrations or batch number of the miRNA labelling kit. However, the fact that hybridization dates segregated in chronological order, from least recent to most recent was unexpected (Figure 17). Although ozone concentration has a clear effect on the 
hybridization procedure (Hicks et al., 2004), it is not likely the cause of this temporal pattern, as ozone concentrations varied in random directions throughout the weeks that hybridization was performed (data not shown). One possible explanation for the consistent change is that the quality of the MilliQ water used to prepare the wash solutions may have decreased with time. MilliQ water has been shown to effect the stability of Alexa Fluor dyes when the filter has not been changed (Genisphere Incorporated, 2004). In this case, the MilliQ filter was changed and the system was cleaned before the first hybridization. However, the rest of the hybridizations were performed before another monthly cleaning cycle was required. In the future, immediately following a cleaning cycle, MilliQ water should either be stored in tightly sealed jugs for use in all subsequent wash solutions or the MilliQ cleaning cycle should be performed more frequently. Another option is to avoid MilliQ water entirely and use deionized reagent grade water to prepare wash buffers (Genisphere Incorporated. 2004).

\subsection{Comparison of mRNA and miRNA Expression Profiles}

Previous research using Affymetrix mRNA arrays showed clear differences in hippocampal mRNA expression between postnatal days 7,14 , and 21 , as well as differences in mRNA expression between High and Low Responders at postnatal day 7 and 14. It was hypothesized that miRNA expression in the hippocampus would follow a similar pattern. This was partially true, as there were distinct differences in miRNA expression between postnatal days 7, 14, and 21. However, unlike mRNA expression, PCA showed no clear differences between the two strains (Figure 22). Significance analysis of microarrays did demonstrate that there were some miRNAs that differed 
significantly between HR and LR rats. However, significant differences were only observed at postnatal days 14 and 21 , which is in contrast with the mRNA expression profiles that showed significant differences in mRNA expression only at postnatal days 7 and 14. Since miRNAs act on target mRNAs, it makes sense that miRNA levels change in response to mRNA levels. Therefore, mRNA expression is expected to change first, followed by changes in miRNA expression. This might explain why mRNAs differed at P7 and P14, while miRNAs did not differ until P14 and P21.

It should be noted that the mRNA and miRNA platforms should not be considered to be directly comparable. For example, if the miRNA data shows greater variability than the mRNA data, it could be due either to greater biological variability, or greater technical variability. Indeed, it has been suggested that in-house microarrays do not provide the same level of sensitivity that commercial arrays do (Bammler et al., 2005). In a study conducted by the Toxicogenomics Research Consortium, microarray data and the reproducibility of the results were evaluated within and between different laboratories as well as within and between different microarray platforms (Bammler et al., 2005). Results indicated that more than half of the variability observed in the data was attributable to the microarray platform, with differences between replicate microarrays and between different laboratories contributing substantially less. They also reported that commercial microarrays, for a variety of reasons, yield results that are more comparable between laboratories, compared to arrays printed in-house. This is not surprising, given that custom arrays require more in-house processing, compared with commercial platforms. However, in-house microarrays offer advantages that commercial microarrays 
do not, including lower financial cost and the flexibility to customize the arrays to include a variety of miRNA probes and controls.

\subsection{MicroRNA Function}

Although the functional roles of the majority of miRNAs are not known, the functions of a subset of miRNAs that differ between strains, and their relation to changes in mRNA expression, are explored below.

\section{3a mik-30}

$m i R-30 b$, and $m i R-30 c$, both of which are upregulated in High Responders versus Low Responders across all ages (Figure 21), comprise a family of miRNAs that have been implicated in the regulation of connective tissue growth factor (CTGF), a protein found in various organs and involved in extracellular matrix remodelling (Duisters et al., 2009). In two rodent models of heart disease, miR-30 was inversely related to the amount of CTGF. In addition, knockdown of $m i R-30$ in cultured cardiomyocytes and fibroblasts increased CTGF levels, while overexpression of miR-30 decreased CTGF levels. CTGF function in the brain is poorly understood. However, it has been localized to amyloid- $\beta$ plaques in Alzheimer's disease and degenerating spinal cord regions in ALS patients, areas known to be affected by neuroinflammation. CTGF may also participate in neuroinflammation-induced dopaminergic neurotoxicity, and thus may be involved in Parkinson's disease pathology (McClain, Phillips, \& Fillmore, 2009). CTGF has been shown to be downregulated in the hippocampi of cocaine abusers, possibly promoting long lasting structural changes in the cytomatrix and synaptic connections that play a role in chronic cocaine addiction (Mash et al,, 2007). This is particularly interesting since overexpression of $m i R-30$ in High Responders should lead to decreased levels of CTGF 
(as observed in cocaine abusers) that may play a potential role in their greater locomotor response to cocaine and propensity to self-administer cocaine (Hooks et al., 1991; Kabbaj et al, 2001). Unfortunately, CTGF was not included on the Affymetrix arrays profiling mRNA expression in High and Low Responders and therefore mRNA expression cannot be commented on (Stead \& Akil, unpublished data)..

\section{3b mik-29}

$m i R-29 a$ and $m i R-29 b$ were also significantly upregulated in High Responders compared to Low Responders, specifically at postnatal day 14 (Figure 22). $m i R-29 a$ has been shown to inversely regulate expression of peripheral myelin protein 22 (pmp22) through in vivo studies demonstrating that over-expression of miR-29a reduces levels of pmp22 while inhibition of endogenous miR-29a increases pmp22 levels (Verrier et al., 2009). Pmp22 codes for a protein that is expressed mainly by myelinating Schwann cells and is localized in compact myelin (Snipes el al., 1992). Pmp22 functions to provide structural support to myelin and is also involved in regulating the growth and differentiation of Schwann cells (Manfioletti et al., 1990; Zoidl et al., 1995). Pmp22 mRNA was also upregulated in High Responders at the same time point (Stead \& Akil, unpublished data). Pmp22 increases very rapidly during development at this timepoint, coinciding with a widespread increase in brain myclination (Garbay et al., 2000). Similarly, miR-29a is rapidly increasing in the same region. It is possible that this rapid increase in $m i R-29 a$ is a direct response to the rapidly increasing pmp $22 \mathrm{mRNA}$ levels also exhibited during development. It is worth noting that since both $m i R-29 a$ and pmp22 are showing such rapid increases in expression over time, it is possible that a longer gestation period for HRs or a shorter gestation period for LRs may result in more 
advanced development in High Responders and thus increased expression at postnatal day 14 .

The miR-29 family has also been shown to indirectly regulate the tumor suppressor p53, a protein that is central to cell cycle regulation and many cellular stress responses. Specifically, the $m i R-29$ family members upregulate p53 levels and induce apoptosis by suppressing p $85 \alpha$ and cell division cycle 42 (CDC42), both of which negatively regulate 53 (Park et al., 2009). Interestingly, CDC42 mRNA is also upregulated in High Responders specifically at this timepoint (Stead \& Akil, unpublished data). Based on mRNA data, upregulation of CDC42 in High Responders should result in decreased apoptosis through suppression of p53. Since neurogenesis and apoptosis are often correlated (Dong et al., 2003), increased CDC42 and decreased apoptosis may be related to the reduced neurogenesis observed in High Responder rats (Lemaire et al, 1999). It is important to note that reduced neurogenesis was reported in adult HRs, thus there is no direct evidence of reduced neurogenesis in HRs at this timepoint.

\section{$4.3 \mathrm{c} \mathrm{miR}-338$}

$m i R-338$, a neuron-specific miRNA, is upregulated in High Responders at PND 14 (Figure 23) and silences a family of mRNAs whose protein products are negative regulators of neuronal differentiation (Barik, 2008). This miRNA would therefore be expected to enhance neuronal differentiation. Transfection of pre-miR-338 into the axons of primary sympathetic neurons decreased cytochrome coxidase (COXIV) mRNA and protein levels and resulted in a decrease in mitochondrial activity, as measured by a reduction in ATP levels. Conversely, the transfection of synthetic anti-miR oligonucleotides that inhibit miR-338 increased COXIV levels and resulted in a 
significant increase in oxidative phosphorylation and norepinephrine uptake in the axons. COXIV is a protein that plays a key role in the assembly of the mitochondrial cytochrome c oxidase complex IV, the last enzyme in the electron transport chain of the mitochondria. Therefore, through suppression of COXIV, miR-338 plays a key role in neuronal differentiation and maturation through the local regulation of axonal protein synthesis and respiration in sympathetic neurons (Aschrafi et al., 2008). Reduced miR338 is thus consistent with the reduced neurogenesis observed in HRs, as fewer neurons would result in reduced neuronal maturation (Lemaire et al., 1999).

\subsection{Limitations and Future Directions}

MicroRNAs work by binding to complementary target sites in an mRNA, thereby preventing translation of the transcript or initiating mRNA degradation. Therefore, if the mode of action is mRNA degradation, we would expect upregulation of a given miRNA to result in downregulation of its target $\mathrm{mRNA}$ and vice versa. As demonstrated, changes in the expression levels of several miRNAs in this study coincide nicely with changes in expression levels of mRNAs from Stead and Akil's mRVA expression study (unpublished data). However, this is not sufficient to conclude the presence of a causal relationship. In order to do so, miRNA expression needs to be directly manipulated in order to observe expression changes in the mRNA target. For example, Care et al. (2007) demonstrated that in vitro overexpression of miR- 133 inhibited cardiac hypertrophy, while suppression of $m i R-133$ by decoy sequences used to sequester endogenous miR133 , induced hypertrophy. In vivo inhibition of miR-133 through injection of chemically engineered RNA molecules called antagomirs (used to silence endogenous miRNA), 
caused marked and sustained cardiac hypertrophy. This direct manipulation of $m i R-/ 33$ allowed for the identification of specific targets of $m i R-133$ that were known to play various roles in cardiac hypertrophy and cardiogenesis.

There are several short-term objectives that will be carried out to complete this study. Real-time PCR, a commonly used tool for validating gene expression studies, will be used to verify these results. For large fold changes, real-time PCR can likely replicate these findings. However, some of the expression changes may fail to replicate given the small fold changes observed through microarray analysis. The Qiagen miScript PCR system will be used to detect and quantify miRNA from a single cDNA synthesis reaction. This system demonstrates highly specific miRVA detection, with the ability to distinguish between miRNA isoforms that differ by only one or two nucleotides. This will be particularly important for determining whether related miRNAs that clustered together were duc to detection of different miRVA isoforms that share similar regulation patterns or due to cross-hybridization of only one differentially expressed miRNA.

To determine the reliability of these results, it is of interest to compare this platform with other commercial platforms by assessing the similarity between the data. Therefore, this custom miRNA microarray platform will be compared to Agilent and Exigon microarray platforms used by collaborators at Health Canada by running identical RNA samples on all platforms and determining correlations between signals.

Various within and between-array normalization strategies will also be compared to determine the most appropriate method for these date. Comparison will be based on the degree of similarity between the reference channel data after normalization. 
The fact that miRNAs identify their mRNA targets based on imperfect sequence complementarity between the miRNA seed region and the 3' UTR of the target mRNA, makes experimental identification of miRNA targets difficult. This has resulted in an explosion of widely available computational target prediction programs, including miRNA target predictions at EMBL, miRanda, mirBase, PicTar, TargetScan, and RNA hybrid (Rajewsky, 2006). It is difficult to state with any confidence which of these available target prediction algorithms produce the most reliable and/or sensitive target predictions. For instance, PicTar and TargetScan produce similar overall sets of predicted target sites, while most other algorithms produce significantly different results. However, without empirically confirming these predicted targets, agreement between algorithms does not mean that the predictions are accurate and/or complete (reviewed by Rajewsky, 2006). Although target prediction programs have clear limitations, identifying potential mRNA targets for miRNAs displaying significant differences in hippocampal expression profiles is an initial step towards determining potential functions. Thus, various target prediction programs will be assessed and potential mRNA targets will be identified. In this study 1 have compared miRNA expression data with mRNA expression data collected using both a different microarray platform and a different generation of selectively bred High and Low Responders, making it difficult to make direct comparisons. A more informative approach would be to run a correlation analysis using mRNA data from the same tissue, as opposed to simply comparing groups. Ideally, protein levels could also be quantificd. Total R.NA was also extracted from the hippocampal tissue for this very reason, and may be used to generate mRVA expression data at a future date for comparison to this miRNA data. 


\subsection{Conclusion}

A rapid increase in stress-related disorders over the last decade (Hellhammer \& Hellhammer, 2008), clearly demonstrates the need for a better understanding of the genetic factors contributing to these disorders. The High Responder-I ow Responder model of spontaneous variation in stress reactivity was used to identify genes that may differ significantly in individuals that are more vulncrable to the negative consequences of stress. Based on the fact that miRNAs have been implicated in stress related disorders (Lchida et al., 2008) and that clear differences in mRNA expression profiles have been demonstrated between High and Low Responders in the hippocampus, this thesis aimed to 1) design a custom miRNA microarray platform and 2) use this platform to characterize miRNA differences between Iligh and Low Responders in the hippocampus at postnatal days 7,14 , and 21 .

As hypothesized, a set of miRNAs were differentially expressed between postnatal days 7,14 , and 21 , in a pattern similar to mRVA expression profiles (Stead \& Akil, unpublished data). Furthermore, at postnatal days 14 and 21 , a subsel of miRNAs were differentially expressed between High and Low Responders, which are implicated in a variety of central nervous system functions, including neuroinflammation (McClain et al., 2009), Schwann cell growth and differentiation (Zoidl et al., 1995), cell apoptosis (Park et al, 2009), and neuronal differentiation and maturation (Aschrafi et al., 2008).

Due to the explosion of miRVA discoveries over the last several years, data illustrating functionality are either limited or absent for the majority of miRNAs. Thus, not all miRNAs identified in this study have a known function. As more research is dedicated to determining miRNA function, a beller understanding of the implications of this research will likely emerge. Future research should aim to characterize the 
expression of mRNA and protein products from the same hippocampal tissue in order to facilitate the discovery of miRNA targets and functions in the brain. 


\section{References}

Antoniou, K., Papathanasiou, G., Papalexi, E., Hyphantis, T., Nomikos, G, G., Spyraki, C., \& Papadopoulou-Daifoti, Z. (2008) Individual responses to novelty are associated with differences in behavioural and neurochemical profiles. Behavioural Brain Research 187:462-472.

Aschrafi, A.. Schwechter, A. D., Mameza, M. G., Natcra-Naranjo. O., Gioio, A. E., \& Kaplan, B. B. (2008) MicroRNA-338 regulates local cytochrome c oxidase IV mRNA levels and oxidative phosphorylation in the axons of sympathetic neurons. The Journal of Neuroscience 28:12581-12590.

Ballenger, J. C., Post, R. M., Jimerson, D. C., Lake, C. R., Murphy, D., Zuckerman, M., \& Cronin, C. (1983) Biochemical correlates of personality traits in normals: An exploratory study. Personality and Individual Differences 4:615-625.

Baltimore, D., Boldin, M. P., O'Connell, R. M., Rao, D. S., \& Taganov, K. D. (2008) MicroRNAs: new regulators of immune cell development and function. Nature Immunology 9:839-845.

Bammler, T., Beyer, R. P., Bhattacharya, S., Boorman, G. A., Boyles, A., Bradford, B. U., Bumgarner, R. E., Bushel, P. R., Chaturvedi, K., Choi, D., Cunningham, M. L., Deng, S., Dressman, H. K., Fannin, R. D., Farin, F. M., Freedman, J. H., Fry, R. C., Harper, A., Humble, M. C., Hurban, P., Kavanagh, T. J., Kaufmann, W. K. Kerr, K. F., Jing, L., Lapidus, J. A., Lasarev, M. R., Li, J., Li, Y. J., Lobenhofer, E. K., Lu, X., Malek, R. L., Milton, S., Nagalla. S. R., O’Malley, J. P., Palmer, V. S., Pattee, P., Paules, R. S., Perou, C. M., Phillips, K., Qin, L. X., Qiu, Y. Quigley, S. D., Rodland, M., Rusyn, I., Samson, L. D., Schwartz. D. A., Shi, Y., Shin. J. L., Sicber, S. O., Slifer, S., Speer, M. C., Spencer, P. S., Sproles, D. I., Swenberg, J. A., Suk, W. A., Sullivan, R. C.. Tian, R., Tennant, R. W., Todd, S. A., Tucker, C. J., Van Houten, B., Weis, B. K., Xuan, S., \& Zarbl, H. (2005) Standardizing global gene expression analysis between laboratories and across platforms, Nature Methods 2:351-356.

Barad, O., Meiri, E., Avniel, A., Aharonov, R., Barzilai, A., Bentwich, I., Einay, L.. Gilad, S., Hurban. P., Karov, Y., Lobenhofer, E. K., Sharon, E., Shiboleth, Y. M., Shtutman, M., Bentwich, Z., \& Einat, P. (2004) MicroRNA expression detected by oligonucleotide microarrays: system establishment and expression profiling in human tissues. Genome Research 14:2486-2494.

Barbato, C., Giorgi, C., Catalanotto, C., \& Cogoni, C. (2008) Thinking about R.NA? MicroRNAs in the brain. Mammalian Genome 19:541-551.

Bardo, M. T., Donohew, R. L., \& Harrington. N. G. (1996) Psychobiology of novelty sceking and drug seeking behaviour. Behavioural Brain Research 77:23-43.

Barik, S. (2008) An intronic microRVA silences genes that are functionally antagonistic to its host gene. Nucleic Acids Research 36:5232-5241. 
Bartel, D. P. (2004) MicroRNAs: genomics, biogenesis, mechanism, and function. Cell 116:281-297.

Baskerville, S., \& Bartel, D. P. (2005) Microarray profiling of microRNAs reveals frequent coexpression with neighboring miRNAs and host genes. RNA 11:241247.

Bernstein, E., Caudy, A. A., Hammond, S. M., \& Hannon, G. J. (2001) Role for a bidentate ribonuclease in the initiation step of RNA interference. Nature 409:363366.

Bernstein, E., Kim, S. Y., Carmell. M. A., Murchison, E. P., Alcom, H., Li, M. Z., Mills. A. A., Elledge, S. J., Anderson, K. V., \& Hannon, G. J. (2003) Dicer is essential for mouse development. Nature Genetics 35:215-217.

Bohnsack, M. T.. Czaplinski, K., \& Gorlich, D. (2004). Exportin 5 is a RanGTPdependent dsRNA-binding protein that mediates nuclear export of pre-miRNAs. RNA 10:185-191.

Bolstad, B. M., Irizarry, R. A., Strand, M. A.. \& Speed, T. P. (2003) A comparison of normalization methods for high density oligonucleotide array data based on variance and bias. Bioinformatics $19: 185-193$.

Borchert, G. M., Lanier, W., \& Davidson. B. L. (2006) RNA polymerase III transcribes human microRNAs. Nat. Struct. Mol. Biol. 13:1097-1101.

Borta, A., \& Schwarting, R. K. (2005) Inhibitory avoidance, pain reactivity, and plusmaze behaviour in Wistar rats with high versus low rearing activity. Physiology and Behaviour 84:387-396.

Bouyer, J. J.. Vallee, M., Deminiere, J. M., Le Moal, M., \& Mayo, W. (1998) Reaction of sleep-wakefulness cycle to stress is related to differences in hypothalamopituitary-adrenal axis reactivily in rat, Brain Research 804:114-124.

Bravo, V., Rosero, S., Ricordi, C., Pastori, R. L. (2006) Instability of miRNA and cDNA derivatives in R.VA preparations. Biochemical and Biophysical Research Communications 353: 1052-1055.

Cai, X., Hagedorn, C. H., \& Cullen, B. R. (2004) Human microRNAs are processed from capped, polyadenylated transcripts that can also function as mRNAs. RNA 10: 1957-1966.

Care, A., Catalucci, D., Felicetti, F., Bonci, D., Addario, A., Gallo, P.. Bang, M. L., Segnalini, P., Gu, Y., Dalton, N. D., Elia, L., Latronico, M. V. G., Hoydal, M., Autore, C., Russo, M. A., Dorn, G. W., Ellingsen, O., Ruiz-Lozana, P., Peterson, 
K. L., Croce, C. M., Peschle, C., \& Condorelli, G. (2007) MicroRNA-133 controls cardiac hypertrophy. Nature Medicine 13:613-618.

Carrington, J. C., \& Ambros, V. (2003) Role of microRNAs in plant and animal development. Science 301:336-338.

Castoldi, M., Schmidt, S., Benes, V., Noerholm, M., Kulozik, A. E., Hentze, M. W., \& Muckenthaler, M. U. (2006) A sensitive array for microRNA cxpression profiling (miChip) based on locked nucleic acids (LNA). RNA 12:913-920.

Chang, S., Johnston, R. J. J., Frokjaer-Jensen, C., Lockery, S., \& Hobert, O. (2004) MicroRNAs act sequentially and asymmetrically to control chemosensory laterality in the nematode. Nature 430:785-789.

Chen, C. Z., Li, L., Lodish, H. F., \& Bartel, D. P. (2004) MicroRNAs modulate hematopoictic lineage differentiation. Science 303:83-86.

Chendrimada, T. P., Finn, K. J., Ji, X., Baillat, D., Gregory, R. I., Liebhaber, S. A., Pasquinelli, A. E., \& Shiekhattar, R. (2007) MicroRNA silencing through RISC recruitment of eIF6. Nature 447:823-828.

Chendrimada, T. P., Gregory, R. I., Kumaraswamy. E.. Norman, J., Cooch, N., Nishikura, K., \& Shiekhattar, R. (2005) TRBP recruits the Dicer complex to Ago2 for microRNA processing and gene silencing. Nature 436:740-744.

Cleveland, W. S. (1979) Robust locally weighted regression and smoothing scatterplots. Journal of the American Statistical Association 74:829-836.

Cleveland, W. S., \& Devlin, S. J. (1988) Locally weighted regression: An approach to regression analysis by local fitting. Journal of the American Statistical Association 83:596-610.

Clinton, S. M., Vazquez, D. M., Kabbaj, M., Kabbaj, M. H., Watson, S. J., \& Akil, H. (2007) Individual differences in novelty-seeking and emotional reactivity correlate with variation in maternal behavior. Hormones and Behavior 51:655664.

Dellu, F., Mayo, W., Piazza, P. V., Le Moal, M., \& Simon, H. (1993) Individual differences in behavioral responses to novelty in rats. Possible relationship with the sensation-seeking trait in man. Personality and Individual Differences 15:411418.

Dellu, F., Mayo, W., Vallee, M., Le Moal, M., \& Simon, H. (1994) Reactivity to novelty during youth as a predictive factor of cognitive impairment in the elderly: a longitudinal study in rats. Brain Research 653:51-56. 
Dellu, F., Piazza, P. V., Mayo, W., Le Moal, M., \& Simon, H. (1996) Novelty-Seeking in Rats-Biobehavioral Characteristics and Possible Relationship with the SensationSeeking Trait in Man. Neuropsychobiology 34:136-145.

Denli, A. M., Tops, B. B., Plasterk, R. H., Ketting, R. F., \& Hannon, G. J. (2004) Processing of primary microRNAs by the Microprocessor complex. Nature 432:231-235.

Deroche, V., Piazza. P. V., Le Moal, M., \& Simon, H. (1993) Individual differences in the psychomotor effects of morphine are predicted by reactivity to novelty and influenced by corticosterone secretion. Brain Research 623:341-344.

Dhabhar, F. S., Miller, A. H., McEwan, B. S., \& Spencer, R. L. (1995) Differential activation of adrenal steroid receptors in neural and immune tissues of SpragueDawley, Fischer 344, and Lewis rats. Journal of Neuroimmunology 56:77-90.

Dhabhar, F. S., McEwan, B. S., \& Spencer, R. L. (1997) Adaptation to prolonged or repeated stress - comparison between rat strains showing intrinsic differences in reactivity to acute stress. Neuroendocrinology 65:360-368.

Dobbin, K. K., Kawasaki, E. S., Petersen, D. W., \& Simon, R. M. (2005) Characterizing dye bias in microarray experiments. Bioinformatics 21:2430-2437.

Dong, H., Csernansky, C. A., Goico, B., \& Csernansky, J. G. (2003) Hippocampal neurogenesis follows kainic acid-induced apoptosis in nconatal rats. The Journal of Neuroscience 23:1742-1749.

Duisters, R. G. Tijsen, A. J., Schroen, B., Leenders, J. J., Lentink, V., van der Made, I., Herias, V., van Leeuwen, R. E., Schellings, M. W., Barenbrug, P., Maessen, J. G., Heymans, S., Pinto, Y. M., \& Creemers, E. E. (2009) miR-133 and miR-30 regulate connective tissue growth factor: implications for a role of microRNAs in myocardial matrix remodelling. Circulation Research 104:170-178.

Eberwine, J., Miyashira, K.. Kacharmina, J. E., \& Job, C. (2001) Local translation of classes of mRNAs that are targeted to neuronal dendrites. Proceedings of the National Academy of Sciences USA 98:7080-7085.

Esau. C., Kang, X., Peralta, E., Hanson, E., Marcusson, E. G., Ravichandran, L. V., Sun, Y., Koo, S., Perera, R. J., Jain, R., Dean, N. M., Freier, S. M., Bennett, C. F., Lollo, B., \& Griffey, R. (2004) MicroRN $\Lambda$ - 143 regulates adipocyte differentiation. Journal of Biological Chemistry 279:52361-52365.

Exner, M., \& Clark, D. (1993) Behaviour in the novel environment predicts responsiveness to $\mathrm{D}$-amphetamine in the rat: a multivariate approach. Behavioural Pharmacology 4:47-56. 
Fare, T. L., Coffey, E. M., Dai, H.. He, Y. D., Kessler, D. A., Kilian, K. A., Koch, J. E.. LeProust, E., Marton, M. J., Meyer, M. R., Stoughton, R. B.. Tokiwa, G. Y., \& Wang, Y. (2003) Effects of Atmospheric Ozone on Microarray Data Quality. Analytical Chemistry 75:4672-4675.

Feng, J., Iwama, A., Satake, M., Kohu, K. (2009) MicroRNA-27 enhances differentiation of myeloblasts into granulocyles by post-transcriptionally downregulating Runx 1 . British Journal of Haematology 145:412-423.

Fiore, R. \& Schratt, G. (2007) MicroRNAs in vertebrate synapse development. The Scientific World Journal 7:167-177.

Garbay, B., Heape, A. M., Sargueil, F., \& Cassagne, C. (2000) Myelin synthesis in the peripheral nervous system. Progress in Neurobiology 61:267-304.

Genisphere Inc. (2004) 3DNA Array 350 Manual, Appendix E: Reducing degradation of Cy 5/Alexa Fluor 647 (not peer reviewed). Accessed at [http://www.genisphere.com/pdf/array.350_10_19_04.pdf].

Gerra, G., Avanzini, P., Zaimovic, A.. Sartori, R., Bocchi, C., Timpano, M., Zambelli, U., Delsignore, R., Gardini. F., Talarico, E., \& Brambilla, F. (1999)

Neurotransmitters, neuroendocrine correlates of sensation-seeking temperament in normal humans. Neuropsychobiology 39:207-213.

Giraldez, A. J., Cinalli, R. M., Glasner, M. E., Enright, A. J., Thomson, J. M., Baskerville, S., Hammond, S. M., Bartel, D. P., \& Schier, A. F. (2005) MicroRNAs regulate brain morphogenesis in zebrafish. Science 308:833-838.

Glantz, L. A., \& Lewis, D. A. (2000) Decreased dendritic spine density on prefrontal cortical pyramidal neurons in schizophrenia. Archives of General Psychiatry 57: 65-73.

Gong, W., Neill, D. B., \& Justice, J. B. (1996) Locomotor response to novelty does not predict cocaine place preference conditioning in rats. Pharmacology, Biochemistry and Behaviour 53:191-196.

Gregory, R. 1., Yan, K. P., Amuthan, G., Chendrimada, T., Doratotaj, B., Cooch, N., \& Shiekhatter, R. (2004) The Microprocessor complex mediates the genesis of microRNAs. Nature 432:235-240.

Griffiths-Jones, S., Saini, H. K., van Dongen, S., \& Enright, A. J. (2008) miRBase: tools for microRNA genomics. NAR 36(Database Issue): D154-D158. [http://microrna.sanger.ac,uk/sequences/]

Griffiths-Jones, S., Grocock, R. J., van Dongen, S., Bateman, A., \& Enright, A. J. (2006) 
miRBase : microRNA sequences, targets and gene nomenclature. Nucleic Acids Research 34, Database issue:D140-D144.

Grishok, A., Pasquinelli, A. E., Conte, D., Li, N., Parrish, S., Ha, I., Baillie, D. L., Fire, A., Ruvkun, G., \& Mello, C. C. (2001) Genes and mechanisms related to RNA interference regulate expression of the small temporal R.NAs that control $C$. Elegans developmental timing. Cell 106:23-34.

Guarnieri, D. J., \& Dileone, R. J. (2008) MicroRNAs: a new class of gene regulators. Annals of Medicine 40:197-208.

Gupta, R., Ruosaari, S., Kulathinal, S., Hollmen, J., \& Auvinen, P. (2007) Microarray image segmentation using additional dye - an experimental study. Molecular and Cellular Probes 21: 321-328.

Han, J., Lee, Y., Yeom, K. H., Kim, Y. K., Jin, H., \& Kim, V. N. (2004) The DroshaDGCR8 complex in primary microRNA processing. Genes and Development 18:3016-3027.

Han, J., Lee, Y., Yeom, K. H., Nam, J. W., Heo, I. Rhee, J. K., Sohn, S. Y., Cho, Y., Zhang, B. T., \& Kim, V. N. (2006) Molecular basis for the recognition of primary microRNAs by the Drosha-DGCR 8 complex. Cell 125:887-901.

Hellhammer, D. H., \& Hellhammer, J. (2008) Neurobehavioural medicine and stressrelated disorders. Key Issues in Mental Health 174:1-10.

Hennessy, E., \& O'Driscoll, L. (2008) Molecular medicine of microRNAs: structure, function and implications for diabetes. Expert Reviews in Molecular Medicine 10: $1-13$.

Hicks, J. S., Cox, W. G., Leung, W. Y., Liu, J., Meyer, R., \& Ruth, J. L. In search of ozone stable dyes for microarray applications. Presented at the $11^{\text {th }}$ Annual International Microarray and Microtechnology Congress, Boston, MA September 20-23, 2004.

Hooks, M. S., Colvin, A. C., Juncos, J. L., \& Justice, J. B. (1992a) Individual differences in basal and cocaine stimulated extracellular dopamine in the nucleus accumbens using quantitative microdialysis. Brain Research 587:306-312.

Hooks, M. S., Jones, G. H., Smith, A. D., Neill. D. B., \& Justice, J. B. (1991) Individual differences in locomotor activity and sensitization. Pharmacology Biochemistry and Behaviour 38:467-470.

Hooks, M. S., Jones, G. H., Smith, A. D., Neill, D. B., \& Justice, J. B. (1991a) Response to novelty predicts the locomotor and nucleus accumbens dopamine response to cocaine. Synapse 9:121-128. 
Hooks, M. S., Juncos, J. L., Justice, J, B., Meiergerd, S. M., Povlock, S. L., Schenk, J. O., \& Kalivas, P. W. (1994) Individual locomotor response to novelty predicts selective alterations in D1 and D2 receptors and mRNAs. The Journal of Neuroscience 14:6144-6152.

Hoshaw, B. A., Hua, K., \& Lewis, M. J. (1999) Response to novelty predicts carly ethanol administration in Sprague-Dawley rats. Research Society of Alcoholism Abstracts 76:18.

Hoshaw, B. A.. Sulkoski, J., \& Lewis, M. J. (2000) The role of response to novelty in self-administration. Research Society of Alcoholism Abstracts 53:15.

Hoshaw, B. A., \& Lewis, M. J. (2001) Behavioural sensitization to ethanol in rats: evidence from the Sprague-Dawley strain. Pharmacology, Biochemistry and Behaviour 68:685--690.

Hutvagner, G. Mclachlan, J., Pasquinelli, A. E., Balint, E., Tuschl, T., \& Zamore, P. D. (2001) A cellular function for the RNA-interference en $z y m e$ Dicer in the maturation of the let-7 small temporal RNA. Science 293:834-838.

Jin, P., Zarnescu, D. C., Ceman, S., Nakamoto, M.. Mowrey, 1., Jongens, T. A., Nelson, D. L.. Moses, K., \& Warren. S. T. (2004) Biochemical and genetic interaction between the fragile $X$ mental retardation protein and the microRNA pathway. Nature Neuroscience 7:113-117.

Kabbaj, M., Le Moal, M., \& Maccari, S. (1996) Hippocampal type I and type II corticosteroid receptors are differentially regulaled by chronic prazosin treatment. Neuroscience 73; $963-970$.

Kabbaj, M., Devine, D. P., Savage, V. R., \& Akil, H. (2000) Neurobiological correlates of individual differences in novelty-secking behavior in the rat: differential expression of stress-related molecules. The Journal of Neuroscience 20:69836988.

Kabbaj, M., \& Akil, H. (2001) Individual differences in novelty-seeking behavior in rats: a c-fos study. Neuroscience 106:535-545.

Kabbaj, M., Norton, C. S., Kollack-Walker, S.. Watson, S. J., Robinson, T. E., \& Akil, H. (2001) Social defeat alters the acquisition of cocaine self-administration in rats: rolc of individual differences in cocainc-taking behavior. Psychopharmacology 158:382-387.

Kabbaj, M. (2004) Neurobiological bases of individual differences in emotional and stress responsiveness. Archives of Neurology 61:1009-1012.

Kabbaj, M., Evans, S., Watson, S. J., \& Akil, H. (2004) The search for the 
neurobiological basis of vulnerability to drug abuse: using microarrays to investigate the role of stress and individual differences. Neuropharmacology
47:111-122.

Kabbaj, M., Morley-Fletcher, S., Le Moal, M., \& Maccari, S. (2007) Individual differences in the effects of chronic prazosin hydrochloride treatment on hippocampal mineralocorticoid and glucocorticoid receptors. European Journal of Neuroscience 25:3312-3318.

Kalinichev, M., White, D. A., \& Holtzman, S. G. (2004) Individual differences in locomotor reactivity to a novel environment and sensitivitiy to opioid drugs in the rat. I. Expression of morphine-induced locomotor sensitization. Psychopharmacology 177:61-67.

Kapsimali, M., Kloosterman, W. P., de Bruijn, E., Rosa, F., Plasterk, R. H., \& Wilson, S. W. (2007) MicroRNAs show a wide diversity of expression profiles in the developing and mature central nervous system. Genome Biology 8:R173.

Kedde, M., Strasser, M. J., Boldajipour, B., Vrielink, J. A., Slanchev, K., le Sage, C., Nagel, R.. Voorhoeve, P. M., van Duijse, J., Orom, U. A., Lund, A. H., Perrakis, A., \& Raz, E. (2007) RNA-binding protein Dndl inhibits microRNA access to target mRNA. Cell 131:1273-1286.

Ketting, R. F., Fischer. S. E., Bernstein, E., Sijen, T., Hannon, G. J., \& Plasterk, R. H. (2001) Dicer functions in RNA interference and in synthesis of small RNA involved in developmental timing in C. Elegans. Genes and Development 15:2654-2659.

Khojasteh, M., Lam, W. L., Ward, R. K., \& MacAulay, C. (2005) A stepwise framework for the normalization of array CGI data. BMC Bioinformatics 6:274-289.

Kim, V. N. (2004) MicroRNA precursors in motion: exportin-5 mediates their nuclear export. Trends in Cell Biology 14:156-159.

Kim, J., Inoue, K., Ishii, J., Vanti, W. B., Voronov, S. V., Murchison, E., Hannon, G., \& Abeliovich, A. (2007) A microR.NA feedback circuit in midbrain dopamine neurons. Science 317:1220-1224.

Kirschbaum, C., Bartussek, D., \& Strasburger, C. J. (1992) Cortisol responses to psychological stress and correlations with personality traits. Personality and Individual Differences 13:1353-1357.

Klebaur, J. E., Bevins, R. A., Segar, T. M., \& Bardo, M. T. (2001a) Individual differences in behavioural responses to novelty and amphetamine selfadministration in male and female rats. Behavioural Pharmacology 12:267-275. 
Klein, M. E., Lioy, D. T., Ma, L., Impey, S., Mandel, G., \& Goodman, R. H. (2007) Homeostatic regulation of MeCP2 expression by a CREB-induced microRNA. Nature Neuroscience 10:1513-1514.

Kloosterman, W. P. \& Plasterk, R. H. (2006) The diverse functions of microR.NAs in animal development and disease. Developmental Cell 11:441-450.

Knappen, D., Vergauwen, L.. Laukens, K., Blust, R. (2009) Best practices for hybridization design in two-colour microarray analysis. Trends in Biolechnology 27:406-414.

Knight, S. W., \& Bass, B. L. (2001) A role for the RNase III enzyme DCR-1 in RNA interference and germ line development in Caenorhabditis elegans. Science 293:2269-2271.

Kosik, K. S. (2006) The neuronal microRNA system. Nature Reviews Neuroscience 7:911-920.

Krichevsky, A. M., King, K. S., Donahuc, C. P., Khrapko, K., \& Kosik, K. S. (2003) A microRNA array reveals extensive regulation of microRNAs during brain development. RNA 9:1274-1284.

Krichevsky, A. M., Sonnlag. K. C., Isacson, O., \& Kosik, K. S. (2006) Specific microRNAs modulate embryonic stem cell derived neurogenesis. Siem Cells 24:857-864.

Lagos-Quintana, M., Rauhut, R., Lendeckel, W., \& Tuschl, T. (2001) Identification of novel genes coding for small expressed RNAs. Science 294:853-858.

Landraf, P., Rusu, M., Sheridan, R., Sewer, A., Iovino, N., Aravin, A., Pfeffer, S., Rice, A., Kamphorst, A. O., Iandthaler, M., Lin, C., Socci, N. D.. Hermida, L., Fulci, V., Chiaretti, S., Foa, R., Schliwka, J., Fuchs, U., Novoscl, A., Muller. R. U., Schermer, B., Bissels, L., Inman, J., Phan, Q., Chien, M., Weir, D. B., Choksi, R., De Vita, G., Frezzetti, D., Trompeter, H. I., Homung, V., Teng, G., Hartmann, G., Palkovits, M., Di Lauro, R., Wernet, P., Macino, G., Rogler, C. E., Nagle, J. W.. Ju, J., Papavasiliou, F. N., Benzing, T., Lichter, P., Tam, W., Brownstein, M. J., Bosio, A., Borkhardt, A., Russo, J. J., Sander, C., Zavolan, M. \& Tuschl, T. (2007) A mammalian microRNA expression atlas based on small RNA library sequencing. Cell 129:1401-1414.

Lau, N. C., Lim, L. P., Weinstein, E. G., \& Bartel, D. P. (2001) An abundant class of tiny RNAs with probable regulatory roles in Caenorhabditis elegans. Science 294:858-862.

Laurent, L. C., Chen, J., Ulitsky, I., Mueller, F. J., Lu, C., Shami, R., Fan, J. B., and 
Loring, J. F. (2008) Comprehensive microRNA profiling reveals a unique human embryonic stem cell signature dominated by a single seed sequence. Stem cells
26:1506-1516.

Lee, R. C., Feinbaum, R. L., \& Ambros, V. (1993) The C. elegans heterochronic gene lin-4 encodes small RNAs with antisense complementarity to lin-14. Cell 75:843854.

Lee, R. C., \& Ambros, V. (2001) An extensive class of small RNAs in Caenorbabditis elegans. Science 294:862-864.

Lee, Y., Ahn, C., Han, J., Choi, H., Kim, J., Yim, J., Lee, J., Provost, P., Radmark, O., Kim, S., \& Kim, V. N. (2003) The nuclear RNase III Drosha initiates microRNA processing. Nature 425:415-419.

Lemaire, V., Aurousseau, C., Le Moal, M., \& Abrous, D. N. (1999) Behavioural trait of reactivity to novelty is related to hippocampal neurogenesis. European Journal of Neuroscience 11:4006-4014.

Lewin, B. (2006) Essential Genes. Upper Saddle River, NJ: Pearson Education, Inc.

Lewis, B. P., Shih, I. H., Jones-Rhoades, M. W., Bartel, D. P., \& Burge, C. B. (2003) Prediction of mammalian microRNA targets. Cell 115:787-798.

Lewis, B. P., Burge, C. B., \& Bartel, D. P. (2005) Conserved seed pairing, often flanked by adenosines, indicates that thousands of human genes are microRNA targets. Cell 120:15-20.

Li, X. \& Carthew, R. W. (2005) A microRNA mediates EGF receptor signalling and promotes photoreceoptor differentiation in the Drosophila eye. Cell 123:12671277.

Li, X., Wang, F., Lee. J. A., \& Gao, F. B. (2006) MicroRNA-9a ensures the precise specification of sensory organ precursors in Drosophila. Genes and Development 20:2793-2805.

Liang, R. Q., Li, W., Li, Y., Tan, C. Y., Li, J. X., Jin, Y. X., \& Ruan, K. C. (2005) An oligonucleotide microarray for microRNA expression analysis based on labeling RNA with quantum dot and nanogold probe. Nucleic Acids Research 33:e17.

Lim, L. P., Lau, N. C., Garrett-Engele, P., Grimson, A., Schelter, J. M., Castle, J., Bartel, D. P., Linsley, P. S., \& Johnson, J. M. (2005) Microarray analysis shows that some microRNAs downregulate large numbers of target mRNAs. Nature 433:769-773.

Lin, S. L., Kim, H., \& Ying, S. Y. (2008) Intron-mediated RNA interference and microRNA (miRNA). Frontiers in Biossience 13:2216-2230. 
Liu, J. (2008) Control of protein synthesis and mRNA degradation by microRNAs. Current Opinion in Cell Biology 20:214-221.

Lund, E., Guttinger, S, Calado, A., Dahlberg, J. E., \& Kutay, U. (2004) Nuclear export of microRNA precursors. Science 303:95-98.

Makeyev, E. V., Zhang, J., Carrasco, M. A., \& Maniatis, T. (2007) The microRNA miR-124 promotes neuronal differentiation by triggering brain-specific alternative pre-mRNA splicing. Molecular Cell 27:435-448.

Mallory, A. C., \& Vaucheret, H. (2004) MicroRVAs: something important between the genes. Current Opinion in Plant Biology 7:120-125.

Manfioletti, G., Ruaro, M. E., Del Sal, G., Philipson, L., \& Schneider. C. (1990) A growth arrest specific (gas) gene codes for a membrane protein. Molecular Cell Biology 10:2924-2930.

Mash, D. C., ffrench-Mullen, J., Adi, N., Oin, Y.. Buck, A., \& Pablo, J. (2007) Gene expression in human hippocampus from cocaine abusers identifies genes which regulate extracellular matrix remodelling. PLOS ONE 2(11):e1187.

McClain, J. A., Phillips, L. L.. \& Fillmore, H. L. (2009) Increased MMP-3 and CTGF expression during lipopolysaccharide-induced dopaminergic neurodegeneration. Neuroscience Letters 460:27-31.

Mellios, N., Huang, H. S., Grigorenko, A., Rogaev, E., \& Akbarian, S. (2008) A set of differentially expressed miRNAs, including miR-30a-5p, act as posttranscriptional inhibitors of BDNF in prefrontal cortex. Human Molecular Genetics, 17: 3030-3042.

Miserendino, M. J. D., Guitart, X., Terwilliger, R. Z., Chi, S.. \& Nestler, E. J. (1994) Individual differences in locomotor activity are associated with levels of tyrosine hydroxylase and neurofilament proteins in the ventral tegmental area of SpragucDawley rats. Molecular and Cellular Neuroscience 4:440-448.

Miska, E. A., Alvarez-Saavedra, E., Townsend, M., Yoshii, A., Sestan, N., Rakic, P., Constantine-Paton, M., \& Horvitz, H. R. (2004) Microarray analysis of microRNA expression in the developing mammalian brain. Genome Biology. 5:R68.

Mourelatos, Z., Dostie, J., Paushkin, S., Sharma, A., Charroux, B., Abel, L., Rappsilber, J., Mann, M., \& Dreyfuss, G. (2002) miRNPs: a novel class of ribonucleoproteins containing numerous microRNAs. Genes and Development 16:720-728.

Murchison, E. P., \& Hannon, G. J. (2004) miRNAs on the move: miRNA biogenesis 
and the RNAi machinery. Current Opinion in Cell Biology 16:223-229.

Naguibneva, I., Ameyar-Zazoua, M., Polesskaya, A., Ait-Si-Ali, S., Groisman, R., Souidi, M., Cuvellier, S., \& Harel-Bellan, A. (2006) The microRNA miR-181 targets the homeobox protein Hox-A11 during mammalian myoblast differentiation. Nature Cell Biology 8:278-284.

Netter, P., Hennig, J., \& Roed, I. S. (1996) Serotonin and dopamine as mediators of sensation seeking behaviour. Neuropsychobiology 34:155-165.

Okamura, K., Ishizuka, A., Siomi, H., \& Siomi, M. C. (2004) Distinct roles for Argonaute proteins in small RNA-directed RNA cleavage pathways. Genes and Development 18: 1655-1666.

Pan, Q., Luo, X, \& Chegini, N. (2008) Differential expression of microRNAs in myometrium and leiomyomas and regulation by ovarian steroids. Journal of Cellular and Molecular Medicine 12:227-240.

Park, S. Y., Lee, J. H., Ha, M. Nam, J. W., \& Kim, V. N. (2009) miR-29 miR.NAs activate $\mathrm{p} 53$ by targeting $\mathrm{p} 85 \mathrm{a}$ and $\mathrm{CDC} 42$. Nature Structural and Molecular Biology 16:23-29.

Pasquinelli, A. E., Reinhart, B. J., Slack, F., Martindale, M. Q., Kudora, M. I., Maller, B., Hayward, D. C., Ball. E. E., Degnan, B., Muller, P., Spring, J., Srinivasan, A., Fishman, M., Finnerty, J., Corbo, J., Levine, M., Leahy, P., Davidson, E., \& Ruvkun, G. (2000) Conservation of the sequence and temporal expression of let-7 heterochronic regulatory RNA. Nature 408:86-89.

Pasquinelli, A. E., \& Ruvkun, G. (2002) Control of developmental timing by microRNAs and their targets. Annual Review of Cell and Developmental Biology 18:495-513.

Penagarikano, O., Mulle, J. G., \& Warren, S. T. (2007) The pathophysiology of fragile $\mathrm{X}$ syndrome. Annual Review of Genomics and Human Genetics 8:109-129.

Peters, L., \& Meister, G. (2007) Argonaute proteins: mediators of RNA silencing. Molecular Cell 26:611-623.

Pevsner, J. (2009). Bioinformations and Functional Genomics (2 $2^{\text {nd }}$ Ed.). New York: John Wiley and Sons.

Piazza, P. V., Deminiere, J. M., Le Moal, M., \& Simon, H. (1989) Factors that predict individual vulnerability to amphetamine self-administration. Science 29:15111513.

Piazza, P. V., Maccara, S., Deminiere, J. M., Le Moal, M., Mormede, P., \& Simon, H. 
(1991) Corticosterone levels determine individual vulnerability to amphetamine self-administration. Proceedings of the National Academy of Sciences 88:20882092.

Piazza, P. V., Rouge-Pont, F., Deminiere, P. V., Kharoubi, M., Le Moal. M., \& Simon, $\mathrm{S}$. (1991) Dopaminergic activity is reduced in the prefrontal cortex and increased in the nucleus accumbens of rats predisposed to develop amphetamine selfadministration. Brain Research 567:169-174.

Piazza, P. V., Deroche, V., Deminiere, J. M., Maccari, S., Le Moal, M., \& Simon, H. (1993) Corticosterone in the range of stress-induced levels possesses reinforcing properties; implications for sensation-seeking behaviors. Proceedings of the National Academy of Sciences 90:11738-11742.

Pierre, P. J., \& Vezina, P. (1997) Predisposition to self-administer amphetamine: the contribution of response to novelty and prior exposure to the drug. Psychopharmacology 129:277-284.

Pierri, J. N., Volk, C. L., Auh, S., Sampson, A., \& Lewis, D. A. (2001) Decreased somal size of deep layer 3 pyramidal neurons in the prefrontal cortex of subjects with schizophrenia. Archives of General Psychiatry 58: 466-473.

Pradervand, S., Weber, J., Thomas, J., Bueno, M., Wirapati, P., Lefort, K., Dotto, P., \& Harshman, K. (2009) Impact of normalization on miRNA microarray expression profiling. RNA 15:493-501.

Quackenbush, J. (2002) Microarray data normalization and Iransformation. Nature Genetics 32:496-501.

Rajewsky, N. (2006) miRNA target predictions in animals. Nature Genetics 38:S8-13.

Ramboz, S., Oosting, R., Amara, D. A., Kung, H. F,, Blier, P., Mendelsohn, M., Mann, J. J.. Brunner, D., \& Hen, R. (1998) Serotonin receptor 1 A knockout: an animal model of anxiety-related disorder. Proceedings of the National Academy of Sciences USA 95:14476-14481.

Rao, Y., Lee, Y., Jarjoura, D., Ruppert, A. S., Liu, C. G.. Hsu, J. C.. Hagan. J. P. (2008) A comparison of normalization techniques for microR NA microarray data. Statistical Applications in Genetics and Molecular Biology 7: Article 22

Reinhart, B. J., Slack, F. J., Basson, M., Pasquinelli, A. E., Bettinger, J. C., Rougvie, A. E., Horvitz, H. R., \& Ruvkun, G. (2000) The 21-nucleotide let-7 RNA regulates developmental timing in Caenorhabditis elegans. Nature 403:901-906.

Rivas, F. V., Tolia, N. H., Song, J. J., Aragon, J. P., Liu, J., Hannon, G. J., \& Joshua- 
Tor, L. (2005) Purified Argonaute2 and an siRNA form recombinant human RISC. Nature Structural and Molecular Biology 12: 340-349.

Roberti, J. W. (2005) Sensation seeking characteristics and neuroendocrine responses to an acute psychological challenge for undergraduates with career interests in forensic sciences. The Internet Journal of Forensic Science 1: no.1.

Rosario, L. A., \& Abercrombic, E. D. (1999) Individual differences in behavioral reactivity: correlation with stress-induced norepinephrine efflux in the hippocampus of Sprague-Dawley rats. Brain Research Bulletin 48:595-602.

Ruegg, R. G., Gilmore, J., Ekstron, R. D., Corrigan, M., Knight, B., Tancer, M., Leatherman, M. E., Carson, S. W., \& Golden, R. N. (1997) Clomipramine challenge responses covary with tridimensional personality questionnaire scores in healthy subjects. Biological Psychiatry 42:1123-1129.

Saigusa, T., Tuinstra, T., Koshikawa, N., \& Cools, A. R. (1999) High and low responders to novelty: effects of a catecholamine synthesis inhibitor on noveltyinduced changes in behaviour and release of accumbal dopamine. Neuroscience 88:1153-1163.

Sarkar, D., Parkin, R., Wyman, S., Bendoraite, A., Sather, C., Delrow, J., Godwin. A. K., Drescher, C., Huber, W., Gentleman, R., \& Tewari, M. (2008) Quality assessment and dala analysis for microRNA expression arrays. Nucleic Acids Research: 1-8.

Schaefer, A., O'Carroll, D., Tan, C. L., Hillman, D., Sugimori, M., Llinas, R., \& Greengard, P. (2007) Cercbellar ncurodegeneration in the absence of microRNAs. The Journal of Experimental Medicine 204:1553-1558.

Schlens, J (2009) A tutorial on principal component analysis. Accessed at [http://www.snl.salk.edu/ shlens/pub/notes/pca.pdf].

Schratt, G. M., Tuebing, F., Nigh, E. A., Kane, C. G., Sabatini, M. E., Kiebler, M., \& Greenberg, M. E. (2006) A brain-specific microRNA regulates dendritic spine development. Nature 439:283-289.

Schwarz, D. S., Hutvagner, G., Du, T., Xu, Z., Aronin, N., \& Zamore, P. D. (2003) Asymmetry in the assembly of the RNAi enzyme complex. Cell 115:199-208.

Sempere, L. F., Freemantle, S., Pitha-Rowe, I., Moss, E., Dmitrovsky, E., \& Ambros, V. (2004) Expression profiling of mammalian microRNAs uncovers a subset of brain-expressed microRNAs with possible roles in murine and human neuronal differentiation. Genome Biology 5:R13.

Sen, G. L., \& Blau, H. M. (2005) Argonaute 2/RISC resides in sites of mammalian mRNA decay known as cytoplasmic bodies. Nature Cell Biology 7: 633-636. 
Shannon, W., Culverhouse, R., \& Duncan, J. (2003) Analyzing microarray data using cluster analysis. Pharmacogenomics 4:41-52.

Smimova, L., Grafe, A., Seiler, A., Schumacher, S., Nitsch, R., \& Wulczyn, F. G. (2005) Regulation of miRNA expression during neural cell specification. European Journal of Neuroscience 21:1469-1477.

Smyth, G. K., \& Speed, T. P. (2003) Normalization of cDNA microarray data. Methods 31:265-273.

Snipes, G. J., Suter, U., Welcher, A. A., \& Shooter, E. M. (1992) Characterization of a novel peripheral nervous system myelin protein (PMP-22/SR13). Journal of Cell Biology 117:225-238.

Song, J. J., \& Joshua-Tor, L. (2006) Argonaute and RNA - getting into the groove. Current Opinion in Structural Biology 16: 5-11.

Sontheimer, E. J. (2005) Assembly and function of RNA silencing complexes. Nature Reviews Molecular Cell Biology 6:127-138.

Stead, J. D. H., Clinton, S., Neal, C., Schneider, J., Jama, A., Miller, S., Vazquez, D. M., Watson, S. J., \& Akil, H. (2006) Selective breeding for divergence in noveltyseeking traits: heritability and enrichment in spontaneous anxicty-related behaviors. Behavior Genetics 36:697-712.

Stead, J. D. H., Neal, C. R., Meng, F., Wang, Y., Evans, S. J., Vazquez, D. M., Watson, S. J., \& Akil, H. (2006) Transcriptional profiling of the developing rat brain reveals that the most dramatic regional differentiation in gene expression occurs postpartum. Journal of Neuroscience 26:345-353.

Sun, Y., Koo, S., White, N., Pcralta, E., Esau, C., Dean, N. M., \& Perera, R. J. (2004) Development of a microarray to detect human and mouse microR.NAs and characterization of expression in human organs. Nucleic Acids Research 32:e188.

Suto, N., Austin, J. D., \& Vezina, P. (2001) Locomotor response to novelty predicts a rat's propensity to self-administer nicotine. Psychopharmacology 158: 175-180.

Tian, Z., Greenc, A. S.. Pietrusz, J. L., Matus, I. R., \& Liang, M. (2008) MicroRNAtarget pairs in the rat kidney identified by microRNA microarray, proteomic, and bioinformatic analysis. Genome Research 18:404-411.

Tusher, V. G., Tibshirani, R., \& Chu, G. (2001) Significance analysis of microarrays applied to the ionizing radiation response. Proceedings of the National Academy of Sciences 98: 5116-5121. 
Uchida, S., Nishida, A., Hara, K., Kamemoto, T., Suetsugi, M., Fujimoto, M., Watanuki, T., Wakabayashi, Y., Otsuki, K., McEwan, B. S., \& Watanabe, Y. (2008)

Characterization of the vulnerability to repeated stress in Fischer 344 rats: possible involvement of microRNA-mediated down-regulation of the glucocorticoid receptor. European Journal of Neuroscience 27: 2250-2261.

Verrier, J. D., Lau, P., Hudson, L., Murashov, A. K., Renne, R., \& Notterpek, L. (2009) Peripheral myelin protein 22 is regulated post-transcriptionally by miRNA-29a. Glia 57:1265-1279.

Visvanathan, J., Lee, S., Lee, B., Lee, J. W., \& Lee, S. K. (2007) The microRNA miR124 antagonizes the anti-neural REST/SCP1 pathway during embryonic CNS development. Genes and Development 21: 744-749.

Vreugdenhil, E., Verissimo, C. S., Mariman, R., Kamphorst. J. T., Barbosa, J. S., Zweers, T., Champagne, D. L., Schouten, T., Meijer, O. C., de Kloet, E. R., \& Fitzsimons, C. P. (2009) MicroRNAs miR-18 and miR-124a downregulate the glucocorticoid receptor: implications for glucocorticoid responsiveness in the brain.

Endocrinology [Epub ahead of print].

Vo, N., Klein, M. E., Varlamova, O., Keller, D. M., Yamamoto, T., Goodman, R. H., \& Impey, S. (2005) A cAMP-response element binding protein-induced microRNA regulates neuronal morphogenesis. Proceedings of the National Academy of Sciences USA 102: 16426-16431.

Wang, H., Ach, R. A., \& Curry, B. (2007) Direct and sensitive miRNA profiling from low-input total RNA. RNA 13:151-159.

Weaver, I. C., G., Cervoni, N., Champagne, F. A., D'Alessio, A. C., Sharma, S., Seckl, J. R., Dymov, S., Szyf, M. \& Meaney, M. J. (2004) Epigenetic programming by maternal behavior. Nature Neuroscience 7: 847-854.

White, D. A., Kalinichev, M., \& Holtzman, S. G. (2007) Locomotor response to novelty as a predictor of reactivity to aversive stimuli in the rat. Brain Research 1149:141-148.

Wienholds, E., Kloosterman. W. P., Miska, E., Alvarez-Saavedra, E., Berezikov, E., de Bruijn, E., Horvitz, H. R., Kauppinen, S., \& Plasterk, R. H. (2005) MicroRNA expression in zebrafish embryonic development. Science 309:310-311.

Wightman, B., Ha, I., \& Ruvkun, G. (1993) Post-transcriptional regulation of the heterochronic gene lin-14 by lin- 4 mediates temporal pattern formation in $C$. elegans. Cell 75:855-862.

Yauk, C. L., Williams, A., Boucher. S., Berndt, L. M., Zhou, G., Zheng, J. L., Rowan- 
Carroll, A., Dong, H., Lambert, I. B., Douglas, G. R., \& Parfett, C. L. (2006) Novel design and controls for focused DNA microarrays: applications in quality assurance/control and normalization for the Health Canada ToxArray. BMC Genomics 7:266.

Yi, R., Qin, Y., Macara, I. G., \& Cullen, B. R. (2003) Exportin-5 mediates the nuclear export of pre-microRNAs and short hairpin RNAs. Genes and Development 17:3011-3016.

Ying, S. Y., \& Lin, S. L. (2005) Intronic microRNAs. Biochemical and Biophysical Research Communications 326:515-520.

Yu, J., Chung, K., Deo, M., Thompson, R. C.. \& Tumer, D. L. (2008) MicroRNA miR124 regulates neurite outgrowth during neuronal differentiation. Experimental Cell Research 314: 2618-2633.

Zeng, Y., \& Cullen, B. R. (2005) Efficient processing of primary microRNA hairpins by Drosha requires flanking nonstructured RNA sequences. The Journal of Biological Chemistry 280: 27595-27603.

Zoidll, G., Blass-Kampmann, S., D’Ursol, D., Schmalenbach, C., \& Muiler. H. W. (1995) Retroviral mediated gene transfer of the peripheral myelin protein PMP22 in Schwann cells: modulation of cell growth. The EMBO Journal 14:1122-1128.

Zuckerman, M., \& Nech, M. (1979) Sensation seeking and psychopathology. Psychiatry Research 1:255-264. 